Jonathan Bokmeyer

ALL RIGHTS RESERVED 
FESCUE

by

JONATHAN BOKMEYER

\author{
A Dissertation submitted to the \\ Graduate School-New Brunswick \\ Rutgers, The State University of New Jersey \\ in partial fulfillment of the requirements \\ for the degree of \\ Doctor of Philosophy \\ Graduate Program in Plant Biology \\ written under the direction of \\ Dr. William A. Meyer \\ and approved by \\ New Brunswick, New Jersey
}

October, 2009 


\title{
ABSTRACT OF THE DISSERTATION
}

\section{Inheritance Characteristics of Brown Patch Resistance in Tall Fescue} by Jonathan Bokmeyer

\author{
Dissertation Director: \\ Dr. William A. Meyer
}

Brown patch, caused by Rhizoctonia solani Kühn, is a devastating disease of tall fescue (Festuca arundinacea Schreb.). Developing genetic resistance is a viable long term control strategy; however, the genetic mechanism of brown patch resistance in tall fescue is not known. The objectives for this research were to (i) calculate the broad and narrow-sense heritability for brown patch resistance, (ii) determine the relative importance of additive and non-additive (dominance and epistatic) gene effects for brown patch resistance, (iii) estimate the general and specific combining abilities of tall fescue parents for brown patch resistance, (iv) estimate the minimum number of effective genes involved in brown patch resistance, and (v) develop a genetic linkage map and identify the presence of quantitative trait loci for brown patch resistance in tall fescue.

To complete these objectives, several field trials were conducted to evaluate the resistance of a diverse background of tall fescue genotypes, as well as parents and progeny from controlled crosses after inoculation with $R$. solani. Expressed Sequence Tags Simple Sequence Repeats (EST-SSRs) along with genomic-SSR markers were used to develop a genetic linkage map of a mapping population derived from a cross between a resistant genotype and a susceptible genotype. 
Analysis of the phenotypic data indicated brown patch resistance in tall fescue is heavily influenced by the environment with phenotypic responses displaying a continuous distribution, both characteristics indicative of quantitative inheritance. Additive genetic variance was more important than non-additive genetic variance in brown patch resistance in tall fescue. It was estimated that one to three genes were segregating for resistance in the progeny that were evaluated. A genotypic recurrent selection program would be the most effective for improving brown patch resistance in tall fescue. Molecular marker analysis revealed the presence of two putative quantitative trait loci. 


\section{ACKNOWLEDGEMENT}

I would like to thank my advisor, Dr. William A. Meyer, for his guidance, support, and patience. I would also like to thank my committee members, Dr. Stacy Bonos, Dr. Bruce Clarke, and Dr. Richard Hurley. My special thanks to Dr. Malay Saha for allowing me to use his lab and resources.

Thank you to all the graduate students who have given me advice and support with my research: Dave Rotter, Rob Shortell, and Matt Koch. I greatly appreciated the advice and help of Ron Bara, Dirk Smith, and Melissa Wilson throughout the duration of my studies. I am grateful to the members of the farm crews for all their help: Adelphia (George Ziemienski, Jim Schumacher, Mike Reynolds, and Alan Habiak) and Hort Farm II (Bill Dickson and Joe Clarke).

Finally I would like to thank my family for their encouragement and support. 
Abstract of the Dissertation ...........................................................

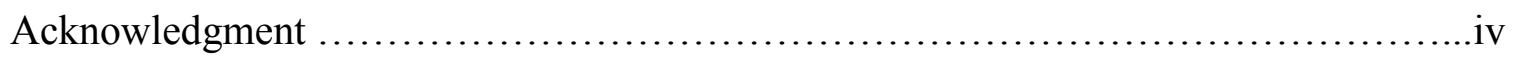

List of Tables .....................................................................

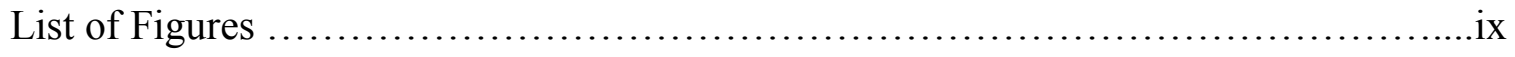

Literature Review ...................................................................

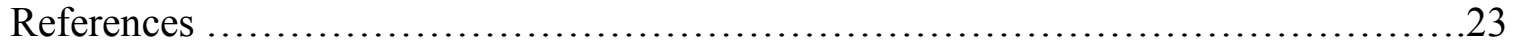

Chapter I

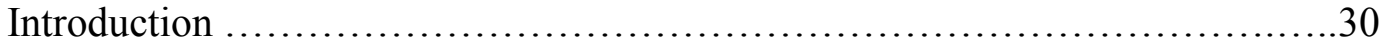

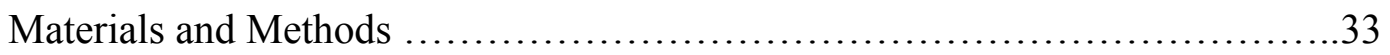

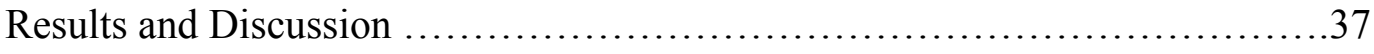

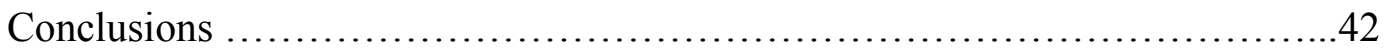

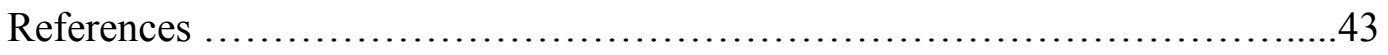

Chapter II

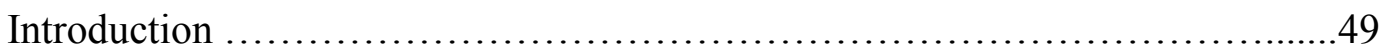

Materials and Methods .................................................5

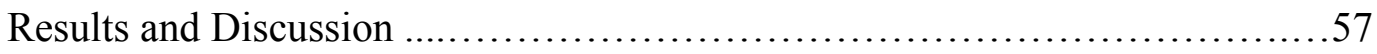

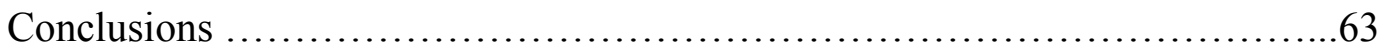

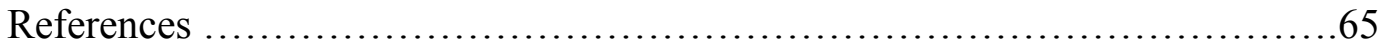

Chapter III

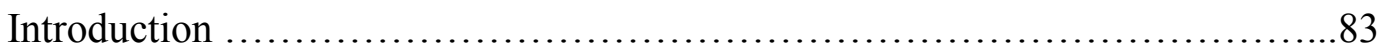




\section{TABLE OF CONTENTS (cont.)}

Page

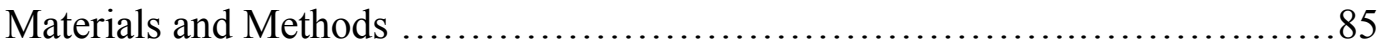

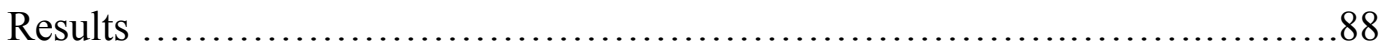

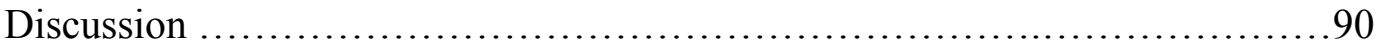

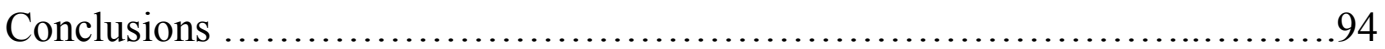

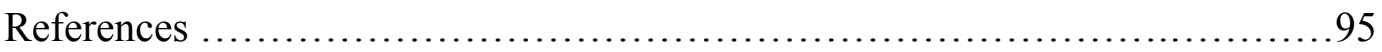

Chapter IV

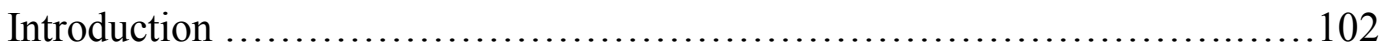

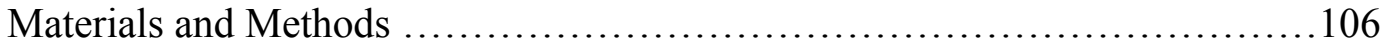

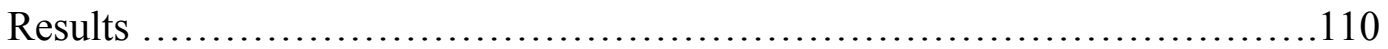

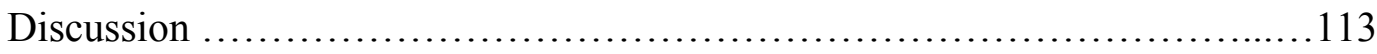

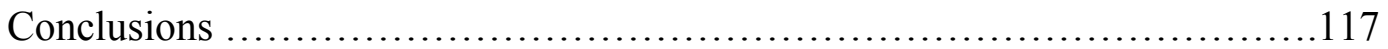

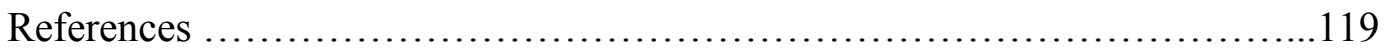

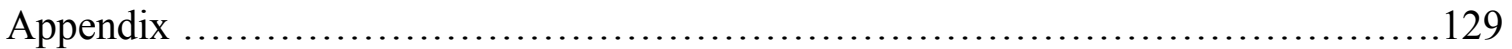

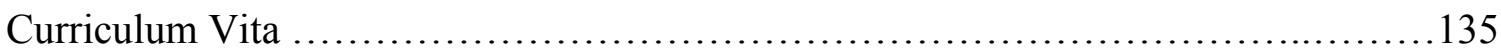




\section{LIST OF TABLES}

Page

Table 1.1. Analysis of variance of brown patch disease severity of 230 tall fescue clones averaged over two locations and two years (2005 and 2006)

Table 1.2. Mean location deviations of tall fescue clone responses to brown patch disease across two locations and two year

Table 1.3. Number of clones at each location that were significantly different from location means using the LSV for comparison $(\mathrm{P}<0.05)$

Table 2.1. Characterization and general combining ability (GCA) of brown patch resistance of six tall fescue parents crossed in a diallel design and evaluated over 2007 and 2008

Table 2.2. Analysis of variance for brown patch resistance in a diallel cross of six tall fescue parents evaluated in a field trial in 2007 and 2008

Table 2.3. Estimation of specific combining ability (SCA) effects in a diallel cross of six tall fescue parents using combined data from 2007 and 2008

Table 2.4. Estimation of minimum number of genes affecting brown patch resistance in a diallel cross of three resistant and three susceptible tall fescue parents ...71

Table 2.5. Percentage of entry sum of squares accounted for by general combining ability (GCA) and specific combining ability (SCA) for brown patch resistance in a diallel cross of six tall fescue parents evaluated in field trial in 2007 and 2008

Table 3.1. Analysis of variance of brown patch disease severity of nine parental tall fescue clones established in mowed spaced-plant trial and evaluated over 2 years (2007 and 2008).97

Table 3.2. Means of parents, progeny, and GCA estimate for nine parental tall fescue genotypes evaluated for brown patch resistance over 2 years (2007 and 2008)

Table 3.3. Analysis of variance of brown patch resistance of nine tall fescue half-sib families evaluated over 2 years (2007 and 2008)

Table 3.4. Narrow-sense heritability and predicted gain from selection for brown patch resistance from a polycross of nine tall fescue genotypes and half-sib progeny evaluated over 2 years (2007 and 2008) 


\section{LIST OF TABLES (cont.)}

Page

Table 4.1. SSRs primer combinations used for the development of a linkage map of tall fescue 123

Table 4.2. Analysis of variance of brown patch disease severity in a tall fescue mapping population averaged over two locations and two years (2007 and 2008)

Table 4.3. Summary of the QTL analysis to a single isolate of $R$. solani in a tall fescue mapping population

Table A. Mean location deviations of tall fescue clones responses to brown patch disease across two locations and two years 


\section{LIST OF FIGURES}

Page

Figure 1.1. Distribution of tall fescue clone response to brown patch disease averaged over two years and two locations

Figure 2.1. Population distribution of $F_{1}$ progeny of a cross between two brown patch resistant tall fescue genotypes (7511 and 7587)

Figure 2.2. Population distribution of $F_{1}$ progeny of a cross between two brown patch resistant tall fescue genotypes (7511 and RP66) .73

Figure 2.3. Population distribution of $F_{1}$ progeny of a cross between two brown patch resistant tall fescue genotypes (RP66 and 7587)

Figure 2.4. Population distribution of $F_{1}$ progeny of a cross between two brown patch susceptible tall fescue genotypes (CL5 and CR15).

Figure 2.5. Population distribution of $F_{1}$ progeny of a cross between two brown patch susceptible tall fescue genotypes (RP34 and CL5)........................... 75

Figure 2.6. Population distribution of $F_{1}$ progeny of a cross between two brown patch susceptible tall fescue genotypes (RP34 and CR15) ........................ 75

Figure 2.7. Population distribution of $F_{1}$ progeny of a cross between a brown patch resistant genotype (7511) and a susceptible tall fescue genotype (CL5)

Figure 2.8. Population distribution of $\mathrm{F}_{1}$ progeny of a cross between a brown patch resistant genotype (7511) and a susceptible tall fescue genotype (CR15) .76

Figure 2.9. Population distribution of $F_{1}$ progeny of a cross between a brown patch resistant (7511) and a susceptible tall fescue genotype (RP34)

Figure 2.10. Population distribution of $F_{1}$ progeny of a cross between a brown patch resistant (7587) and a susceptible tall fescue genotype (CL5)...

Figure 2.11. Population distribution of $F_{1}$ progeny of a cross between a brown patch resistant (7587) and a susceptible tall fescue genotype (CR15) .78

Figure 2.12. Population distribution of $F_{1}$ progeny of a cross between a brown patch resistant (7587) and a susceptible tall fescue genotype (RP34)

Figure 2.13. Population distribution of $F_{1}$ progeny of a cross between a brown patch resistant (RP66) and a susceptible tall fescue genotype (CL5) 


\section{LIST OF FIGURES (cont.)}

Page

Figure 2.14. Population distribution of $F_{1}$ progeny of a cross between a brown patch resistant (RP66) and a susceptible tall fescue genotype (CR15)

Figure 2.15. Population distribution of $\mathrm{F}_{1}$ progeny of a cross between a brown patch resistant (RP66) and a susceptible tall fescue genotype (RP34)

Figure 2.16. Mid-parent-offspring regression of $F_{1}$ population means regressed on the mid-parent value from 15 crosses between six tall fescue parental genotypes evaluated for brown patch resistance in 2007

Figure 2.17. Mid-parent-offspring regression of $F_{1}$ population means regressed on the mid-parent value from 15 crosses between six tall fescue parental genotypes evaluated for brown patch resistance in 2008

Figure 3.1. Distribution of half-sib progeny from a polycross of nine tall fescue genotypes evaluated for brown patch resistance over 2 years (2007 and 2008)

Figure 4.1. Distribution of brown patch disease severity in a mapping population of 190 individuals from a cross between a resistant genotype (ATM 110) and a susceptible genotype (110-7) evaluated over two year and two locations (2007 and 2008)

Figure 4.2. Linkage map of the mapping population derived from the cross between resistant genotype (ATM-21) and susceptible genotype (110-7) use for QTL analysis 


\section{Literature Review}

\section{Tall Fescue}

Tall fescue (Festuca arundinaceae Schreb.) is cool-season grass that was introduced into the United States during the late half of the $19^{\text {th }}$ Century (Buckner et al., 1979). Researchers took special note of tall fescue in the late 1800's when it was observed as being more resistant to crown rust (Puccinia coronata Dda.) then meadow fescue (F.pratensis Huds) which at the time was the prominent forage species (Buckner et al., 1979). Tall fescue did not gain prominence as a forage grass until the early 1940's when Oregon and Kentucky released 'Alta' and 'Kentucky 31', respectively. At this time quality seed became available and the production and utilization of tall fescue increased substantially (Buckner et al., 1979).

It was not until 1981, that tall fescue entered the turfgrass industry with the release of the turf type cultivar 'Rebel' (Funk et al., 1981). Since that time, breeders have continued to improve tall fescue for color, growth habit, texture, and disease and insect resistance (Morris, 2006). A large amount of genetic variation exists within the tall fescue turfgrass cultivars. Watkins and Meyer (2004) used principal component analysis of morphological measurements to assign tall fescue cultivars into six groups; Semidwarf, Early semi-dwarf, Dwarf, Standard, and Forage/early standard. Although significant improvements have been made in tall fescue since the release of the first cultivars, the selection and breeding of improved turfgrass cultivars for disease resistance is still needed. 


\section{Brown Patch Disease}

Brown patch caused by Rhizoctonia solani Kühn is a soil borne pathogen that is regarded as one of the most destructive pathogens on both warm and cool-season turfgrass species (Burpee and Martin, 1992). Brown patch was first reported on turfgrass in 1914 when it was discovered as a pathogen of creeping bentgrass (Agrostis palustris Huds.) in the turf garden of F.W. Taylor (Piper and Coe, 1919). Since then brown patch has been reported to cause damage on the following turfgrass species; annual bluegrass (Poa annua L.), Kentucky bluegrass (Poa pratensis L.), colonial bentgrass (Agrostis tenuis Sibth.), velvet bentgrass (Agrostis canina L.), red fescue (Festuca rubra subsp. rubra L.), Chewings fescue (Festuca rubra subsp. commutate Gaud.), sheep fescue (Festuca ovina L.), tall fescue, annual ryegrass (Lolium multiflorum Lam.), perennial ryegrass (Lolium perenne L.), St. Augustinegrass (Stenotaphrum secundatum (Walt.) Kuntze), bermudagrass (Cynodon dactylon (L.) Pers.), buffalograss (Buchloe dactyloides (Nutt.) Engelm.), and zoysiagrass (Zoysia japonica Steud.) (Couch, 1995). Cool season turfgrasses are highly susceptible to brown patch in the summer months during periods of warm, humid weather. In contrast, on warm-season turfgrasses brown patch commonly occurs during the spring when these turfgrass species are breaking dormancy or in the fall as they approach dormancy (Burpee and Martin, 1992). Damage sustained by brown patch is commonly restricted to the leaves of the plant, with regenerating growth beginning shortly after the disease subsides. However, if plants are subjected to 
prolonged conditions that are favorable for disease development, the result may be the death of the plant (Smith et al., 1989).

\section{Symptoms}

Symptoms of infection appear as circular patches of discolored turf ranging in size from $5-60 \mathrm{~cm}$ in diameter (Smiley et al., 2005). Symptom expression will vary depending on the turfgrass species, height of cut, and weather conditions. On turfgrass maintained at a height of cut below $0.5 \mathrm{~cm}$, such as golf course greens, the patches first appear purplish-green in color before turning to a light brown (Couch, 1995; Smiley et al., 2005). Under conditions of higher mowing heights; such as home lawns, parks, and athletic fields, the primary symptom of brown patch is circular patches of light brown color (Couch, 1995; Smiley et al., 2005). On close-cut turf, a dark purplish or grayish brown border, referred to as a smoke ring, may be present on the edges of the discolored patches (Burpee and Martin, 1992). Symptoms may develop on individual leaf blades and appear as dull tan lesion. Under intense disease pressure, these lesions can continue to grow, encompassing large portions of the leaf. This can result in the entire leaf becoming necrotic (Couch, 1995).

\section{The Casual Organism}

Rhizoctonia solani Kühn (teleomorph; Thanatephorous cucmeris (Frank) Donk) is the causal agent of brown patch. Since it produces no spores, $R$. solani can only be 
identified from mycelial and sclerotial states (Smith et al., 1989). Important taxonomic characteristics include; tan to brown mycelium with right angle branching, constriction at the septa and the formation of a septum in the branch near the point of origin, the absence of asexual spores, the absence of clamp connections, the absence of rhizomorphs, dark brown sclerotia, multinucleate hyphal cells, presence of dolipore septum, and an optimum growth range between $20-30^{\circ} \mathrm{C}$ (Blazier and Conway, 2004; Couch, 1995; Smiley et al., 2005).

Hyphal fusion among isolates of Rhizoctonia species has lead to the assignment of these fungi to anastomosis groups (AGs) (Ogoshi, 1987). If no fusion occurs at the junction of the hyphae of two isolates they are considered to be in different AGs. However, if fusion occurs between the two isolates, followed by an interesting phenomenon in which five or six cells on either side of the fusion die, the isolates are classified as being from the same AG (Anderson, 1982). To date, fourteen different AGs of $R$. solani have been reported on a variety of different host plants (Zhao et al., 2006). Isolates in common AGs are believed to be more genetically homogeneous than isolates in different AGs (Ogoshi, 1987). It has also been suggested by several authors that AGs may be host specific (Burpee and Martin, 1992; Martin and Lucas, 1984; Yitbarek et al., 1987). Isolates of $R$. solani taken from turfgrass have been classified in to anastomosis groups AG-1-1, AG-2-2, AG-4, and AG-5 (Burpee and Martin, 1992).

\section{Control}

Disease forecasting models have been developed to predict when outbreaks of brown patch may occur; therefore, enabling turf managers to apply fungicides as needed 
to control disease development. The earliest model used to predict the occurrence of brown patch was based only on air temperature (Dahl, 1933). Schumann et al. (1994) developed a disease forecasting model based on environmental parameters associated with disease development such as daily mean air and soil temperatures, rainfall-irrigation events, and relative humidity. Fidanza et al. (1996) developed a forecasting model based on the mean relative humidity and minimum daily temperature to predict brown patch outbreaks. While both prediction models take into account many environmental variables, Gross et al. (1998) suggested that leaf wetness is the environmental variable that dictates whether or not an infection event will occur; whereas temperature determines the speed and extent of the infection.

Reducing leaf wetness to control brown patch is an idea that was illustrated by Dickson (1930) who observed that poling on golf course greens in the morning greatly reduced the occurrence of brown patch. Along with limiting the duration of leaf wetness, decreasing the amount of fertilizer applied to the turf will also reduce brown patch severity. Burpee (1995) studied the interactions between mowing height, nitrogen fertility, and cultivars of tall fescue to determine the effect they had on brown patch severity. In this study, the effect of mowing height on brown patch severity was not consistent across cultivars; however, there was a significant increase in disease severity as nitrogen levels increased from $24.4 \mathrm{~kg} \mathrm{~N}$ per ha per month to $48.8 \mathrm{~kg} \mathrm{~N}$ per ha per month (Burpee, 1995).

Cultural control options can reduce disease incidence but in environments where there is high disease pressure, brown patch will remain a recurrent seasonal problem (Smith et al., 1989). Currently, fungicides are the most effective tool in reducing disease 
severity. Calendar based applications are still widely used to control diseases of turfgrass. Using a curative approach or implementing a disease forecasting model to time pesticide applications is an important component of an integrated pest management program. Using these approaches as opposed to a calendar based program may result in reduced amounts of fungicide inputs (Settle et al., 2001). Lastly, the development of resistant cultivars would provide an effective control strategy, which potentially could reduce the amount of fungicides needed to maintain a healthy turfgrass throughout the growing season. In a study evaluating fungicides for control of brown patch and dollar spot (Sclerotinia homoeocarpa Bennet.) on creeping bentgrass, Settle et al. (2001) found that choosing cultivars with higher levels of resistance to these diseases influenced fungicide requirements.

\section{Evaluation of Brown Patch Resistance in Tall Fescue}

Tall fescue cultivar evaluations have shown that a large amount of diversity exists in response to brown patch (Clarke et al., 1985; Zarlengo et al., 1994). Burpee (1992) evaluated 35 cultivars of tall fescue grown in a growth chamber that were inoculated with a single isolate of $R$. solani. Based on the disease data taken after inoculation, the cultivars of tall fescue evaluated in this study were statistically separated into highly susceptible and moderately susceptible. Burpee (1992) also evaluated 21 tall fescue cultivars in a field trial that had been established from seed three years earlier. The field trial was not inoculated for brown patch, but as seen in the growth chamber, the tall fescue cultivars segregated for moderate and high levels of susceptibility. Burpee (1995) 
also reported significant differences of brown patch resistance observed among four tall fescue cultivars and one blend that had been established from seed and inoculated with a single isolate of $R$. solani.

Complete resistance to brown patch has not been observed in tall fescue trials. Studies have been conducted that examined certain morphological aspects of tall fescue to determine what influence they may have on resistance to brown patch. Green II et al. (1999) reported that the difference in susceptibility of two tall fescue cultivars, 'Mojave' and 'Kentucky 31', was a function of variance in leaf width and lesion expansion rate. They found that the narrow leaves of Mojave developed lesions that covered a greater area of the leaf width compared to the lesions that developed on the wider leaves of Kentucky 31. The greater amount of leaf area covered by the lesions on Mojave resulted in higher levels of disease severity. They also reported that lesion expansion was slower on Kentucky 31 which could account for less disease when compared with Mojave (Green II et al., 1999).

It has also been documented that the density of the turf canopy influences brown patch severity. Geisler et al. (1996) reported that there was an increase in the leaf wetness period as well as an increase in relative humidity in high-density turf canopies as opposed to low-density turf canopies. These changes in the micro-environment were correlated with increased brown patch disease in the high-density turf canopies. Another factor that was attributed to an increase in brown patch severity in high-density canopies was blade proximity. In high-density canopies the fungal hyphae was able to spread more rapidly than in low-density canopies and inter-blade hyphal growth occurred more frequently in high-density canopies (Geisler et al., 1996). These studies have shed light 
on some of the physiological and environmental factors that play a role in resistance, but they did not address potential genetic factors that may be involved. In order to develop new cultivars with improved resistance, the genetic factors of brown patch resistance must be determined.

\section{Breeding for Resistance}

The least expensive, most effective, and safest way of controlling a plant disease is the use of resistant cultivars (Agrios, 1997). Plants have two main mechanisms to cope with diseases, resistance and tolerance. Resistance is the ability of a plant to inhibit the growth and development of a pathogen. Tolerance is the ability of the plant to function and reproduce despite the presence of a pathogen (Fehr, 1987). The goal of a plant breeder is to develop cultivars that are resistant to pathogens. In order to achieve this goal, the inheritance of the trait must be determined.

Selection methods for disease improvement differ depending on whether the trait being improved is qualitatively or quantitatively inherited. Qualitative resistance is controlled by major genes for resistance and is easily integrated into a breeding program; however, this form of resistance is usually only effective against one strain of the pathogen (Flor, 1971). Quantitative resistance is under the control of a large number of genes (polygenes), each with a small additive effect on resistance. Polygenic resistance is effective across a large number of races of a pathogen and is considered a more durable form of resistance (Browning and Frey, 1969; Hooker, 1967). 
Conflicting reports can be found in the literature describing the inheritance of resistance to R. solani. Researchers have reported that there are multiple genes involved in the inheritance of rice sheath blight ( $R$. solani) resistance and consider it to be a polygenic quantitative trait (Li et al., 1995; Zou et al., 2000). Conversely, other researchers have reported resistance of rice sheath blight to be controlled by major genes (Che et al., 2003; Pan et al., 1999). Kasuga and Inoue (2001) reported multiple genes involved in sheath blight resistance in sorghum (Sorghum bicolor (L.) Moench). Zhao et al. (2006) reported continuously distributed populations for banded leaf and sheath blight (R. solani) in maize (Zea mays L.), indicative of a quantitatively inherited trait.

\section{Heritability}

Heritability is the proportion of the observed variation in a progeny that is inherited (Poehlman and Sleper, 1995), and it used by plant breeders to estimate expected improvements due to selection (Nyquist, 1991). Heritability can be expressed in the broad-sense or narrow-sense (Fehr, 1987). Heritability in the broad-sense is the ratio of the total genetic variance to the phenotypic variance, while heritability in the narrowsense is the ratio of additive genetic variance to the phenotypic variance (Dudley and Moll, 1969). Heritability ratios are calculated from observations on various genotypes grown in a series of environments, sampling sites, and years (Gorden et al., 1972). The phenotypic variance is the total variance among phenotypes when grown over the range of environments of interest to the breeder. The total genetic variance is the portion of the phenotypic variance which can be attributed to genotypic differences among the 
phenotypes. The total genetic variance can be further subdivided into additive genetic variance, dominance genetic variance, and epistatic genetic variance (Dudley and Moll, 1969). Traits with high heritability, indicating less influence by the environment, can be improved more rapidly and with less intensive evaluation than traits with low heritability (Nyquist, 1991). An understanding of the ratio of the additive genetic variance to the total genetic variance is important in cross pollinated grasses since the most effective breeding design maximizes the utilization of the additive genetic variation, which is usually achieved through some form of recurrent selection (Vogel and Pendersen, 1993).

Broad-sense heritability estimates can be determined by using variance components derived from the mean square of the analysis of variance. The method of calculation is represented by the formula:

$H=\sigma_{g}^{2} /\left(\sigma_{g}^{2}+\sigma_{\text {gy }}^{2}+\sigma_{\text {gl }}^{2}+\sigma_{\text {gyl }}^{2}+\sigma_{e}^{2}\right)$

$\sigma^{2} \mathrm{~g}=$ the total genetic variance of clones, $\sigma_{\mathrm{gy}}^{2}=$ genotype $\times$ year variance, $\sigma_{\mathrm{gl}}^{2}=$ genotype $\times$ location variance, $\sigma_{\text {gyl }}^{2}=$ genotype $\times$ year $\times$ location variance, and $\sigma_{\mathrm{e}}^{2}=$ experimental error variance (Poehlman and Sleper, 1995).

Narrow-sense heritability can be estimated by progeny parent regression. The regression of progeny performance on parent performance is based on resemblance between relatives and measures additive variance as a proportion of the phenotypic variance (Poehlman and Sleper, 1995). One of the principal uses of heritability estimates is to predict gain from selection. Gain from selection can be calculated using the formula $\mathrm{Gs}=i \sigma_{\mathrm{p}} h^{2}$, where Gs is the genetic gain from selection, $i$ is a constant based on selection intensity, $\sigma_{\mathrm{p}}$ is the standard deviation of the phenotypic variance, and $h^{2}$ is the narrowsense heritability (Poehlman and Sleper, 1995). 
Several studies have been conducted to evaluate the broad and narrow-sense heritability estimates of forage traits in tall fescue. Burton and DeVane (1953) estimated the broad-sense heritability of seed yield, forage yield, rating of greenness, and disease resistance for tall fescue by using clonally propagated material. The genetic variance for each trait was derived from the mean squares for clones and error in the regular analysis of variance by separating out the variance components according to the following formula:

$V_{e}+N V_{g}=$ the expectation of the clone mean square

$\mathrm{V}_{\mathrm{e}}=$ the expectation of the error mean square

$\mathrm{V}_{\mathrm{g}}=$ the total genetic variance

$\mathrm{N}=$ the number of replications of each clone.

This research illustrated the advantages of calculating the total genetic variance using replicated clones as opposed to single plants. The first advantage is that the total genetic variance does not depend upon the assumption that environmental variance is equal for the segregating and non-segregating populations. The second advantage is this method of calculation reduces the amount of genotype $\times$ environmental variance that is carried over into the estimate of the genetic variance (Burton and DeVane, 1953). In this study, the broad-sense heritability calculated on a six plant mean basis as opposed to a single plant basis was higher for all traits. Likewise, the predicted gain from selection for each trait was highest when the genetic variance calculated from the six plant mean was used in the formula instead the genetic variance calculated on a single plant basis.

Nguyen and Sleper (1983a) analyzed parents and progeny of tall fescue from a polycross and estimated the narrow-sense heritability for seed yield and reproductive 
characters. Predicted genetic gains from selection of $33,45,27,34$, and $14 \%$ of the population mean for maturity score, number of panicles, panicle length, seed yield, and 100-weight, respectively, were estimated from the narrow-sense heritability. It was concluded that the genetic variability in these populations indicated excellent opportunities for improving seed yield.

Bughrara et al. (1991) calculated both the broad-sense and narrow-sense heritability estimates for improved digestibility in tall fescue using variance components calculated from an analysis of variance. The broad-sense heritability estimates ranged from 0.03 to 0.35 while the narrow-sense heritability estimates ranged from 0.25 to 0.85 . The narrow-sense heritability estimates were used to predict the genetic gain from selection. Based on predicted gain per selection which ranged from $21 \%$ to $53 \%$ of the population mean, Bughrara et al. (1991) concluded that a phenotypic selection by clonal evaluation without progeny testing would be efficient in improving digestibility in tall fescue.

Heritability estimates have also been calculated for other turfgrass pathosystems. Hurley and Funk (1985) reported the broad-sense heritability of resistance to Sclerotinia homeocarpa in Poa trivialis. Plants were evaluated in the greenhouse, field/sun, and field/shade with broad-sense heritability estimates ranging from 0.57 to 0.90 on a three plant mean basis. Broad-sense heritability estimates were calculated on a family basis for stem rust (Puccinia graminis subsp graminicola Urban) resistance in perennial ryegrass (Rose-Fricker et al. 1986). They found that the broad-sense heritability estimates decreased over time and concluded that selection for resistance needed to be made during early anthesis. Broad-sense heritability estimate of 0.56 on a single plant basis and 0.90 
on an 11-plant mean basis for dollar spot (Sclerotinia homeocarpa) resistance in creeping bentgrass was reported by Bonos et al. (2003) indicated the need for replication in selection of resistant clones. To determine the narrow-sense heritability of dollar spot resistance in creeping bentgrass Bonos (2006) evaluated progeny from resistant $x$ resistant, resistant $\times$ susceptible, and susceptible $\times$ susceptible crosses. A high narrowsense heritability estimate of 0.79 was estimated from mid-parent progeny regression indicating that most of the genetic variation for dollar spot resistance in the populations studied could be attributed to additive genetic variance. Han et al. (2006) reported the narrow-sense heritability of gray leaf spot (Pyricularia oryzae Cavara) resistance in perennial ryegrass to be 0.57 to 0.76 . Based on the moderate to high narrow-sense heritability estimates they reported that resistance could be improved through a genotypic recurrent selection program.

Both the broad-sense and narrow-sense heritability estimates for the degree of damage caused by $R$. solani in sorghum (Sorghum bicolor (L.) Moench) was calculated by Kasuga and Inoue (2001). The broad-sense heritability estimate was 0.935 and the narrow-sense heritability estimate was 0.773 . These estimates indicate a strong genetic component for resistance in sorghum with additive genetic variance accounting for the majority of genetic variation observed.

\section{Stability Analysis}

Understanding how to integrate the genotype $\times$ environment $(G \times E)$ interaction into making selections for improvement has long been the subject of research (Allard and 
Bradshaw, 1964). Stability analysis is a method to evaluate the performance of genotypes over multiple years and locations. The larger the $\mathrm{G} \times \mathrm{E}$ interaction, the less correlation there is between the genotype and the phenotype, which reduces the effectiveness of selection (Comstock and Moll, 1963; Nguyen et al., 1980). By identifying stable genotypes in preliminary evaluations, those that show a minimum interaction with the environment, will lead to an increase in the number of stable genotypes used in advanced testing (Eberhart and Russell, 1966). There are several definitions of stability that can be found throughout the literature. Authors have classified a genotype as stable if the response of the genotype over several environments was equivalent to that of the mean response of all genotypes in the trial (Shukla, 1972), equivalent to the best performing genotype in each environment (Linn and Binns, 1988) or significantly greater than the mean response of genotypes at each location (Casler et al., 2001). Other authors have used ranking systems to determine if a genotype is stable over multiple environments (Fox et al., 1990; Kang and Pham, 1991). While there may be no consensus as to what stability methods works best for a particular breeding program, there can be no denying the impact that $\mathrm{G} \times \mathrm{E}$ interaction has upon quantitative genetics and plant breeding (Hill, 1975). Comstock and Moll (1963) noted that genetic facts are inferred from observation made on phenotypes, and there is the potential for $G \times$ E interaction to effect the phenotype of all quantitative characters, therefore $\mathrm{G} \times \mathrm{E}$ interaction is in some way involved with most quantitative genetics and plant breeding problems.

\section{Combining Abilities}


Sprague and Tatum (1942) reported the use of combining ability to study quantitative traits. The mean performance of progeny from a particular parent, when expressed as a deviation from the mean of all other crosses is called the general combining ability (GCA). Therefore, any cross then has an 'expected' value which is the sum of the GCA of the two parental lines. The deviation of a specific cross from the expected value is called the specific combining ability (SCA). The GCA is a measurement of the additive genetic variance and the SCA is measurement of nonadditive genetic variance (Falconer and Mackay, 1996).

A diallel cross analysis following the statistical methods presented by Griffing (1956) allows for the estimation of both the general and specific combining ability. These combining ability estimates can be used to determine the relative importance of the additive vs. non-additive gene effects influencing the trait of interest as well as identify potential parents that can incorporated into a breeding program (Araujo and Coulman, 2002; Becelaere and Miller, 2004; Cisar et al., 1981). In an open-pollinated species, polycross mating can also be implemented to develop half-sib progenies that can be studied to determine GCA (Nguyen and Sleper, 1983a).

Nguyen et al. (1982) used a diallel design to evaluate inheritance of leaf tensile strength, fiber content, in vitro dry matter digestibility, and herbage yield in nine forage genotypes of tall fescue. The results from the diallel analysis indicated that GCA was significant for most traits, whereas SCA was only significant for one trait. It was concluded that hybrid development of tall fescue cultivars utilizing non-additive genetic variance would not be practical for forage quality. It was also suggested that a polycross 
mating design should be used over a more complicated diallel design to screen clones for high GCA for development of synthetic cultivars.

A diallel design consisting of five tall fescue parents and a second consisting of six tall fescue parents were used to study the inheritance of resistance to infection by Drechslera sorokiniana (Sacc.) Subram. and Jain (Linscombe et al., 1983). The analysis of variance from each diallel experiment indicated that GCA was a significant source of variation for lesion coverage and size; however, SCA was not significant. The presence of significant GCA and the lack of significant SCA suggest that resistance to $D$. sorokiniana is primarily controlled by additive gene action in the tall fescue genotypes studied.

Bonos (2006) analyzed a diallel cross of three creeping bentgrass genotypes and reported that both GCA and SCA effects were significant for dollar spot resistance; however, the GCA accounted for a greater proportion of the mean squares then the SCA. Based on these findings, it was suggested that selecting for parents with significant GCA would be effective for improving dollar spot resistance. Han et al. (2006) also concluded that additive gene effects were the major factor in gray leaf spot resistance in the perennial ryegrass populations they studied. Analysis of two diallel designs consisting of six parents and eight parents revealed that GCA effects accounted for more of the genetic variation then the SCA effects. It was concluded that resistance could be improved through a genotypic recurrent selection program.

A diallel analysis of resistance to sheath blight in sorghum was conducted by Kasuga and Inoue (2001). It was reported that resistance was controlled by multiple genes and that additive and dominant gene effects influenced resistance which was 
consistent with the broad and narrow-sense heritability reported in that study. The information pertaining to gene action is invaluable to a plant breeder, as decisions must be made pertaining to the mating design that will maximize improvements.

\section{Minimum Number of Effective Genes}

Burton (1951) noted that an understanding of gene action and number of genes controlling the expression of a quantitative character is of great value to a plant breeder. The minimum number of effective genes that could be controlling a trait of interest can be calculated based on the formula of Wright (1968)

$$
n=\left(\mathrm{P}_{1}-\mathrm{P}_{2}\right)^{2} / 8\left(\sigma^{2} \mathrm{~F}_{2}-\sigma_{\mathrm{E}}^{2}\right)
$$

where $\mathrm{n}=$ number of genes, $\mathrm{P}_{1}=$ mean resistance of parent $1, \mathrm{P}_{2}=$ mean resistance of parent $2, \sigma^{2} F_{2}=$ variance of $F_{2}$ population, and $\sigma_{E}^{2}$ environmental variance among replicates of a parental clone pooled for all parental clones. This method of estimation is based on the assumptions that the genes have equal effects, no dominance or epistasis is present, and that no two loci are in the same chromosome (Poehlman and Sleper, 1995). In very few cases do these assumptions hold true, the actual number of genes is usually higher than what is estimated using this formula. For practical breeding purposes this formula can be used to estimate if the quantitative character is regulated by a large or small number of genes (Poehlman and Sleper, 1995).

\section{Detection of Major Genes}


The detection of a major gene can be determined using the formula described by Lynch and Walsh (1998) that was first proposed by Fain (1978):

$$
\operatorname{Var}\left(\bar{o}_{i}\right)=a+b_{1} \bar{o}_{i}+b_{2} \bar{o}_{i}^{2}
$$

where $\operatorname{Var}\left(\bar{o}_{i}\right)$ is the phenotypic variance with $i$ th sibship and $\bar{o}_{i}$ is the mid-parental value for this sibship. A significant value of $b_{2}$ is taken as an indication of a major gene. The theory behind this formula is that for a character that is influenced by a few major genes, the parents with the most extreme phenotypes will be homozygotes and the parents with intermediate phenotypes will be heterozygotes. This relationship would result in a quadratic regression of offspring variance on mid-parent phenotypic values (Lynch and Walsh, 1998).

\section{Quantitative Trait Loci}

Marker assisted selection in plant breeding shows promise for improving traits that fall into four major categories (i) traits that are difficult to manage through conventional phenotypic selection (time consuming to measure or low heritability), (ii) traits which selection depends upon specific environments or development stages that influence the expression of the target phenotype, (iii) maintenance of recessive alleles during backcrossing or speeding up backcross breeding in general, and (iv) pyramiding multiple monogenic traits or several quantitative trait loci (QTL) for a single target trait with complex inheritance (Xu and Crouch, 2008). Genetic linkage maps provide the framework for the study of genome structure, localization of genes of interest, and the identification of QTL (Liebhard et al., 2003). The use of molecular based linkage maps has become an effective tool to identify QTL associated with disease resistance in plants. 
As previously noted, several reports have documented the quantitative nature of resistance to the pathogen $R$. solani in several field crops (Li et al., 1995; Zhao et al., 2006; Zou et al., 2000). Breeding for resistance to this pathogen has been slow because of the strong environmental interaction and lack of resistant germplasm that can be incorporated into a breeding program. To determine the presence of QTL for rice sheath blight resistance in rice (Oryza sativa L.), Li et al (1995) studied a $\mathrm{F}_{4}$ bulked population from a cross between a resistant variety 'Tequing”' and a susceptible variety 'Lemont' for two years of field disease evaluation. Restriction fragment length polymorphism (RFLP) markers were used to construct a genetic linkage map and six putative QTLs were identified for rice sheath blight resistance. All together these six putative QTLs explained $47 \%$ of phenotypic variation of the rice population. Zou et al (2000) developed a $F_{2}$ clonal population from a cross between resistant variety 'Jasmine 85 ' and susceptible variety Tequing and evaluated disease resistance over two years. A genetic linkage map was constructed using RFLP markers and from this study, six putative QTLs were also identified. Theses six putative QTLs explained 21.2, 26.5, 22.2, 10.1, 9.8, and 31.2\% of the total phenotypic variation. Unfortunately there was no agreement between the putative QTLs reported for rice sheath blight in either study of Li et al (2005) or Zou et al (2000). In an effort to confirm the existence of QTLs for rice sheath blight, Pinson et al. (2005) developed a mapping population between a cross of the varieties Tequing and Lemont as reported by Li et al (1995). RFLP markers were used to construct the genetic linkage map. From this experiment six QTLs were indentified that overlapped the same genomic locations that were previously reported as putative QTLs for rice sheath blight resistance by Li et al. (1995) and Zou et al. (2000). This confirmation of six QTLs for 
resistance to $R$. solani in rice across multiple populations is a major step in developing marker assisted selection in rice breeding.

Zhoa et al. (2006) reported the first identification of putative QTLs for banded leaf and sheath blight ( $R$. solani) in maize (Zea mays L.). Simple sequence repeat (SSR) markers were used to construct a genetic linkage map from a mapping population of $\mathrm{F}_{2}$ individuals derived from the cross of inbreds R15 (resistant) and 478 (susceptible). Eleven putative QTLs for resistance to banded leaf and sheath blight in maize were identified. The effect of the environment on disease resistance was evident in this study with only four of the eleven putative QTLs present across two locations.

In recent years the identification of QTLs for disease resistance in turfgrass species has also been documented. Warnke et al. (2004) developed a genetic linkage map of annual x perennial ryegrass population using amplified fragment length polymorphism (AFLP), random amplification of polymorphic DNA (RAPD), RFLP, and SSR markers. Curley et al (2005) used the genetic linkage map of Warnke et al. (2004) and supplemented additional RFLP data from Sim et al. (2005) and found several putative QTLs for gray leaf spot resistance. The strongest QTL for resistance explained 20 and $30 \%$ of the phenotypic variance depending on the experiment. Muylle et al (2005) identified four QTLs for crown rust (Puccinia coronata F. sp. lolli) resistance in a perennial ryegrass population. The QTLs explained 12.5, 24.9, 5.5, and 2.6\% of the phenotypic variance.

The significance of these genetic studies may be ultimately realized by comparative mapping. In ryegrass this has been done using a common set heterologous RFLP and SSR markers which has enabled researcher to characterize the ryegrass 
genome relative to the oat (Avena sativa L.), rice, tall fescue, and wheat (Triticum aestivum L.) genomes due in large part to the conserved synteny observed among the Poaceae family (Curley et al., 2005; Jones et al, 2002a; Jones et al., 2002b; Sim et al., 2007). These genome relationships ultimately allow for the cross species transfer of information which can enhance our understanding of the underlying genetic mechanisms controlling traits such as disease resistance.

Saha et al. (2005) developed the first PCR-based genetic linkage map of tall fescue $(2 n=6 x=42)$ using SSR and amplified fragment length polymorphisms (AFLP) markers. The SSRs that were used to develop the genetic linkage map of tall fescue (Saha et al., 2005) were also shown to be transferable across several members of the Poaceae family (Saha et al., 2004). Saha et al. (2006) also reported the development of the first genomic-SSR markers from tall fescue that are transferable across other forage, turf, and cereal grass species, indicating the potential for use in comparative genome studies. 


\section{Goal of This Thesis}

This thesis reports the following:

1. The broad-sense heritability and stability analysis of brown patch resistance of 230 tall fescue genotypes,

2. inheritance characteristics of brown patch resistance in tall fescue i.e. narrowsense heritability, minimum number of genes influencing resistance, and the general and specific combing ability of brown patch resistance in tall fescue, and

3. the development of a genetic linkage map of tall fescue and the subsequent identification of putative QTLs associated with brown patch resistance in tall fescue. 


\section{REFERENCES}

Agrios, G. 1997. Plant pathology. Academic Press, San Diego.

Allard, R.W. and A.D. Bradshaw. 1964. Implications of genotype-environmental interactions in applied plant breeding. Crop Sci. 4:503-508.

Anderson, N. A. 1982. The genetics and pathology of Rhizoctonia solani. Annu. Rev. Phytopathol. 20:329-347.

Araujo M. R. A. and B. E. Coulman. 2002. Genetic variation, heritability and progeny testing in meadow bromegrass. Plant Breeding 121:417-424.

Becelaere, G.V., and J.F. Miller. 2004. Combining ability for resistance to Sclerotinia head rot in sunflower. Crop Sci. 44:1542-1545.

Blazier, S.R. and K.E. Conway. 2004. Characterization of Rhizoctonia solani isolates associated with patch diseases of turfgrass. Proc. Okla. Acad. Sci. 84: 41-51.

Bonos, S.A. 2006. Heritability of dollar spot resistance in creeping bentgrass. Phytopathology 96:808-812.

Bonos, S.A., M.A. Casler, and W.A. Meyer. 2003. Inheritance of dollar spot resistance in creeping bentgrass. Crop Sci. 43:2189-2196.

Browning, J.A. and K.J. Frey. 1969. Multiline cultivars as a means of disease control. Annu. Rev. Phytopathol. 7:355-382.

Bughrara S. S., D. A. Sleper, and G. F. Krause. 1991. Genetic variation in tall fescue digestibility estimated using a prepared cellulose solution. Crop Sci. 31:883-889.

Buckner, R.C., J.B. Powell, and R.V. Frakes. 1979. Historical Development. In R.C. Buckner and L.P. Bush Eds. Tall Fescue. Agron. Monogr. 20. ASA, CSSA, and SSSA, Madison, WI.

Burton, G.W. 1951. Quantitative inheritance in pearl millet (Pennisetum glaucum). J. Amer. Soc. Agron. 43: 409-417.

Burton, G.W. and E.H. Devane. 1953. Estimating heritability in tall fescue (Festuca arundinacea) from replicated clonal material. Agron. J. 45:478-481.

Burpee, L.L. 1992. Assessment of resistance to Rhizoctonia solani in tall fescue based on disease progress and crop recover. Plant Dis. 76: 1065-1068.

Burpee, L.L. 1995. Interactions among mowing height, nitrogen fertility, and cultivar affect the severity of Rhizoctonia blight of tall fescue. Plant Dis. 79:721-726. 
Burpee, L.L. and B. Martin. 1992. Biology of Rhizoctonia species associated with turfgrasses. Plant Dis. 76:112-117.

Casler, M.D., K.P. Vogel, J.A. Balasko, J.D. Berdahl, D.A. Miller, J.L. Hansen, and J.O. Fritz. 2001. Latitudinal and longitudinal adaptation of smooth bromegrass populations. Crop Sci. 41:1456-1460.

Cisar, G., C.M. Brown, and H. Jedlinski. 1982. Diallel analyses for tolerance in winter wheat to the barley yellow dwarf virus. Crop Sci. 22:328-333.

Clarke, B.B., C. R. Funk, and P. M. Halisky. 1985. Development of Festuca arundinaceae Schreb. cultivars with improved resistance to Rhizoctonia solani Kuhn. Pages 641-646 Proc. Int. Turfgrass Res. Conf., $5^{\text {th }}$. L. Lemaire, ed. INRA Publications, Paris.

Comstock, R. E. and R. H. Moll. 1963. Genotype-environment interactions. Statistical Genetics and Plant Breeding (ed. W.D. Hanson and H.F. Robinson). National Academy of Sciences-National Research Council Publication 982,164-196.

Couch, H. 1995. Disease of turfgrasses. Krieger Publishing Company.

Curley, J., S.C. Sim, S. Warnke, S. Leong, R. Barker, and G. Jung. 2005. QTL mapping of resistance to gray leaf spot in ryegrass. Theor. Appl. Genet. 111:1107-1117.

Dahl, A.S. 1933. Effect of temperature on brown patch of turf. Phytopathology 23:8.

Dickinson, L.S. 1930. The effect of air temperature on the pathogenicity of Rhizoctonia solani parasitizing grasses of putting-green turf. Phytopathology 20:597-608.

Dudley, J. W. and R. H. Moll. 1969. Interpretation and use of estimates of heritability and genetic variance in plant breeding. Crop Sci. 9:257-262.

Eberhart, S.A. and W.A. Russell. 1966. Stability parameters for comparing varieties. Crop Sci. 6:36-40.

Falconer, D.S. and T.F.C. Mackay. 1996. Introduction to quantitative genetics. Longman Grp. Ltd., Essex, England.

Fain, P.R. 1978. Characteristics of simple sibship variance tests for the detection of major loci and application to height, weight, and spatial performance. Ann. Hum. Genet. 42:109-120.

Fehr, W.R. 1987. Principles of cultivar development. Vol. 1. Theory and technique. Iowa State University, Ames, IA 
Fidanza, M.A., P.H. Dernoeden, and A.P. Grybauskas. 1996. Development and field validation of a brown patch warning model for perennial ryegrass turf.

Phytopathology 86:385-390.

Flor, H.H. 1971. Current status of the gene-for-gene concept. Annu. Rev. Phytopathol. 9:275-296.

Fox P.N., B. Skovmand, B.K. Thompson, H.-J. Braun and R. Cormier. 1990. Yield and adaptation of hexaploid spring triticale. Euphytica 47:57-64.

Funk, C.R., R.E. Engel, W.K. Dickson, and R.H. Hurley. 1981. Registration of 'Rebel' tall fescue. Crop Sci. 21:632

Giesler L.J., G. Y. Yuen, and G.L. Horst. 1996. The microclimate in tall fescue turf as affected by canopy density and its influence on brown patch disease. Plant Dis. 80:398-394.

Gordon, I.L., D.E. Byth, and L.N. Balaam. 1972. Variance of heritability ratios estimated from phenotypic variance components. Biometrics 28:401-415.

Green II, D.E., L.L. Burpee, and K.L. Stevenson. 1999. Components of resistance to Rhizoctonia solani associated with two tall fescue cultivars. Plant Dis. 83:834838.

Griffing, B. 1956. Concept of general and specific combining ability in relation to diallel crossing systems. Aus. J. Biol. Sci. 9:464-493.

Gross, M.K., J.B. Santini, I. Tikhonova, and R. Latin. 1998. The influence of temperature and leaf wetness duration on infection of perennial ryegrass by Rhizoctonia solani. Plant Dis. 82:1012-1016.

Han, Y., S.A. Bonos, B.B. Clarke, and W.A. Meyer. 2006. Inheritance of resistance to gray leaf spot disease in perennial ryegrass. Crop Sci. 46:1143-1148.

Hill, J. 1975. Genotype-environment interactions - a challenge for plant breeding. J. Agric. Sci. Camb. 85: 477-493.

Hooker, A.L. 1967. The genetics and expression of resistance in plants to rusts of the genus Puccinia. Annu. Rev. Phytopathol. 5:163-168.

Hurley, R.H. and C.R. Funk. 1985. Genetic variability in disease reaction, turf quality, leaf color, leaf texture, plant density, and seed shattering of selected genotypes of Poa Trivialis. p. 221-226 In Proceedings of the fifth international turfgrass research conference. Avignon, France. July 1-5 July 1985. INRA Publications Paris. 
Jones, E.S., M.P. Dupal, J.L. Dumsday, L.J. Hughes, and J.W. Forster. 2002a. An SSRbased genetic linkage map for perennial ryegrass (Lolium perenne L.). Theor. Appl. Genet. 105:577-584.

Jones, E.S. N.L. Mahoney, M.D. Hayward, I.P. Armstead, J.G. Jones, M.O. Humphreys, I.P. King, T. Kishida, T. Yamada, F. Balfourier, G. Charmet, and J.W. Forster. $2002 \mathrm{~b}$. An enhanced molecular marker based genetic map of perennial ryegrass (Lolium perenne) reveals comparative relationships with other Poaceae genomes. Genome 45:282-295.

Kasuga, S. and N. Inoue. 2001. Diallel analysis of the resistance to sheath blight (Rhizoctonia solani Kühn) in sorghum. Grassland Sci. 47:45-49.

Kang, M.S. and H.N. Pham. 1991. Simultaneous selection for yielding and stable crop genotypes. Agron. J. 83:161-165.

Lin, C.S. and M.R. Binns. 1988. A superiority measure of cultivar performance for cultivar x location data. Canadian Journal of Plant Science 63:193-198.

Li, Z. K., S.R.M. Pinson, M.A. Marchetti, J.W. Stansel, and W.D. Park. 1995. Characterization of quantitative trait loci (QTLs) in cultivated rice contributing to field resistance to sheath blight (Rhizoctonia solani). Theor. Appl. Genet. 91:382:388.

Liebhard, R., B. Koller,. L. Gianfranceschi, C. Gessler. 2003. Creating a saturated reference map for the apple (Malus $x$ domestica Borkh.) genome. Theor. Appl. Genet. 106:1497-1508.

Linscombe, S.D., C.E. Watson, Jr, L.E. Trevathan. 1983. Inheritance of resistance to infection by Drechslera srohiniana in tall fescue. Crop Sci. 23:1085-1087.

Lynch, M., and B. Walsh. 1998. Genetics Analysis of Quantitative Traits. Sinauer Associates, Inc., Sunderland, MA.

Martin, S.B. and L.T. Lucas. 1984. Characterization and pathogenicity of Rhizoctonia spp. and binucleate Rhizoctonia-like fungi from turfgrasses in North Carolina. Phytopathology 74:170-175.

Morris, K.N. 2006. National tall fescue test -2001. Final report. 2002-05. NTEP No. 0612. National Turfgrass Evaluation Program. USDA-ARS. Beltsville, MD.

Muylle, H., J. Baert, E.Van Bockstaele, J. Pertijs, and I. Roldan-Ruiz. 2005. Four QTLs determine crown rust (Puccinia coronata $\mathrm{f}$. sp. lolii) resistance in perennial ryegrass (Lolium perenne) population. Heredity 95:348-357. 
Nguyen, H.T., D.A. Sleper, and K.L. Hunt. 1980. Genotype X environment interactions and stability analysis for herbage yield of tall fescue synthetics. Crop Sci. 20:221-224.

Nguyen, H.Y., D.A. Sleper, and A.G. Matches. 1982. Inheritance of forage quality and its relationship to leaf tensile strength in tall fescue. Crop Sci. 22:67-72.

Nguyen, H. T. and D. A. Sleper. 1983a. Theory and application of half-sib mating in forage grass breeding. Theor. Appl. Genet. 64:187-196.

Nguyen, H. T. and D. A. Sleper. 1983b. Genetic variability of seed yield and reproductive characters in tall fescue. Crop Sci. 23:621-626.

Nyquist, W. 1991. Estimation of heritability and prediction of selection response in plant populations. Crit. Rev. Plant Sci. 10(3):235-322.

Ogoshi, A. 1987. Ecology and pathogenicity of anastomosis and intraspecific groups of Rhizoctonia solani Kühn. Annu. Rev. Phytopathol. 25:125-143.

Pinson, S.R.M., F.M. Capdevielle, and J.H. Oard. 2005. Confirming QTLs and finding additional loci conditioning sheath blight resistance in rice using recombinant inbred lines. Crop Sci. 45:503-519.

Piper, C.V. and H.S. Coe. 1919. Rhizoctonia in lawns and pastures. Phytopathology 9:89-92.

Poehlman, J.M. and D.A. Sleper. 1995. Breeding Field Crops. Iowa State University Press, Ames

Rose-Fricker, C.A., W.A. Meyer, and W.E. Kronstad. 1986. Inheritance of resistance to stem rust (Puccinia graminis subsp. graminicola) in six perennial ryegrass (Lolium perenne) crosses. Plant Disease 70:678-681

Saha, M.C., M.A.R. Mian, I. Eujayl, J.C. Zwonitzer, L. Wang, and G.D. May. 2004. Tall fescue EST-SSR markers with transferability across several grass species. Theor. Appl. Genet. 109:783-781.

Saha, M.C., R. Mian, J.C. Zwonitzer, K. Chekhovskiy and A.A. Hopkins. 2005. An SSR-and AFLP-based genetic linkage map of tall fescue (Festuca arundinaceae Schreb.). Theor. Appl. Genet. 110:323-336.

Saha, M.C., J.D. Cooper, M.A.R. Mian, K. Chekhovskiy, and G.D. May. 2006. Tall fescue genomic SSR markers: development and transferability across multiple grass species. Theor. Appl. Genet. 113:1449-1458. 
Schumann, G.L., B.B. Clarke, L.V. Rowley, and L.L. Burpee. 1994. Use of environmental parameters and immunoassays to predict Rhizoctonia blight and schedule fungicide applications on creeping bentgrass. Crop Prot. 13:211-218.

Settle, D., J. Fry and N. Tisserat. 2001. Dollar spot and brown patch fungicide management strategies in four creeping bentgrass cultivars. Crop Sci. 41:11901197.

Shukla, G. K. 1972. Some statistical aspects of partitioning genotype-environment components of variability. Heredity 29:237-245.

Sim, S., T. Chang, J. Curley, S.E. Warnke, R.E. Barker, and G. Jung. 2005. Chromosomal rearrangements differentiating in the ryegrass genome form the Triticeae, oat, and rice genomes using common heterologous RFLP probes. Theor. Appl. Genet. 110:1011-1019.

Sim, S., K. Diesburg, M. Casler, and G. Jung. 2007. Mapping and comparative analysis of QTL for crown rust resistance in an Italian x perennial ryegrass population. Phytopathology 97:767-776.

Smiley, R.W., P.H. Dernoeden, and B.B. Clarke. 2005. Compendium of turfgrass diseases. $3^{\text {rd }}$ ed. The American Phytopathological Society. St. Paul, Mn.

Smith, J.D., N. Jackson, and A.W. Woolhouse. 1989. Fungal diseases of amenity turf grasses. E. and F.N. Spon, London. 25:266-275.

Sprague, G.F. and L.A. Tatum. 1942. General vs. specific combining ability in single crosses of corn. J. Amer. Soc. Agron. 34:923-932.

Vogel, K. P. and J. F. Pedersen. 1993. Breeding systems for cross-pollinated perennial grasses. Plant Breed. Rev. 11:251-274.

Warnke, S.E., R.E Barker, G. Jung, S. Sim, M.A. Mian, M.C. Saha, L.A. Brilman, M.P. Dupal, and J.W. Forster. 2004. Genetic linkage mapping of an annual $\mathrm{x}$ perennial ryegrass population. Theor. Appl. Genet. 109: 294-304.

Watkins, E. and W.A. Meyer. 2004. Morphological Characterization of turf-type tall fescue genotypes. HortScience 39:615-619.

Wright, S. 1968. Evolution and the genetics of populations, Vol.1. Genetic and biometric foundations. Univ. of Chicago Press, Chicago.

$\mathrm{Xu}, \mathrm{Y}$. and J.H. Crouch. 2008. Marker-assisted selection in plant breeding: from publications to practice. Crop Sci. 48:391-407 
Yitbarek, S.M., P. R., Verma, and R.A.A. Morall. 1987. Anastomosis groups, pathogenicity, and specificity of Rhizoctonia solani isolates from seedling and adult rapeseed/conola plants and soils in Saskatchewan. Can. J. Plant Pathol. 9: 6-13.

Zarlengo P.J., C.S. Rothrock, and J.W. King. 1994. Influence of shading of the response of tall fescue cultivars to Rhizoctonia solani AG-1 IA. Plant Dis. 78:126-129.

Zhao, M., Z. Zhang, S. Zhang, W. Li, D.P. Jeffers, T. Rong, and G. Pan. 2006.

Quantitative trait loci for resistance to banded leaf and sheath blight in maize. Crop Sci. 46:1039-1045.

Zou, J.H., X.B. Pan, Z.X. Chen, J.Y. Xu, J.F. Lu, W. Zhai, and L.H. Zhu. 2000. Mapping quantitative trait loci controlling sheath blight resistance in two rice cultivars (Oryza sativa L.). Theor. Appl. Genet. 101:569-573. 


\section{Chapter I.}

\section{Broad-sense and stability analysis of brown patch resistance in tall fescue}

\section{INTRODUCTION}

Tall fescue (Festuca arundinacea Schreb.) is a cool season turfgrass that is commonly utilized throughout the North American transition zone for residential lawns, athletic fields, golf course roughs, and lower maintenance parks and recreation areas (Beard, 1973). The most devastating disease of tall fescue is brown patch, caused by Rhizoctonia solani Kühn. Brown patch can reduce the overall quality and aesthetics of the turf stand (Couch, 1985; Martin and Lucas, 1984) and reduce stand density when disease is severe.

Current control options to reduce disease severity include restricting the amount of nitrogen applied to the turf (Burpee, 1995), limiting the duration of leaf wetness (Fidanza et al., 1996; Gross et al., 1998), and in some cases, the use of fungicides (Fidanza and Dernoeden, 1996; Smiley et al., 2005). The development of resistant cultivars would provide the most practical, long term approach to controlling brown patch. It has been documented by several authors that significant differences in susceptibility to brown patch exist among tall fescue cultivars (Burpee, 1995; Geisler et al., 1996; Green II et al., 1999).

Currently, the disease resistance mechanism of brown patch resistance in tall fescue is not fully understood. Green II et al. (1999) postulated that disease severity was a function of variation in leaf width and concluded that the wider leaf blades of the 
cultivar 'Kentucky 31' had less disease than the finer leafed cultivar 'Mojave'. Geisler et al. (1996) evaluated resistance of tall fescue to brown patch by comparing dense - vs. open - canopies and found that a higher canopy density increased disease severity. They reported that a higher canopy density compared to a lower canopy density created a more favorable environment for brown patch by increasing relative humidity and leaf wetness. It was also suggested that hyphal expansion occurs more readily in dense canopies due to the close proximity of leaf blades.

Plant breeders use heritability estimates to determine the influence of the environmental and genetic factors affecting the trait of interest and what selection procedure should be implemented to make improvements. Heritability can be defined as the proportion of the observed variation in a progeny that is inherited (Poehlman and Sleper, 1995). The extent to which replicated testing is required for selection will depend on the heritability estimate (Nyquist, 1991). Broad-sense heritability is the ratio of total genetic (additive, dominance, and epistatic) variance to phenotypic variance (Dudley and Moll, 1969). This estimate gives plant breeders an understanding to what extent a trait is influenced by the genotype as opposed to the environment.

Burton and Devane (1953) used replicated clones of tall fescue to determine broad-sense heritability of several plant characteristics on a single plant basis as well as on an entry mean basis. This method has been used by Bonos et al. (2003) to determine the broad-sense heritability estimate of dollar spot (caused by the fungus Sclerotinia homoeocarpa F.T. Bennet) resistance in creeping bentgrass (Agrostis stolonifera L.). This technique was utilized in this study to determine the broad-sense heritability estimate of brown patch resistance in tall fescue. 
Along with heritability estimates, understanding the magnitude of genotype-byenvironment $(\mathrm{G} \times \mathrm{E})$ interaction of the trait being studied is critical in developing an effective breeding program. The larger the $\mathrm{G} \times \mathrm{E}$ interaction, the less correlation there is between the genotype and the phenotype, which reduces the effectiveness of selection (Comstock and Moll, 1963). Stability analysis is a method to evaluate the performance of genotypes over multiple years and locations. By identifying stable genotypes in preliminary evaluations, those that show a minimum interaction with the environment, will lead to an increase in the number of stable genotypes used in advanced testing (Eberhart and Russell, 1966).

There are several definitions of stability that can be found throughout the literature. Authors have classified a genotype as stable if the response of the genotype over several environments was equivalent to that of the mean response of all genotypes in the trial (Shukla, 1972), equivalent to the best performing genotype in each environment (Linn and Binns, 1988) or significantly greater than the mean response of genotypes at each location (Casler et al., 2001). Other authors have used ranking systems to determine if a genotype is stable over multiple environments (Fox et al., 1990; Kang and Pham, 1991). Each stability statistic interprets the $G \times E$ interactions differently; therefore it is up to the plant breeder to determine what method will provide the most relevant information to accomplish their breeding objectives.

The objectives of this study were to (i) determine broad-sense heritability of brown patch resistance of 230 tall fescue genotypes; and (ii) determine the stability of resistance to brown patch. 


\section{MATERIALS AND METHODS}

\section{Field Trials}

Two-hundred and thirty tall fescue genotypes were selected for evaluation in this study. The genotypes were randomly selected from plants growing at the Rutgers Plant Biology and Pathology Research and Extension Farm in Freehold, NJ and consisted of experimental breeding material and germplasm recently collected from Europe. In the summer of 2004, a single tiller was removed from each of the 230 genotypes. Each tiller was then transplanted into a $5.1 \times 5.1 \mathrm{~cm}$ cell filled with BX potting media (Pro-Mix HP, K.C. Shafer, York, PA) and placed in a greenhouse for optimum growing conditions. In the fall of 2004, each genotype had increased to a sufficient size and was then divided into 12 separate vegetative replications remaining under greenhouse conditions through the fall and winter.

In April of 2005, field studies were established at two locations. Site 1 was located at the Horticultural Research Farm II in North Brunswick, NJ, and Site 2 was located at the Rutgers Plant Biology and Pathology Research and Extension Farm in Freehold, NJ. The field trial at Site 1 was located in a field bordered on the eastern side by a row of trees and a wood line on the southern side. The soil type was a Nixon loam (fine-loamy, mixed, mesic Typic Hapludult). The field trial at Site 2 was located in an open field with no physical barriers within close proximity; the soil type was a Freehold sandy-loam (fine-loamy, mixed, active, mesic Aquic Hapludult). Each field experiment was arranged in a randomized complete block design with six replications. To prepare 
each site, the existing turf (Perennial ryegrass Lolium perenne L.) was sprayed with glyphosate in the fall of 2004 and the dead plant material was not removed from the field prior to transplanting. The plants were transplanted into the field $31 \mathrm{~cm}$ apart. Plants at both sites were mowed two times per week during the growing season at a height of 6.4 $\mathrm{cm}$ and each experimental turf area received approximately $14 \mathrm{~g} \mathrm{~N} \mathrm{~m}^{-2}$ annually in 2005 and 2006.

\section{Inoculation Method}

Two isolates of $R$. solani were used as inoculum for both field studies. Both isolates were collected from Agrostis species growing at The Valentine Turfgrass Research Center, The Pennsylvania State University, University Park, PA. Inoculum was prepared by growing the $R$. solani isolates on sterilized Kentucky bluegrass seeds following the method described by Bonos et al. (2003). Inoculum of both isolates were mixed together in equal proportion and then placed in a drop spreader and applied at a rate of $0.8 \mathrm{~g} \mathrm{~m}^{-2}$. To ensure favorable conditions for disease development, light irrigation was applied immediately after inoculation. To encourage growth and development of the pathogen, light irrigation was periodically applied in the afternoon during the course of the study. Assessment of brown patch disease severity was made in July and August in 2005 and 2006 using a 1-9 scale: nine represented 0 to 5\% diseased turf, eight represented 5 to $15 \%$ diseased turf, seven represented 15 to $30 \%$ diseased turf, six represented 30 to $45 \%$ diseased turf, five represented 45 to $55 \%$ diseased turf, four represented 55 to $70 \%$ diseased turf, three represented 70 to $85 \%$ diseased turf, two 
represented 85 to $95 \%$ diseased turf, and one represented 95 to $100 \%$ diseased turf. Since there has been no report of completely brown patch resistant genotypes of tall fescue, levels of resistance and susceptibility were defined for this study using visual analysis. Based on visual analysis, an acceptable level of disease was $\leq 30 \%$; any clone below this threshold was designated as resistant. An unacceptable level of disease was $\geq$ $50 \%$ and any clone above this threshold was designated as susceptible.

\section{Statistical Analysis}

All data analysis was conducted on percent disease using the average of the rating dates from each year. Brown patch disease data collected from the two locations over two years was subject to analysis of variance. The analysis of variance was generated by PROC GLM (SAS Institute, Cary, NC) due to an unbalance data set. Broad-sense heritability estimates were determined from restricted maximum likelihood (REML) variance and covariance components using the random model PROC MIXED (SAS Institute, Cary, NC). All effects were considered random because locations were not chosen with respect to specific ecological properties, years were not chosen with respect to expected climatic conditions (Gorden et al., 1972), and no information on disease resistance of tall fescue clones was known before the initiation of the study. Heritability was calculated on a clonal mean (Hc) basis as well as on a single-plant basis (Hsp). The formulas are as follows:

$$
\begin{aligned}
& \mathrm{Hc}=\sigma_{\mathrm{c}}^{2} /\left(\sigma_{\mathrm{c}}^{2}+\sigma_{\mathrm{cy}}^{2} / \mathrm{y}+\sigma_{\mathrm{cl}}^{2} / 1+\sigma_{\mathrm{cr}(\mathrm{l})}^{2} / \mathrm{rl}+\sigma_{\mathrm{cyl}}^{2} / \mathrm{ly}+\sigma_{\mathrm{e}}^{2} / \mathrm{rly}\right) \\
& \mathrm{Hsp}=\sigma_{\mathrm{d}}^{2} /\left(\sigma_{\mathrm{c}}^{2}+\sigma_{\mathrm{cy}}^{2}+\sigma_{\mathrm{cl}}^{2}+\sigma_{\mathrm{cr}(\mathrm{l})}^{2}+\sigma_{\mathrm{cyl}}^{2}+\sigma_{\mathrm{e}}^{2}\right)
\end{aligned}
$$


$\sigma^{2} \mathrm{c}=$ the total genetic variance of clones, $\sigma_{\mathrm{cy}}^{2}=$ clone $\times$ year variance, $\sigma_{\mathrm{cl}}^{2}=$ clone $\times$ location variance, $\sigma_{\text {cr(l) }}^{2}=$ clone $\times$ rep within location variance, $\sigma_{\text {cyl }}^{2}=$ clone $\times$ year $\times$ location variance, and $\sigma_{\mathrm{e}}^{2}=$ experimental error (clone $\times$ year $\times$ rep within location). Letters in the denominator refer to the number of replications (6), rep(locations) (12) locations (2), and years (2) (Poehlman and Sleper, 1995).

Stability analysis was conducted to determine the response of each clone across environments. The method described below is similar to the analysis conducted by Casler et al. (2001) and Bonos et al. (2004a). For this analysis, each location in each year was considered a separate environment. For each environment, the clone means were computed and converted into a deviation from the location mean using the formula $x_{i j}=X_{i j}-M_{j}$, where $X_{i j}=$ the observation of the $i$ th population at the $j$ th location and $M_{j}=$ mean of the $j$ th location (Casler et al. 2001). The Least Significant Value (LSV) for $\alpha=$ 0.05 was computed using the formula $\mathrm{ta} / 2, \mathrm{dfe}\left[\left(\mathrm{MSe}^{* 2}\right) / \mathrm{r}\right]$, where MSe was determined from the error term for analysis of variance from each location and $\mathrm{r}=$ number of reps. Negative deviations from the location mean indicated that a clone exhibited a lower than average percent brown patch disease severity for that environment. Positive deviations from the location mean indicated that a clone exhibited a higher than average percent brown patch disease severity for that environment. A clone was considered stable across environments if it had a deviation from the location mean significantly less than (stable resistant) or greater than (stable susceptible) the LSV for all locations. 


\section{RESULTS AND DISCUSSION}

\section{Brown Patch Severity}

Analysis of variance of percent brown patch disease among tall fescue clones over two locations and two years resulted in all major effects and clone $\times$ environment interactions being significant (Table 1.1). Average percent brown patch disease severity in 2005 was $45 \%$ (Site 1) and $44 \%$ (Site 2). Disease averages decreased in 2006 to 41 $\%$ (Site 1 ) and $34 \%$ (Site 2). Differences in disease severity observed between locations can be attributed to different environmental conditions at each site. The field trial at Site 1 was bordered by trees and shrubs on the eastern and southern side, which may have led to a decrease in air movement, possibly resulting in prolonged leaf wetness. This resulted in increased disease pressure, as opposed to the field trial at Site 2 that was planted in an open field, allowing for ample air circulation. Significant differences in disease severity over years may have been caused by fluctuation in relative humidity and rainfall events.

Significant differences in brown patch resistance were observed among the different tall fescue genotypes evaluated in this study, with the average percent disease over two locations and two years ranging from $21 \%$ to $60 \%$ (Fig. 1.1). No discrete reaction classes of susceptibility or resistance were observed; rather there was a continuous distribution of responses to brown patch (Fig. 1.1). Some clones displayed moderate levels of resistance across multiple environments but no clone exhibited complete resistance. The lack of complete resistance, the observation of a continuous distribution of phenotypes, and the high influence of the environment on disease severity 
suggests that brown patch resistance is quantitatively inherited (Poehlman and Sleper, 1995).

\section{Broad-Sense Heritability}

Although all clone $\times$ environment interactions were significant, the main effect of clone had the largest variance component, illustrating there is a genetic component to resistance (Table 1.1). By using clonal replications to calculate heritability and evaluating them over multiple years and locations, we are able to account for the significant clone $\times$ environment variance and remove it from the total genetic variance (Burton and Devane, 1953). If the clones were only evaluated in one location over one year, the heritability estimate would be biased upwards because the underlying clone $\times$ environment variance would not be detected (Dudley and Moll, 1969).

The broad-sense heritability for tall fescue clones evaluated over two years and two locations was 0.74 , while on single plant basis it was only 0.25 (Table 1.1 ). The broad-sense heritability estimate based on clones was similar to Watkins et al. (2009), although they did not use replicated clones. This broad-sense heritability estimate is lower than what has been reported for resistance to $R$. Solani in sorghum (Sorghum bicolor (L.) Moench) (Kasuga and Inoue, 2001) and turfgrass disease resistance to other fungal pathogens (Bonos et al., 2003; Bonos et al., 2004b). The difference between estimates based upon clonal and single plant basis illustrates the effect of the environment on brown patch resistance in tall fescue. Since there is a large environmental effect, replication is important to get a true estimate of the response of a 
particular clone (genotype) to brown patch disease. Environmental variation can be reduced by increasing clonal replications at each location. By doing this, clones exhibiting resistance among multiple environments will be identified. Based upon the broad-sense heritability estimated here, the most efficient selection program for brown patch resistance would be on a replicated clonal basis over multiple years and environments. The broad-sense heritability based on a single plant basis was quite low (0.25), indicating that selection based on non-replicated single plants in one environment would not be very efficient in improving brown patch resistance in tall fescue. Bonos et al. (2003) also reported a large difference between broad-sense heritability estimates for dollar spot resistance in creeping bentgrass based on a clonal basis vs. single plant basis, however our single plant estimate was much lower (0.25 vs. 0.51$)$. It is important to note that this broad-sense heritability estimate only pertains to these clones evaluated over these different environments. Since broad-sense heritability accounts for all genetic effects (additive, dominance, and epistatic), this should be the maximum heritability expected when selection is based on clonal replications.

\section{Stability Analysis}

When stability was analyzed by comparing the mean of each clone at a particular location to the location mean, no clone was significantly different from all four location means. Twenty-four (10\%) of the clones had an overall percent disease $\leq 30 \%$ over both years and locations. Of those resistant genotypes, five were significantly less than the LSV in three of the four environments and seven genotypes were significantly less than 
the LSV in two of the four environments (Table 1.2 and Appendix Table A). Thirty-three (14\%) of the clones had an overall percent disease $\geq 50 \%$ over both years and locations. Of those susceptible clones, one clone was significantly greater than the LSV in three of the four environments and six clones were significantly greater than the LSV in two of the four environments (Table 1.2 and Appendix Table A). Although no clone was stable across all four environments, all clones that were categorized as resistant had negative deviations over all locations; likewise all clones categorized as susceptible had positive deviations over all locations. One explanation for the lack of stability over all four environments that was observed in this study was that in 2006 at Site 2 (Freehold), the mean percent disease for that location was only $34 \%$. This indicated that disease pressure was not as severe as the other three environments in which the clones were evaluated. When we summarized the number of clones at each location that were significantly above or below the location mean using the LSV (Table 1.3), the least amount of difference was observed at Freehold in 2006. A clone evaluated in this environment that performed better, but not significantly different from the location mean would still have to be considered stable for resistance because of the low location mean. The results from this stability analysis differ from that of other turfgrass pathosystems. For example, Bonos and colleagues (2004a) evaluated bentgrass clones for dollar spot resistance over multiple locations and years and were able to identify individual clones that were positively stable (resistant) or negatively stable (susceptible) across all environments. The lack of stability also demonstrates that brown patch disease severity is greatly influenced by the environment in which the plants are grown. Trials evaluating clones over multiple years 
and locations will be necessary in order to successfully identify superior genotypes for brown patch resistance to be used in breeding programs. 


\section{CONCLUSIONS}

The findings of this study illustrate the large amount of genetic variation that is present among different tall fescue genotypes in response to brown patch. Moderate broad-sense heritability estimates were observed indicating a strong environment influence on this trait. The significant interactions between clone and environment suggest that evaluation for resistance to brown patch should be conducted over multiple locations, years, and replications to identify genotypes that exhibit superior performance (Dudley and Moll, 1969). Stability analysis was able to identify genotypes of tall fescue that were stable for resistance over multiple environments. Therefore, these stable genotypes can be incorporated into a breeding program to improve brown patch resistance in tall fescue. The strong environmental effect and continuous distribution of responses to brown patch support the idea that brown patch resistance in tall fescue is quantitatively inherited. A recurrent selection program using replicated genotypes should be an effective tool in breeding for resistance to brown patch in tall fescue. 


\section{REFERENCES}

Beard, J.B. 1973. Turfgrass: Science and Culture. Prentice-Hall, Englewood Cliffs, NJ.

Bonos, S.A., M.A. Casler, and W.A. Meyer. 2003. Inheritance of dollar spot resistance in creeping bentgrass. Crop Sci. 43:2189-2196.

Bonos, S.A., M.A. Casler, and W.A. Meyer. 2004a Plant responses and characteristics associated with dollar spot resistance in creeping bentgrass. Crop Sci. 44:17631769.

Bonos, S.A., C. Kubik, B.B. Clarke, and W.A. Meyer. 2004b. Breeding perennial ryegrass for resistance to gray leaf spot. Crop Sci. 44:575-580.

Burton G.W. and E.H. Devane. 1953. Estimating heritability in tall fescue (Festuca arundinacea) from replicated clonal material. Agron. J. 45:478-481.

Burpee, L.L. 1995. Interactions among mowing height, nitrogen fertility, and cultivar affect the severity of Rhizoctonia blight of tall fescue. Plant Dis. 79:721-726.

Casler, M.D., K.P. Vogel, J.A. Balasko, J.D. Berdahl, D.A. Miller, J.L. Hansen, and J.O. Fritz. 2001. Latitudinal and longitudinal adaptation of smooth bromegrass populations. Crop Sci. 41:1456-1460.

Comstock, R. E. and R. H. Moll. 1963. Genotype-environment interactions. Statistical Genetics and Plant Breeding (ed. W.D. Hanson and H.F. Robinson). National Academy of Sciences-National Research Council Publication 982,164-196.

Couch, H.B. 1985. Turfgrass (several cultivated spp.). Plant Dis. 69:672-675.

Dudley, J. W. and R. H. Moll. 1969. Interpretation and use of estimates of heritability and genetic variance in plant breeding. Crop Sci. 9:257-262.

Eberhart, S.A. and W.A. Russell. 1966. Stability parameters for comparing varieties. Crop Sci. 6:36-40.

Fidanza, M.A., P.H. Dernoeden, and A.P. Grybauskas. 1996. Development and field validation of a brown patch warning model for perennial ryegrass turf. Phytopathology 86:385-390.

Fidanza, M.A. and P.H. Dernoeden. 1996. Brown patch severity in perennial ryegrass as influenced by irrigation, fungicides, and fertilizers. Crop Sci. 36:1631-1638.

Fox P.N., B. Skovmand, B.K. Thompson, H.-J. Braun and R. Cormier. 1990. Yield and adaptation of hexaploid spring triticale. Euphytica 47:57-64. 
Giesler L.J., G. Y. Yuen, and G.L. Horst. 1996. The microclimate in tall fescue turf as affected by canopy density and its influence on brown patch disease. Plant Dis. 80:398-394.

Gordon, I.L., D.E. Byth, and L.N. Balaam. 1972. Variance of heritability ratios estimated from phenotypic variance components. Biometrics 28:401-415.

Green II, D.E., L.L. Burpee, and K.L. Stevenson. 1999. Components of resistance to Rhizoctonia solani associated with two tall fescue cultivars. Plant Dis. 83:834838.

Gross, M.K., J.B. Santini, I. Tikhonova, and R. Latin. 1998. The influence of temperature and leaf wetness duration on infection of perennial ryegrass by Rhizoctonia solani. Plant Dis. 82:1012-1016.

Kang, M.S. and H.N. Pham. 1991. Simultaneous selection for yielding and stable crop genotypes. Agron. J .83:161-165.

Lin, C.S. and M.R. Binns. 1988. A superiority measure of cultivar performance for cultivar x location data. Canadian Journal of Plant Science 63:193-198.

Martin, S.B. and L.T. Lucas. 1984. Characterization and pathogenicity of Rhizoctonia spp. and binucleate Rhizoctonia-like fungi from turfgrasses in North Carolina. Phytopathology 74:170-175.

Nyquist, W. 1991. Estimation of heritability and prediction of selection response in plant populations. Crit. Rev. Plant Sci. 10(3):235-322.

Poehlman, J.M. and D.A. Sleper. 1995. Breeding Field Crops. Iowa State University Press, Ames.

Shukla, G. K. 1972. Some statistical aspects of partitioning genotype-environment components of variability. Heredity 29:237-245.

Smiley, R.W., P.H. Dernoeden, and B.B. Clarke. 2005. Compendium of turfgrass diseases. $3^{\text {rd }}$ ed. The American Phytopathological Society. St. Paul, MN.

Watkins, E., S.A. Bonos, and W.A. Meyer. 2009. Heritability of brown patch resistance in tall fescue. Int. Turfgrass Soc. Res. 11:271-282. 
Table 1.1. Analysis of variance of brown patch disease severity of 230 tall fescue clones averaged over two locations and two years (2005 and 2006).

\begin{tabular}{|c|c|c|c|}
\hline Sources of Variation & df & Means Square & $\begin{array}{l}\text { Variance } \\
\text { component }\end{array}$ \\
\hline Year & 1 & $72228.73^{* * *}$ & \\
\hline Location & 1 & $21171.47 * * *$ & \\
\hline Rep(Location) & 10 & $1433.94 * * *$ & \\
\hline Year $\times$ Location & 1 & $12768.01 * * *$ & \\
\hline Year $\times$ Rep(Location) & 10 & $923.19 * * *$ & \\
\hline Clone & 229 & $16161.55^{* * *}$ & 50.9711 \\
\hline Clone $\times$ Year & 229 & $399.74 * * *$ & 8.1284 \\
\hline Clone $\times$ Location & 229 & $229.18^{* * * *}$ & 0.1384 \\
\hline Clone $\times \operatorname{Rep}($ Location $)$ & 2288 & $144.02 * * *$ & 0.8008 \\
\hline Clone $\times$ Year $\times$ Location & 229 & $202.88^{* * *}$ & 3.5307 \\
\hline $\begin{array}{l}\text { Error Clone } \times \text { Year } \times \\
\text { Rep(Location) }\end{array}$ & 2445 & $119.72 * * *$ & 5.1017 \\
\hline \multicolumn{4}{|l|}{$\mathrm{Hc}^{\mathrm{z}}=0.74$} \\
\hline Hsp $=0.25$ & & & \\
\hline
\end{tabular}


Table 1.2. Mean location deviations of tall fescue clone responses to brown patch disease across two locations and two years.

\begin{tabular}{|c|c|c|c|c|c|c|c|}
\hline & \multirow{3}{*}{ Clone $^{\mathrm{z}}$} & \multirow{3}{*}{ Designation $^{\mathrm{y}}$} & \multirow{3}{*}{$\begin{array}{c}\text { Brown } \\
\text { Patch Avg. }\end{array}$} & \multicolumn{2}{|c|}{ Freehold } & \multicolumn{2}{|c|}{ North Brunswick } \\
\hline & & & & 2005 & 2006 & 2005 & 2006 \\
\hline & & & & \multicolumn{4}{|c|}{----Deviation from location year means---- } \\
\hline 1 & 79 & $\mathrm{R}$ & 21 & $-27^{w}$ & -7 & -21 & -26 \\
\hline 2 & 193 & $\mathrm{R}$ & 21 & -20 & -9 & -29 & -23 \\
\hline 3 & 161 & $\mathrm{R}$ & 23 & -19 & -16 & -16 & -24 \\
\hline 4 & 224 & $\mathrm{R}$ & 23 & -24 & -3 & -21 & -24 \\
\hline 5 & 257 & $\mathrm{R}$ & 23 & -18 & -14 & -15 & -25 \\
\hline 6 & 175 & $\mathrm{R}$ & 24 & -25 & -10 & -17 & -17 \\
\hline 7 & 136 & $\mathrm{R}$ & 24 & -23 & -8 & -14 & -22 \\
\hline 8 & 256 & $\mathrm{R}$ & 24 & -8 & -17 & -19 & -24 \\
\hline 9 & 93 & $\mathrm{R}$ & 25 & -18 & -17 & -18 & -10 \\
\hline 10 & 148 & $\mathrm{R}$ & 27 & -5 & -11 & -14 & -28 \\
\hline 11 & 184 & S & 56 & 19 & 13 & 11 & 17 \\
\hline 12 & 187 & S & 56 & 13 & 14 & 17 & 17 \\
\hline 13 & 75 & $\mathrm{~S}$ & 57 & 16 & 18 & 16 & 14 \\
\hline 14 & 172 & $\mathrm{~S}$ & 57 & 11 & 10 & 22 & 20 \\
\hline 15 & 173 & $\mathrm{~S}$ & 58 & 20 & 10 & 23 & 15 \\
\hline 16 & 86 & S & 58 & 14 & 19 & 22 & 15 \\
\hline 17 & 44 & S & 58 & 27 & 10 & 26 & 8 \\
\hline 18 & 249 & S & 59 & 12 & 38 & 3 & 19 \\
\hline 19 & 13 & S & 60 & 21 & 12 & 19 & 20 \\
\hline 20 & 171 & S & 60 & 23 & 20 & 12 & 21 \\
\hline \multicolumn{3}{|c|}{$\operatorname{LSD}(0.05)$ or $\operatorname{LSV}(0.05)$} & 7.5 & 16.4 & 18.4 & 14.9 & 20.2 \\
\hline
\end{tabular}

${ }^{\mathrm{Z}}$ Only 10 clones representing resistant and susceptible classes are presented.

${ }^{\mathrm{W}}$ Bold numbers indicated significance above the LSV value.

${ }^{\mathrm{Y}} \mathrm{R}=$ Resistance $\leq 30 \%$ disease, $\mathrm{S}=$ Susceptible $\geq 50 \%$ disease.

$\mathrm{X}$ Percent brown patch disease severity averaged across two locations and two years. 
Table 1.3. Number of clones at each location that were significantly different from location means using the LSV for comparison $(\mathrm{P}<0.05)$.

\begin{tabular}{lcccc}
\hline & \multicolumn{2}{c}{ Freehold } & \multicolumn{2}{c}{ North Brunswick } \\
& 2005 & 2006 & 2005 & 2006 \\
\hline Lower & 11 & 1 & 20 & 14 \\
No Difference & 211 & 225 & 196 & 210 \\
Higher & 8 & 4 & 14 & 6 \\
\hline
\end{tabular}


Figure 1.1. Distribution of tall fescue clone response to brown patch disease averaged over two years and two locations.

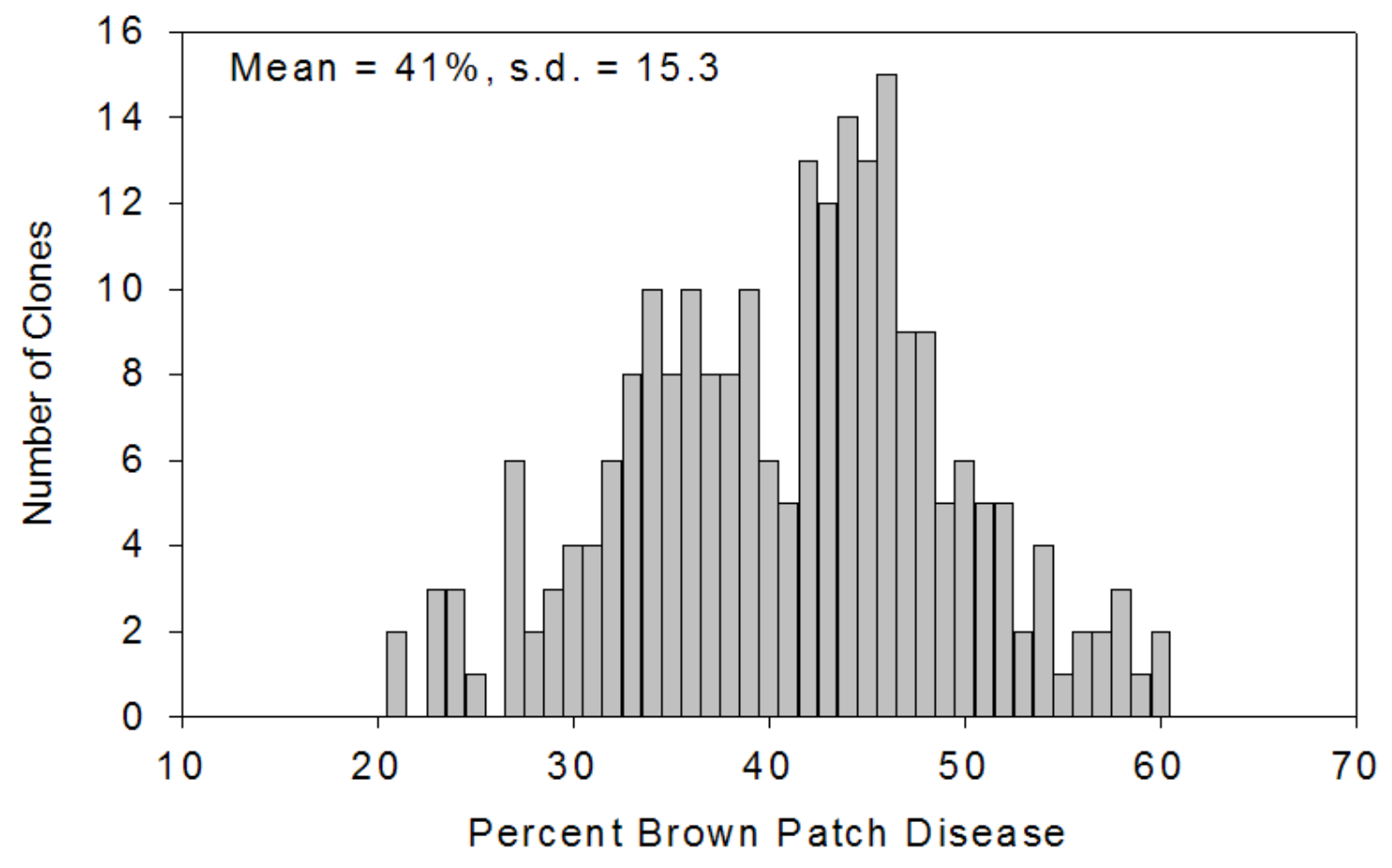




\section{Chapter II.}

\section{Diallel analysis of brown patch resistance in tall fescue}

\section{INTRODUCTION}

Heritability is used by plant breeders to estimate the improvements that can be expected due to selection (Nyquist, 1991). Broad-sense heritability is an estimate of the total genetic (additive, dominance, and epistatic) variance contributing to the observed phenotype (Dudley and Moll, 1969) which indicates to what extent the trait is determined by the genotype as opposed to the environment (Nyquist, 1991). Broad-sense heritability estimates have been reported for brown patch (Rhizoctonia solani Kühn) resistance in tall fescue (Festuca arundinaceae Schreb.), with values ranging from 0.55 - 0.76 (Bokmeyer et al., 2009; Watkins et al., 2009). These estimates indicate that while there is a genetic component to resistance, the environment also has a significant influence on the phenotype.

Narrow-sense heritability estimates of brown patch resistance in tall fescue have not been reported. To develop synthetic cultivars for an out-crossing species such as tall fescue, narrow-sense heritability is a more informative estimate than the broad-sense heritability estimate. Narrow-sense heritability estimates the degree that additive effects have in determining the phenotypic variance (effects that are transferred from parents to progeny) (Nyquist, 1991). The narrow-sense heritability estimate will determine the most efficient selection technique to improve brown patch resistance. 
Selection methods for disease improvement differ depending on whether the trait being improved is qualitatively or quantitatively inherited. Qualitative resistance is controlled by major genes for resistance and is easily integrated into a breeding program; however, this form of resistance is usually only effective against one strain of the pathogen (Flor, 1971). Quantitative resistance is under the control of a large number of genes (polygenes), each with a small additive effect on resistance. Polygenic resistance is effective across a large number of races of a pathogen and is considered a more durable form of resistance (Browning and Frey, 1969; Hooker, 1967). Researchers study rice (Oryza sativa L.) have reported that there are multiple genes involved in the inheritance of rice sheath blight ( $R$. solani) resistance and consider it to be a polygenic quantitative trait (Li et al., 1995; Zou et al., 2000). Conversely, other researchers have reported resistance of rice sheath blight to be controlled by major genes (Che et al., 2003; Pan et al., 1999). Very little information regarding the genetic inheritance of brown patch resistance in tall fescue is known. Bokmeyer et al. (2009) proposed that brown patch resistance was a quantitative trait due to the large environmental influence on disease severity and continuous range of phenotypes observed among various genotypes of tall fescue evaluated over two years and two locations. No studies have reported the number of genes that may be controlling brown patch resistance in tall fescue.

Diallel crosses can be used to determine the amount of genetic variation due to additive or non-additive (dominance and epistatic) gene effects. A diallel cross analysis following the statistical methods presented by Griffing (1956) allows for the estimation of both the general and specific combining ability. These combining ability estimates can be used to determine the relative importance of the additive vs. non-additive gene effects 
influencing resistance as well as identify potential parents that can contribute to resistance if incorporated into a breeding program. This technique has been used in other turfgrass pathosystems to identify parents that can be incorporated into breeding programs for improving disease resistance (Bonos, 2006; Han et al., 2006) and was also used by Kasuga and Inque (2001) to study sheath blight (R. solani) resistance in sorghum (Sorghum bicolor (L.) Moench).

Since little is known regarding the type of gene action or combining ability associated with brown patch resistance in tall fescue, a diallel mating design was employed to study these effects. The objectives for this research were to (i) estimate the general and specific combining abilities of tall fescue parents, (ii) determine the relative importance of additive and non-additive (dominance and epistatic) gene effects for brown patch resistance, (iii) calculate the narrow-sense heritability for brown patch resistance, (iv) estimate the minimum number of effective genes involved in brown patch resistance, and (v) determine if a major gene was segregating for brown patch resistance in tall fescue. 


\section{MATERIALS AND METHODS}

\section{Diallel Design}

Six parents were used in a diallel cross in the spring of 2006. These parents were selected from germplasm collected from old turf areas in the United States starting in 1962. The germplasm has been maintained at the New Jersey Agriculture Experiment Station (NJAES) and has undergone 12-15 cycles of selection for improved turf quality. Three resistant and three susceptible tall fescue genotypes were selected as parents based on disease data from a previous trial evaluating tall fescue genotypes for brown patch resistance. A genotype was classified as resistant having $\leq 30 \%$ disease infection. A genotype was classified as susceptible having $\geq 50 \%$ disease infection. Each parent plant was increased by clonal propagation so that a diallel mating design could be used. In the fall of 2005, parental clones were planted in the field prior to the beginning of winter to fulfill vernalization requirements. In the spring of 2006, the parental clones were brought into a greenhouse and flowering was induced by the use of supplemental overhead lighting set for $18 \mathrm{~h}$ days. Before anthesis, individual clones of each parent were matched together and isolated from all other controlled crosses with plastic partitions. To determine if selfing would occur during the controlled crosses, an individual clone of each parent was placed in isolation. No viable seed was harvested from the isolated parents. Both parents in each cross were used as male and female and pollen transfer was facilitated by manual tapping of the inflorescences. 
Seed was harvested from both parents in every controlled cross and allowed to dry down. Seed was sown into a seed tray and placed in a cold room to break dormancy. Once the seeds germinated, 100 seedlings were randomly selected from every parent used in the crosses. A field experiment was established at Rutgers Plant Biology and Pathology Research and Extension Farm in Freehold, NJ. The soil type was a Freehold sandy-loam (fine-loamy, mixed, active, mesic Aquic Hapludult). The seedlings were planted in the field on 10 Oct. 2006 along with 24 vegetative replicates of the six parents used in the crosses. The field experiment was arranged in a randomized complete block design with four replications. Each replication consisted of 25 progeny from each parent as well as six vegetative clones of the six parents used in the crosses. Plants were planted $31 \mathrm{~cm}$ apart and were mowed with a Toro Groundsmaster two times per week during the growing season at a height of $6.4 \mathrm{~cm}$. A total of $13.4 \mathrm{~g} \mathrm{~N} \mathrm{~m}^{-2}$ was applied to the field trial in 2007 and 2008. In April of 2007 and 2008 applications of 34-0-0 (N$\mathrm{P}-\mathrm{K}$ ) fertilizer was applied at $4 \mathrm{~g} \mathrm{~N} \mathrm{~m}^{-2}$. In May, June, and July of 2007 and 2008 applications of 16-2-7 (N-P-K) fertilizer was applied at a rate of $4 \mathrm{~g} \mathrm{~N} \mathrm{~m}^{-2}, 2.7 \mathrm{~g} \mathrm{~N} \mathrm{~m}^{-2}$, and $2.7 \mathrm{~g} \mathrm{~N} \mathrm{~m}^{-2}$ respectively. Pythium blight (Pythium aphanidermatum) was prevented with labeled rates of Subdue (metalaxyl).

Inoculum was prepared by growing a single isolate of $R$. solani on sterilized Kentucky bluegrass seed following the method described by Bonos et al. (2003). The isolate was collected from Agrostis species growing at The Valentine Turfgrass Research Center, The Pennsylvania State University, University Park, PA. Pathogencity of the $R$. solani isolate on tall fescue was confirmed in a growth chamber study prior to initiation of this experiment. The prepared inoculum was then placed in a drop spreader and 
applied to the field at a rate of $0.8 \mathrm{~g} \mathrm{~m}^{-2}$. The field trial was inoculated 18 June 2007 and again on 20 June 2008. To ensure favorable conditions for disease development, light irrigation was applied to the field immediately after inoculation. To encourage growth and development of the pathogen, light irrigation was periodically applied in the afternoon during the course of the study. Monthly mean temperatures for June, July, and August for 2007 were $21.1,23.3$, and $23.8^{\circ} \mathrm{C}$ respectively. Monthly mean temperatures for June, July, and August for 2008 were 23, 24.6, and $23.4^{\circ} \mathrm{C}$ respectively. Assessment of brown patch disease severity was made in July and August in 2007 and 2008 using a 1-9 scale: nine represented 0 to $5 \%$ diseased turf, eight represented 5 to $15 \%$ diseased turf, seven represented 15 to $30 \%$ diseased turf, six represented 30 to $45 \%$ diseased turf, five represented 45 to $55 \%$ diseased turf, four represented 55 to $70 \%$ diseased turf, three represented 70 to $85 \%$ diseased turf, two represented 85 to $95 \%$ diseased turf, and one represented 95 to $100 \%$ diseased turf. For data analysis, each 1-9 value was assigned the mid-point percent value for the disease range that it represented. All data analysis was conducted on percent disease using the combined average across both years.

\section{Statistical Analysis}

\section{Combining Abilities}

All data from the diallel cross was subjected to analysis of variance using Griffing's (1956) method 1 (includes parents, F1 progeny, and reciprocals) model 1 (fixed effects). The model for the combining ability analysis was

$$
X_{i j k}=u+g_{i}+g_{j}+s_{i j}+r_{i j}+b_{k}+e_{i j k}
$$


where $X_{i j k}=$ observed brown patch resistance of $i j$ th cross in the $k$ th block, $u=$ population mean, $g_{i}=$ general combining ability (GCA) effect of the $i$ th parent, $g_{j}=\mathrm{GCA}$ effect of the $j$ th parent, $s_{i j}=$ specific combining ability (SCA) effect for $i j$ th cross, $r_{i j}=$ reciprocal effect for $i j$ th cross, $b_{k}=$ effect of the $k$ th block, $e_{i j k}=$ residual effect. Data was analyzed using DIALLEL-SAS05 (Zhang et al., 2005).

\section{Narrow-Sense Heritability Estimates}

Narrow-sense heritability was estimated using mid-parent-progeny regression analysis (Poehlman and Sleper, 1995). Means of the $F_{1}$ progeny were regressed against the average percent disease of the two parents and the slope of the regression line was equal to the narrow-sense heritability. Analysis for each year was conducted separately.

\section{Minimum Number of Effective Genes}

The minimum number of effective genes that could be controlling brown patch resistance in tall fescue was calculated based on the formula of Wright (1968)

$$
n=\left(\mathrm{P}_{1}-\mathrm{P}_{2}\right)^{2} / 8\left(\sigma^{2} \mathrm{~F}_{2}-\sigma_{\mathrm{E}}^{2}\right)
$$

where $\mathrm{n}=$ number of genes, $\mathrm{P}_{1}=$ mean resistance of parent $1, \mathrm{P}_{2}=$ mean resistance of parent $2, \sigma^{2} F_{2}=$ variance of $F_{2}$ population, and $\sigma_{E}^{2}$ environmental variance among replicates of a parental clone pooled for all parental clones. This method of estimation is based on the assumptions that the genes have equal effects, no dominance or epistasis is present, and that no two loci are in the same chromosome (Poehlman and Sleper, 1995). 


\section{Detection of Major Genes}

The detection of a major gene was determined using the formula described by Lynch and Walsh (1998) that was first proposed by Fain (1978):

$$
\operatorname{Var}\left(\bar{o}_{i}\right)=a+b_{1} \bar{o}_{i}+b_{2}{\overline{o_{i}}}^{2}
$$

where $\operatorname{Var}\left(\bar{o}_{i}\right)$ is the phenotypic variance with $i$ th sibship and $\bar{o}_{i}$ is the mid-parental value for this sibship. A significant value of $b_{2}$ is taken as an indication of a major gene. The theory behind this formula is that for a character that is influenced by a few major genes, the parents with the most extreme phenotypes will be homozygotes and the parents with intermediate phenotypes will be heterozygotes. This relationship would result in a quadratic regression of offspring variance on mid-parent phenotypic values (Lynch and Walsh, 1998). 


\section{RESULTS AND DISCUSSION}

\section{Parent and Progeny Response to Brown Patch}

Significant differences in brown patch resistance were observed between the resistant and susceptible parents used for the controlled crosses (Table 2.1). All three resistant parents had significantly less disease than the three susceptible parents. Results from the analysis of variance (Table 2.2) indicated that reciprocal and cross $\times$ year effects were not significant; therefore, progeny data is presented as the combined average of each controlled cross including its reciprocal cross over 2007 and 2008 (Table 2.3). Although there was not a significant cross $\times$ year effect, the main effect of year was significant indicating the magnitude of brown patch severity changed from 2007 to 2008 . Significant differences of progeny means were also observed. The three resistant $\times$ resistant crosses resulted in the progeny with the least amount of disease, while the three susceptible $\times$ susceptible crosses resulted in progeny with the greatest amount of disease (Table 2.3). This provides a clear example that parent selection does influence disease resistance to brown patch in tall fescue.

The population distribution of the progeny displayed a large amount of genetic variation for brown patch resistance. In all fifteen controlled crosses no discrete reaction classes of resistance or susceptibility were observed among the progeny, rather a continuous distribution of phenotypic responses of brown patch resistance were observed (Figs. $1-15$ ). Similar continuous phenotypic distributions of progeny have been reported for rice sheath blight resistance (Li et al., 1995) and banded leaf and sheath blight in 
maize (Zea mays L.) (Zhao et al., 2006). The lack of discrete reaction classes as well as the influence of the environment on disease severity supports the hypothesis that brown patch resistance in tall fescue is quantitatively inherited as suggested by Bokmeyer et al. (2009).

\section{Combining Abilities}

Analysis of variance was performed on the diallel cross using combined data from the field trial evaluated for brown patch resistance in 2007 and 2008. The mean squares of the analysis of variance are presented in Table 2.2. The main effect of cross was significant indicating that the genetic factors that are transmitted from the parents to the offspring does influence the level of brown patch resistance. GCA and SCA effects were both significant implying the involvement of additive and non-additive gene effects in the phenotypic expression of brown patch resistance. An indication of the relative importance of GCA and SCA in predicting progeny performance can be determined by the proportion that each effect accounts for in the sum of squares (Cisar et al., 1982; Becelaere and Miller 2004). The proportion of the entry sum of squares of both GCA and SCA are shown in Table 2.5. The GCA accounts for a much greater proportion of the sum of squares than SCA suggesting that additive gene effects are relatively more important that non-additive gene effects in the phenotypic expression of brown patch resistance. GCA also accounted for greater proportion of the mean square value than SCA for sheath blight resistance in sorghum (Kasuga and Inoue, 2001). Similar findings have also been reported for other turfgrass pathosystems (Bonos, 2006; Han et al., 2006). 
Although the GCA is a more reliable indicator of progeny performance than SCA, nonadditive gene effects will still affect the performance of progeny from certain parental combinations and should not be overlooked.

The GCA effects quantify the contribution of each parent to its progenies response to brown patch. To determine how efficiently each parent transmitted disease resistance to its progeny, the GCA of each parent was calculated and compared to its own overall disease resistance (Table 2.1). Due to the significant GCA $\times$ year interaction, GCA estimates are presented for both years (Table 2.1). All three resistant parents had a significant negative GCA values over both years indicating that they transmitted brown patch resistance to their progenies. All three susceptible parents had significant positive GCA values over both years indicating that they transmitted susceptibility to their progenies. Parent 7511 had the least amount of disease over both years and contributed the most to resistance based on its GCA values. Parent CL5 contributed the most to susceptibility, having the highest significant GCA value as well as the most disease severity over both years. All GCA values decreased in 2008 compared to 2007 (Table 2.1). This trend is most evident with parent RP66 in which the level of significance of its GCA value decrease from 2007 to 2008 . The decrease in the GCA values could be a result of the strong influence of the environment on disease severity as overall disease severity increased from 2007 to 2008 (Fig. 2.16 and 2.17).

Significant SCA effects indicate that levels of resistance of certain progeny were higher or lower than expected on the basis of the GCA of the two parents that were involved in the cross. Only two of the fifteen controlled crosses were significant for SCA effects (Table 2.3). The controlled cross between resistant parents 7511 and RP66 
resulted in a significant positive SCA effect, indicating that the combination of these two parents resulted in progeny that were more susceptible than what was predicted based on each parents GCA value. The controlled cross between resistant parent RP66 and the susceptible parent CR15 had a significant negative SCA effect, indicating there is a beneficial combination to resistance between these two parents. Based on the proportion of the sum of squares it appears that in most instances brown patch resistance can be accurately predicted from GCA values of the parents; however, the two crosses that were significant for SCA is an example that in some cases a more complex type of inheritance may be involved. Bonos (2006) reported the presence of non-additive effects for dollar spot resistance in creeping bentgrass as did Han et al. (2006) evaluating gray leaf spot resistance in perennial ryegrass. This result indicates that progeny evaluation is necessary in the selection of parents to be used in a breeding program for brown patch resistance to avoid the non-additive effects for susceptibility seen in the cross between the two resistant parents 7511 and RP66.

\section{Narrow-Sense Heritability}

Narrow-sense heritability estimates of brown patch resistance using mid-parent progeny mean regression were $0.62( \pm 0.07)$ in 2007 (Fig. 2.16) and $0.57( \pm 0.07)$ in 2008 (Fig. 2.17). These estimates are equal to and lower than reported for sheath blight resistance in sorghum (Kasuga and Inoue, 2001). Narrow-sense heritability is a measure of additive gene effects contributing to the phenotypic expression of a particular trait (Nyquist, 1991). Additive gene effects are what can be effectively selected for in a 
breeding program and can be used to predict the gain from selection. Researchers have reported broad-sense heritability estimates of brown patch resistance in tall fescue with values ranging from 0.55-0.76 (Bokmeyer et al., 2009; Watkins et al., 2009). Broadsense heritability estimates are useful in studying a quantitative trait because they give an estimate of the overall heritability of a trait but it does not partition the genetic variance (additive, dominance, or epistatic). The moderate narrow-sense heritability estimates from this study coupled with the broad-sense heritability estimate previously reported indicate that additive gene effects contribute more to brown patch resistance than dominant or epistatic gene effects. This is consistent with the finding of the combining abilities analysis which indicated that the genetic component of brown patch resistance was primarily influenced by additive gene effects as opposed to non-additive gene effects. The narrow-sense heritability estimates for brown patch resistance are lower than what has been reported in the literature for estimates of other turfgrass diseases (Bonos et al., 2006; Bonos et al., 2004; Han et al., 2006) indicating a stronger environmental influence on brown patch resistance than seen with other turfgrass pathosystems.

\section{Number of Effective Genes}

The minimum number of effective genes contributing to brown patch resistance was calculated for all resistant $\times$ susceptible crosses and values ranged from 1.0-3.2 (Table 2.4). These estimates may be biased due to the presence of non-additive gene effects which were detected in the combining ability analysis which violates an assumption of this formula. Similar results for the number of effective genes were 
reported for other turfgrass pathosystems (Bonos, 2006: Han et al., 2006). This range of effective genes supports the idea that brown patch resistance in tall fescue is quantitatively inherited, with multiple genes having equal effects for resistance.

\section{Major Gene}

The continuous phenotypic distribution observed in this study suggests that brown patch resistance is influenced by many genes having equal effects. However, if the frequency of major alleles is low or the environmental variation has a greater effect than an individual gene, the presence of a major gene can be overlooked (Lynch and Walsh, 1998). Using the formula that was proposed by Fain (1978) and presented by Lynch and Walsh (1998) a significant value of $b^{2}$ is taken as an indication of a major gene. The $\mathrm{P}$ value $=0.29$ for the quadratic $b^{2}$ term indicates that a major gene is not segregating through the progenies evaluated in this study. This is similar to the result reported by Bonos (2006) for dollar spot resistance in creeping bentgrass. This result indicates that the variation in resistance among the progeny can be attributed to environmental variation as well as multiple genes for resistance, further supporting the idea that brown patch resistance may be inherited quantitatively. 


\section{CONCLUSIONS}

Significant variation was observed between the progeny means of controlled crosses for brown patch resistance. The GCA effects accounted for a much greater proportion of the sum of squares than SCA effects suggesting that additive gene effects are relatively more important than non-additive gene effects in the phenotypic expression of brown patch resistance. Resistant parent 7511 was identified as having good general combining ability and could be incorporated into a breeding program for brown patch resistance. The detection of significant SCA effects for some of the parents indicated that progeny performed better or worse than what was predicted by the average performance of their parents. To successfully breed for resistance, progeny testing is needed to avoid the unfavorable combinations which yield significant positive SCA effects as seen in the cross between parent RP66 and 7511, which resulted in increased disease susceptibility. Likewise, progeny testing will also allow for the selection of beneficial combinations between parents resulting in negative SCA effects which occurred between the cross of parent RP66 and CR15 and resulted in increased disease resistance. The limitation to this study is that the genotypes for this analysis were considered fixed effects; therefore these findings apply only to these populations studied.

The moderate narrow-sense heritability estimates ( 0.62 and 0.57$)$ when compared to previously reported broad-sense heritability estimates $(0.54-0.76)$ (Bokmeyer et al., 2009; Watkins et al., 2009) also indicates that additive gene effects are more prevalent that non-additive gene effects. The minimum number of effective genes segregating in the resistant $\times$ susceptible crosses ranged from $1-3$ genes depending upon the parents 
used in the cross. No major genes segregating through the populations were detected and the observation of continuous phenotypic responses to brown patch supports the idea that brown patch resistance is quantitatively inherited. The data from this study suggests that resistance to brown patch can be improved by progeny testing and selecting parents with significant GCA values to be used in a breeding program. 


\section{REFERENCES}

Becelaere, G.V., and J.F. Miller. 2004. Combining ability for resistance to Sclerotinia head rot in sunflower. Crop Sci. 44:1542-1545.

Bokmeyer, J.M, S.A Bonos, and W.A. Meyer. 2009. Broad-sense heritability and stability analysis of brown patch resistance in tall fescue. HortScience 44:289292.

Bonos, S.A. 2006. Heritability of dollar spot resistance in creeping bentgrass. Phytopathology 96:808-812.

Bonos, S.A., M.A. Casler, and W.A. Meyer. 2003. Inheritance of dollar spot resistance in creeping bentgrass. Crop Sci. 43:2189-2196.

Bonos, S.A., B.B. Clarke, and W.A. Meyer. 2006. Breeding for disease resistance in the major cool-season turfgrass. Annu. Rev. Phytopathol. 44:213-234.

Bonos, S.A., C. Kubik, B.B. Clarke, and W.A. Meyer. 2004. Breeding perennial ryegrass for resistance to gray leaf spot. Crop Sci. 44:575-580.

Browning, J.A. and K.J. Frey. 1969. Multiline cultivars as a means of disease control. Annu. Rev. Phytopathol. 7:355-382.

Che, K.P., Q. C. Zhan, Q.H. Xing, Z.P. Wang, D.M. Jin, D.J. He, and B. Wang. 2003. Tagging and mapping of rice sheath blight resistant gene. Theor. Appl. Genet. 106:293-297.

Cisar, G., C.M. Brown, and H. Jedlinski. 1982. Diallel analyses for tolerance in winter wheat to the barley yellow dwarf virus. Crop. Sci. 22:328-333.

Dudley, J. W. and R. H. Moll. 1969. Interpretation and use of estimates of heritability and genetic variance in plant breeding. Crop Sci. 9:257-262.

Fain, P.R. 1978. Characteristics of simple sibship variance tests for the detection of major loci and application to height, weight, and spatial performance. Ann. Hum. Genet. 42:109-120.

Flor, H.H. 1971. Current status of the gene-for-gene concept. Annu. Rev. Phytopathol. 9:275-296.

Giesler L.J., G. Y. Yuen, and G.L. Horst. 1996. The microclimate in tall fescue turf as affected by canopy density and its influence on brown patch disease. Plant Dis. 80:398-394. 
Green II, D.E., L.L. Burpee, and K.L. Stevenson. 1999. Components of resistance to Rhizoctonia solani associated with two tall fescue cultivars. Plant Dis. 83:834838.

Griffing, B. 1956. Concept of general and specific combining ability in relation to diallel crossing systems. Aus. J. Biol. Sci. 9:464-493.

Han, Y., S.A. Bonos, B.B. Clarke, and W.A. Meyer. 2006. Inheritance of resistance to gray leaf spot disease in perennial ryegrass. Crop Sci. 46:1143-1148.

Hooker, A.L. 1967. The genetics and expression of resistance in plants to rusts of the genus puccinia. Annu. Rev. Phytopathol. 5:163-168.

Kasuga, S. and N. Inoue. 2001. Diallel analysis of the resistance to sheath blight (Rhizoctonia solani Kühn) in sorghum. Grassland Sci. 47:45-49.

Li, Z. K., S.R.M. Pinson, M.A. Marchetti, J.W. Stansel, and W.D. Park. 1995. Characterization of quantitative trait loci (QTLs) in cultivated rice contributing to field resistance to sheath blight (Rhizoctonia solani). Theor. Appl. Genet. 91:382:388.

Lynch, M., and B. Walsh. 1998. Genetics Analysis of Quantitative Traits. Sinauer Associates, Inc., Sunderland, MA.

Nyquist, W. 1991. Estimation of heritability and prediction of selection response in plant populations. Crit. Rev. Plant Sci. 10(3):235-322.

Pan, X.B., M.C. Rush, X.Y. Sha, Q.J. Xie, S.D. Linscombe, S.R. Stetina, and J.H. Oard. 1999. Major gene, nonallelic sheath blight resistance from the rice cultivars Jasmine85 and Teqing. Crop Sci. 39:338-346.

Poehlman, J.M. and D.A. Sleper. 1995. Breeding field Crops. Iowa State University Press, Ames.

Watkins, E., S.A. Bonos, and W.A. Meyer. 2009. Heritability of brown patch resistance in tall fescue. Int. Turfgrass Soc. Res. J. 11:271-282.

Wright, S. 1968. Evolution and the genetics of populations, Vol.1. Genetic and biometric foundations. Univ. of Chicago Press, Chicago.

Zhang, Y., M.S. Kang, and K.R. Lamkey. 2005. DIALLEL-SAS05: A comprehensive program for Griffing's and Gardener-Eberhart analyses. Agron. J. 97:1097-1106.

Zhao, M., Z. Zhang, S. Zhang, W. Li, D.P. Jeffers, T. Rong, and G, Pan. 2006. Quantitative trait loci for resistance to banded leaf and sheath blight in maize. Crop Sci. 46:1039-1045. 
Zou, J.H., X.B. Pan, Z.X. Chen, J.Y. Xu, J.F. Lu, W. Zhai, and L.H. Zhu. 2000. Mapping quantitative trait loci controlling sheath blight resistance in two rice cultivars (Oryza sativa L.) Theor. Appl. Genet. 101:569-573. 
Table 2.1. Characterization and general combining ability (GCA) of brown patch resistance of six tall fescue parents crossed in a diallel design and evaluated over 2007 and 2008 .

\begin{tabular}{lcccc}
\hline Parent ID & $\begin{array}{c}\text { Resistance } \\
\text { designation }^{\mathrm{z}}\end{array}$ & $\begin{array}{c}\text { Brown patch disease } \\
\text { severity }^{\mathrm{y}}(\%)\end{array}$ & GCA 2007 & GCA 2008 \\
\hline 7511 & $\mathrm{R}$ & 21 & $-13.81^{* * *}$ & $-8.78^{* * *}$ \\
7587 & $\mathrm{R}$ & 32 & $-7.81^{* * *}$ & $-4.27^{* * *}$ \\
RP66 & $\mathrm{R}$ & 32 & $-10.99^{* * *}$ & $-2.38^{*}$ \\
CL5 & $\mathrm{S}$ & 59 & $18.35^{* * *}$ & $6.29 * * *$ \\
CR15 & $\mathrm{S}$ & 59 & $7.51^{* * *}$ & $5.51^{* * *}$ \\
RP34 & $\mathrm{S}$ & 54 & $6.74 * * *$ & $3.63^{* * *}$ \\
LSD $(\mathrm{P} \leq 0.05)$ & & 10.4 & 0.8 & 2.1 \\
\hline
\end{tabular}

* Significant at the 0.05 probability level *** Significant at the 0.001 probability level

${ }^{\mathrm{Z}} \mathrm{R}$, resistant; S, susceptible. Resistance and susceptibility were determined from previous field trial. Resistance was defined as $\geq 30 \%$ diseased tissue.

${ }^{\mathrm{y}}$ Average resistance combined from 2007 and 2008. 
Table 2.2. Analysis of variance for brown patch resistance in a diallel cross of six tall fescue parents evaluated in a field trial in 2007 and 2008.

\begin{tabular}{|c|c|c|}
\hline Source of Variation $^{\mathrm{z}}$ & $\mathrm{df}$ & Mean Square \\
\hline Year & 1 & $11485.4 * *$ \\
\hline Rep (year) & 6 & $116.8 * *$ \\
\hline Cross & 35 & $554.2 * *$ \\
\hline GCA & 5 & $3458.1 * *$ \\
\hline SCA & 15 & $125.3 * *$ \\
\hline Reciprocal & 15 & 15.1 \\
\hline Maternal & 5 & 35 \\
\hline Non-maternal & 10 & 5.2 \\
\hline Cross $\times$ year & 35 & 38.6 \\
\hline GCA $\times$ year & 5 & $135.7 * *$ \\
\hline $\mathrm{SCA} \times$ year & 15 & 26.4 \\
\hline Reciprocal $\times$ year & 15 & 18.5 \\
\hline Maternal $\times$ year & 5 & 31.3 \\
\hline Non-maternal $\times$ year & 10 & 12.1 \\
\hline Error & 210 & 47.4 \\
\hline
\end{tabular}

** Significant at the 0.01 probability level.

${ }^{\mathrm{z}}$ GCA, general combining ability; SCA, specific combining ability. 
Table 2.3. Estimation of specific combining ability (SCA) effects in a diallel cross of six tall fescue parents using combined data from 2007 and 2008.

\begin{tabular}{lccccc}
\hline Parents & $7511(\mathrm{R})$ & $7587(\mathrm{R})$ & RP66 (R) & CL5 (S) & CR15 (S) \\
\hline 7587 (R) & $0.94^{\mathrm{z}}$ & & & & \\
& $32^{\mathrm{y}}$ & & & & \\
RP66 (R) & $2.04^{*}$ & 0.47 & 35 & & \\
CL5 (S) & 34 & 1.08 & -1.19 & & \\
& 0.76 & 48 & 44 & & \\
CR15 (S) & 43 & -1.71 & $-1.94^{*}$ & -1.5 & \\
& 0.12 & 39 & 44 & 51 & \\
RP34 (S) & 39 & 0.01 & -1.17 & -0.54 & -1.26 \\
& -1.02 & 41 & 42 & 52 & 48 \\
\hline
\end{tabular}

* Significant at 0.05 probability level.

${ }^{\mathrm{z}} \mathrm{SCA}$ effects

${ }^{\mathrm{y}}$ Data in italics designate disease severity $(\%)$ : LSD $(\mathrm{P} \leq 0.05)=4 \%$. 
Table 2.4. Estimation of minimum number of genes affecting brown patch resistance in a diallel cross of three resistant and three susceptible tall fescue parents.

\begin{tabular}{lc}
\hline Cross & \\
Resistant $\times$ Susceptible & Minimum number of effective genes \\
\hline $7587 \times$ CL5 & 2.6 \\
$7587 \times$ CR15 & 2.7 \\
$7587 \times$ RP34 & 1.2 \\
$7511 \times$ CL5 & 2.4 \\
$7511 \times$ CR15 & 3.2 \\
$7511 \times$ RP34 & 2.4 \\
RP66 × CL5 & 1.1 \\
RP66 $\times$ CR15 & 1.2 \\
RP66 $\times$ RP34 & 1.0 \\
\hline
\end{tabular}


Table 2.5. Percentage of entry sum of squares accounted for by general combining ability (GCA) and specific combining ability (SCA) for brown patch resistance in a diallel cross of six tall fescue parents evaluated in field trial in 2007 and 2008.

\begin{tabular}{lc}
\hline Source & Percentage of sum of squares \\
\hline GCA & 90 \\
SCA & 10 \\
\hline
\end{tabular}


Figure 2.1. Population distribution of $F_{1}$ progeny of a cross between two brown patch resistant tall fescue genotypes (7511 and 7587).

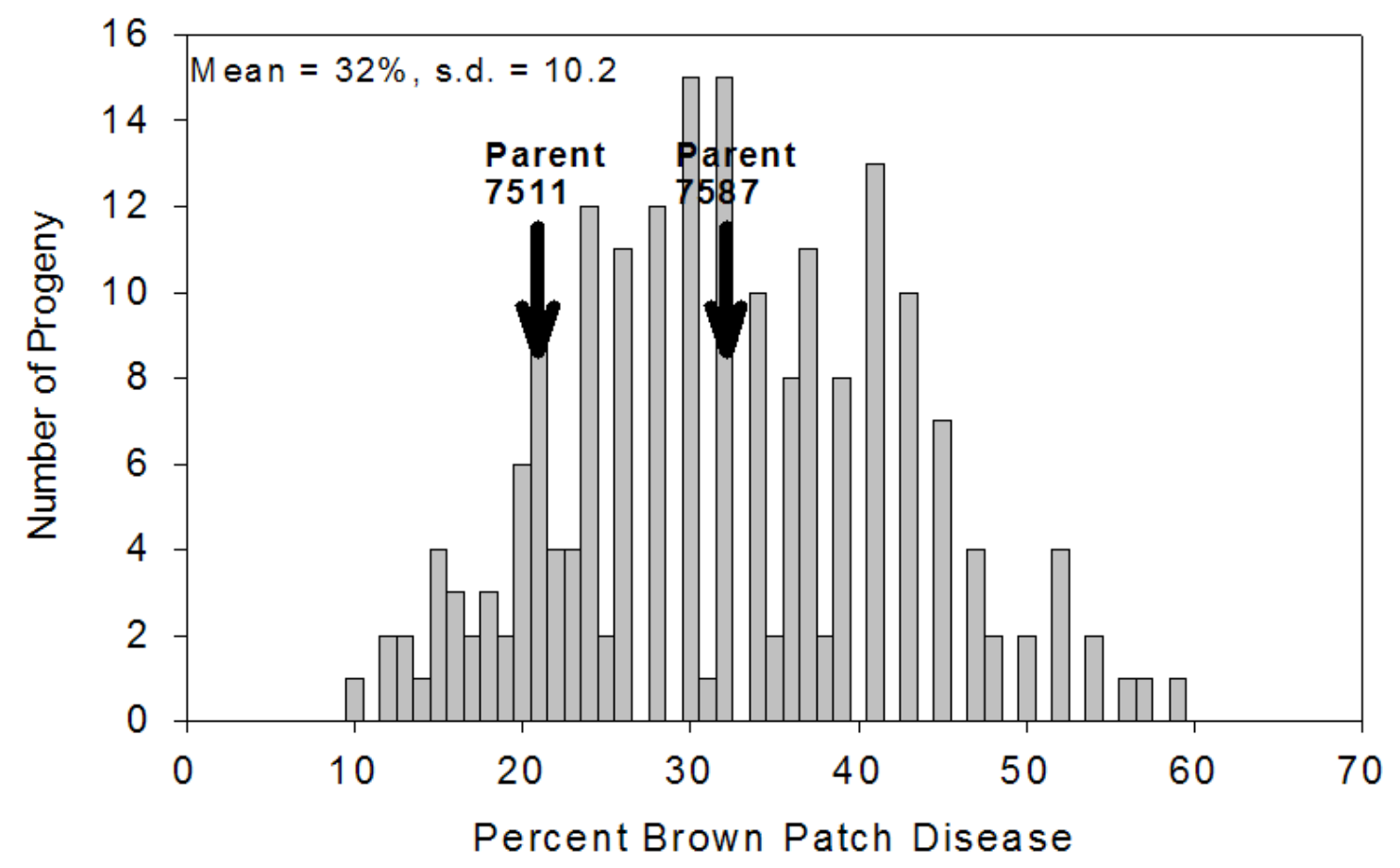

Figure 2.2. Population distribution of $\mathrm{F}_{1}$ progeny of a cross between two brown patch resistant tall fescue genotypes (7511 and RP66).

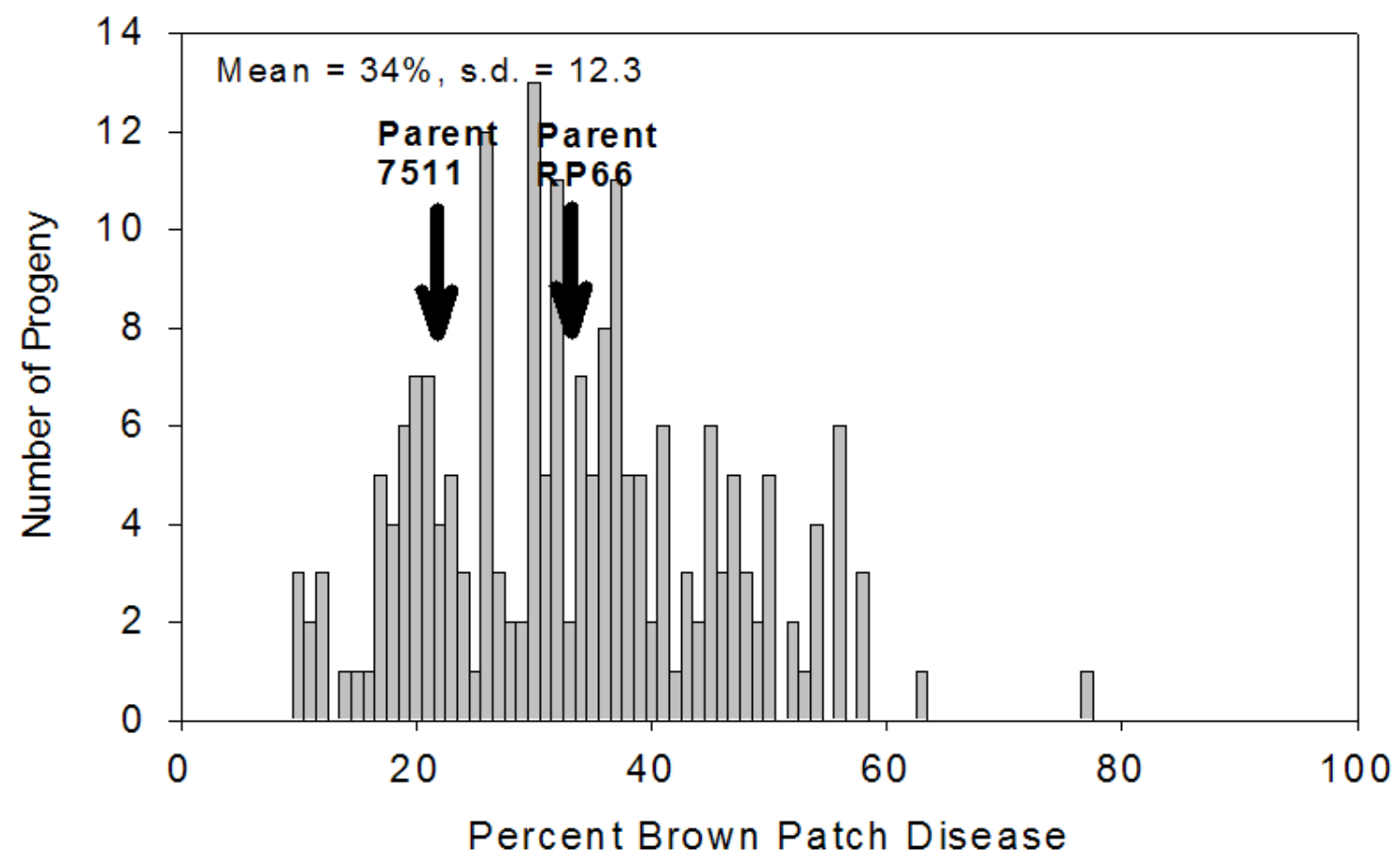


Figure 2.3. Population distribution of $F_{1}$ progeny of a cross between two brown patch resistant tall fescue genotypes (RP66 and 7587).

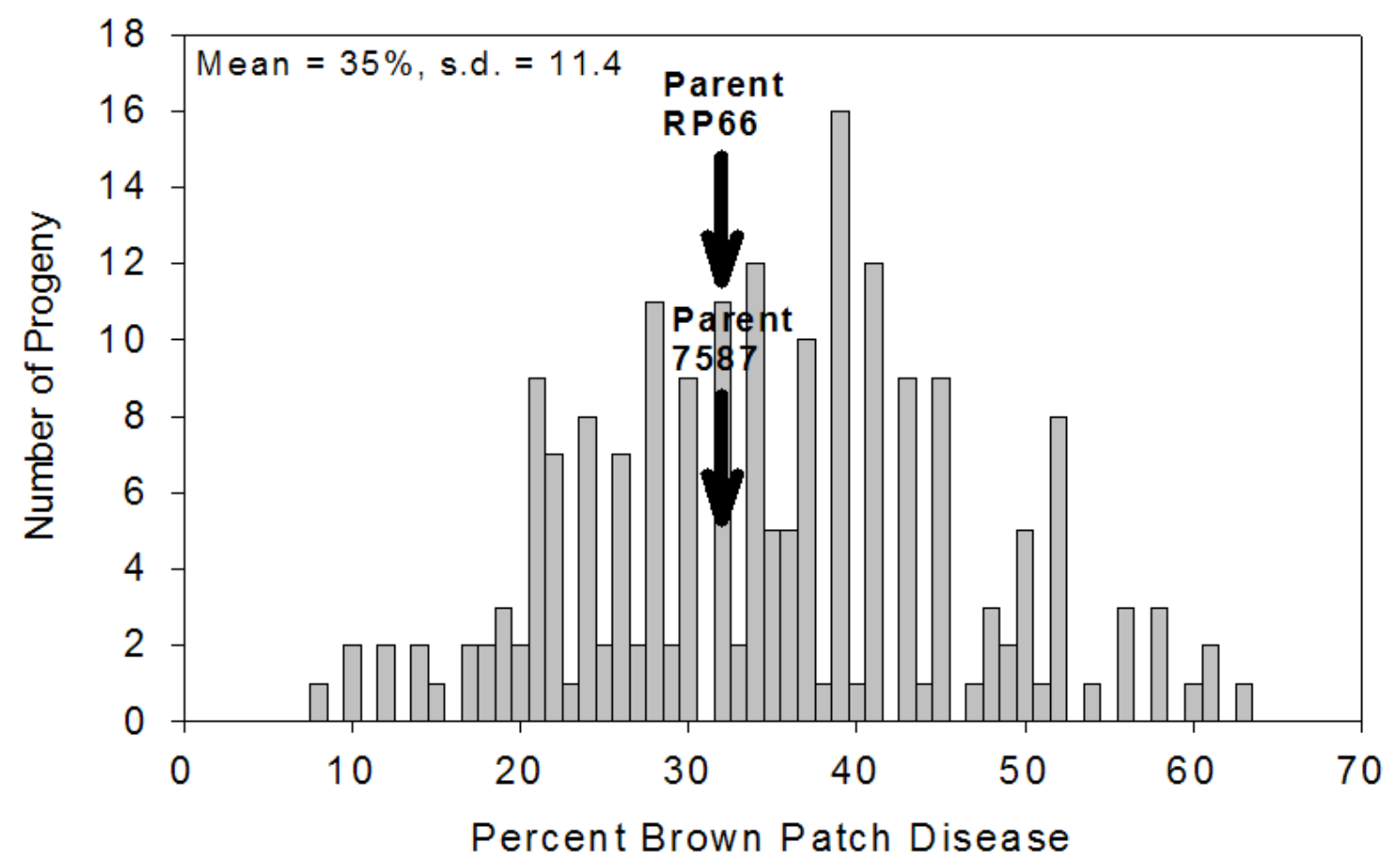

Figure 2.4. Population distribution of $F_{1}$ progeny of a cross between two brown patch susceptible tall fescue genotypes (CL5 and CR15).

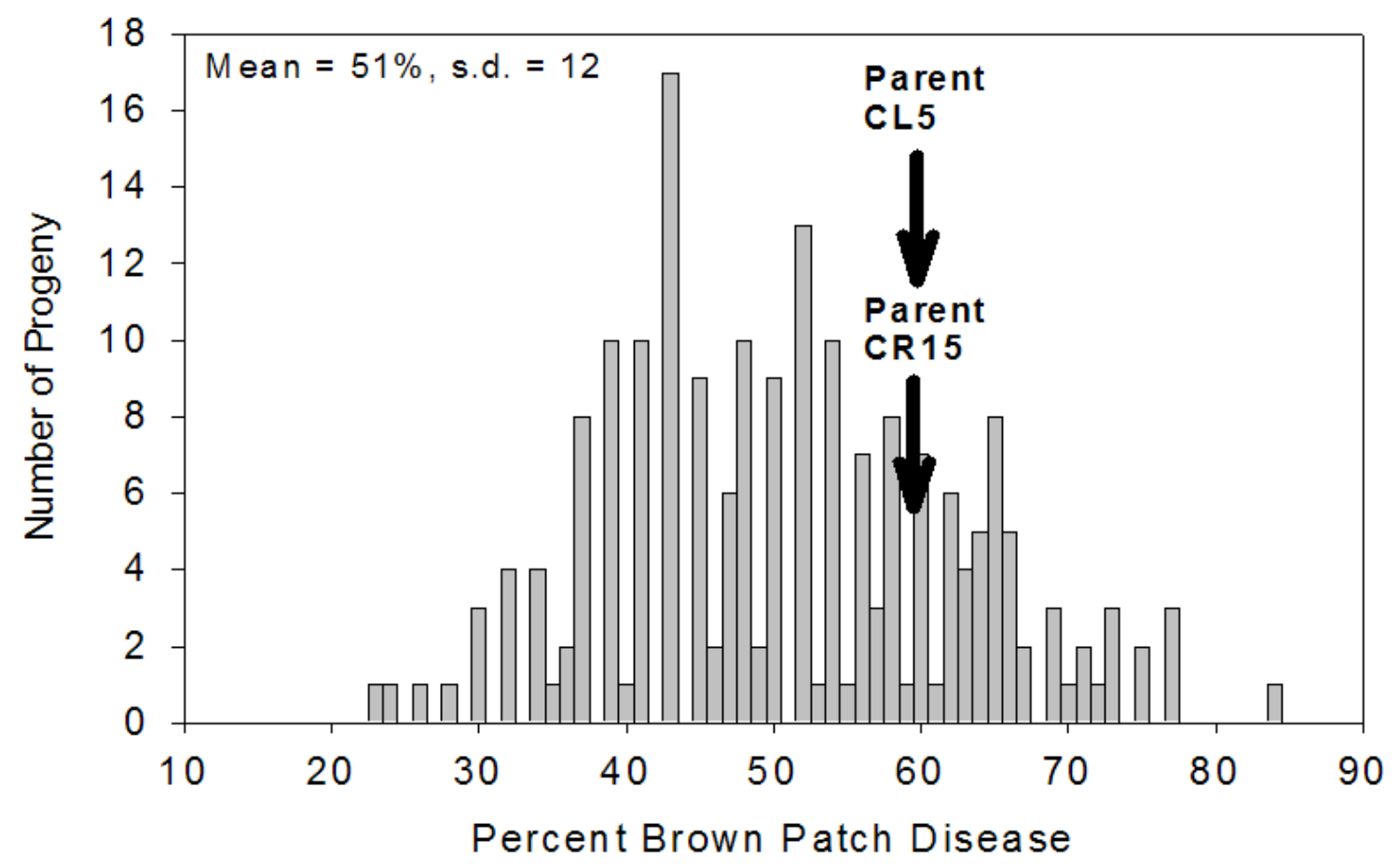


Figure 2.5. Population distribution of $F_{1}$ progeny of a cross between two brown patch susceptible tall fescue genotypes (RP34 and CL5).

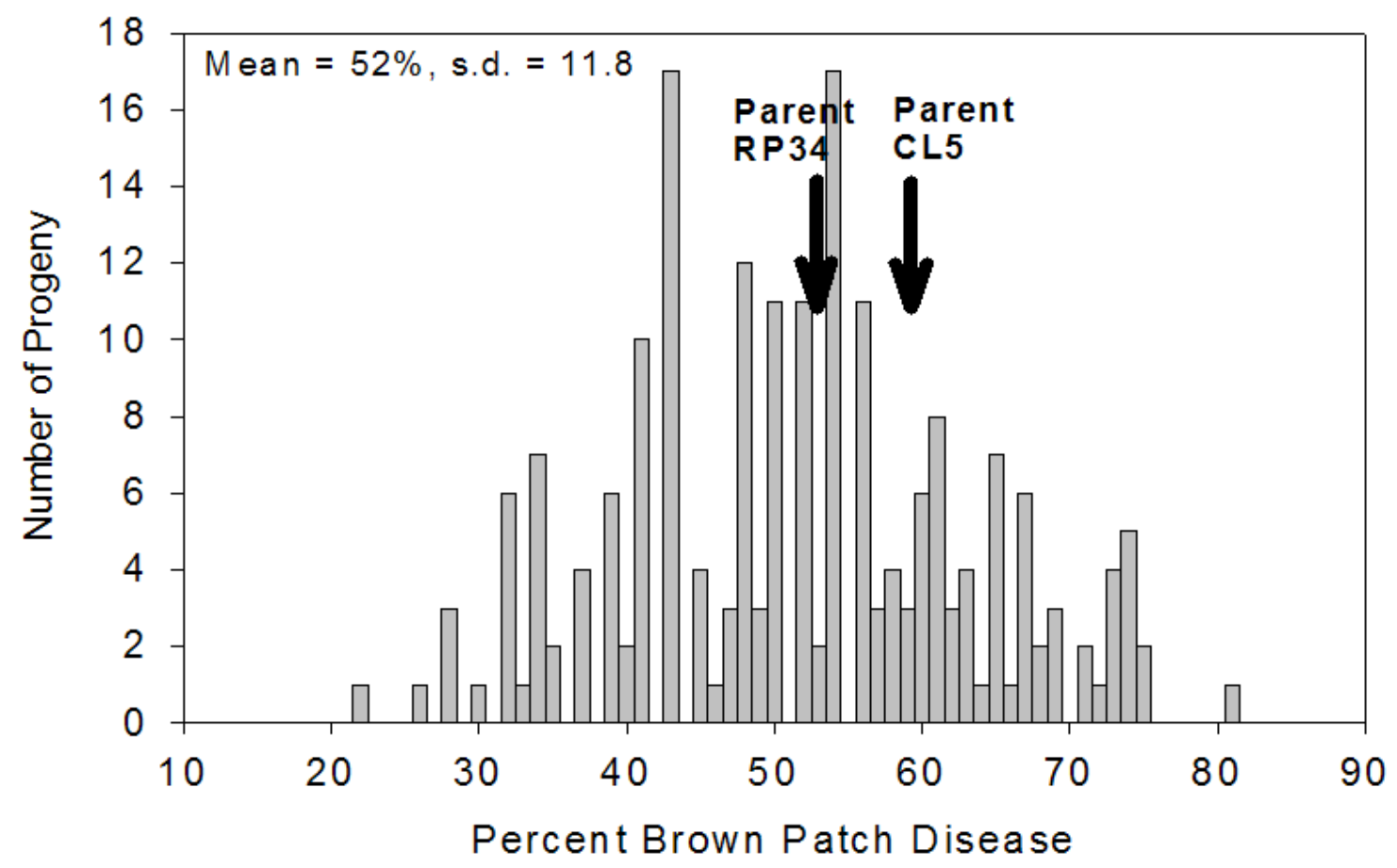

Figure 2.6. Population distribution of $F_{1}$ progeny of a cross between two brown patch susceptible tall fescue genotypes (RP34 and CR15).

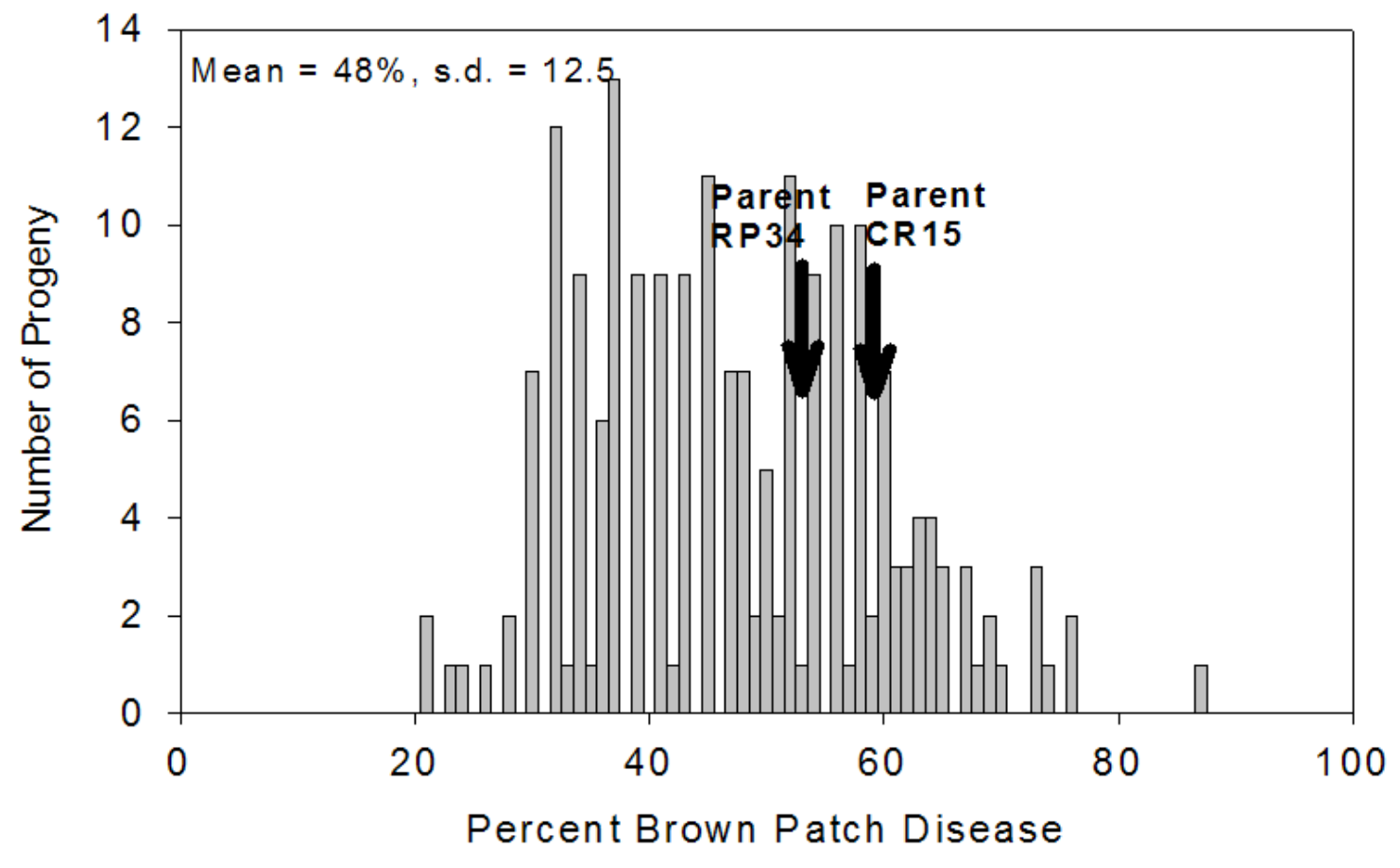


Figure 2.7. Population distribution of $F_{1}$ progeny of a cross between a brown patch resistant genotype (7511) and a susceptible tall fescue genotype (CL5).

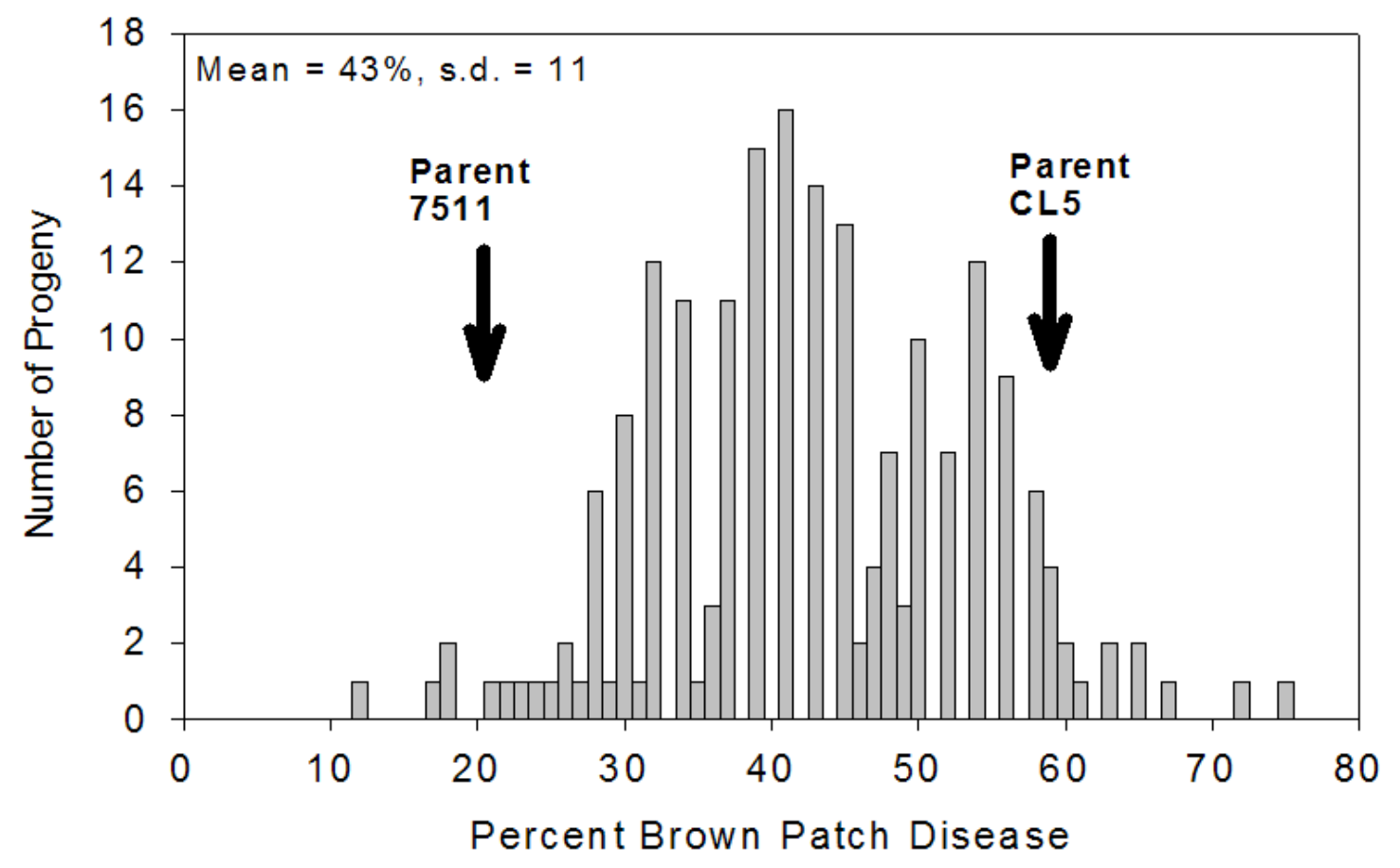

Figure 2.8. Population distribution of $F_{1}$ progeny of a cross between a brown patch resistant genotype (7511) and a susceptible tall fescue genotype (CR15).

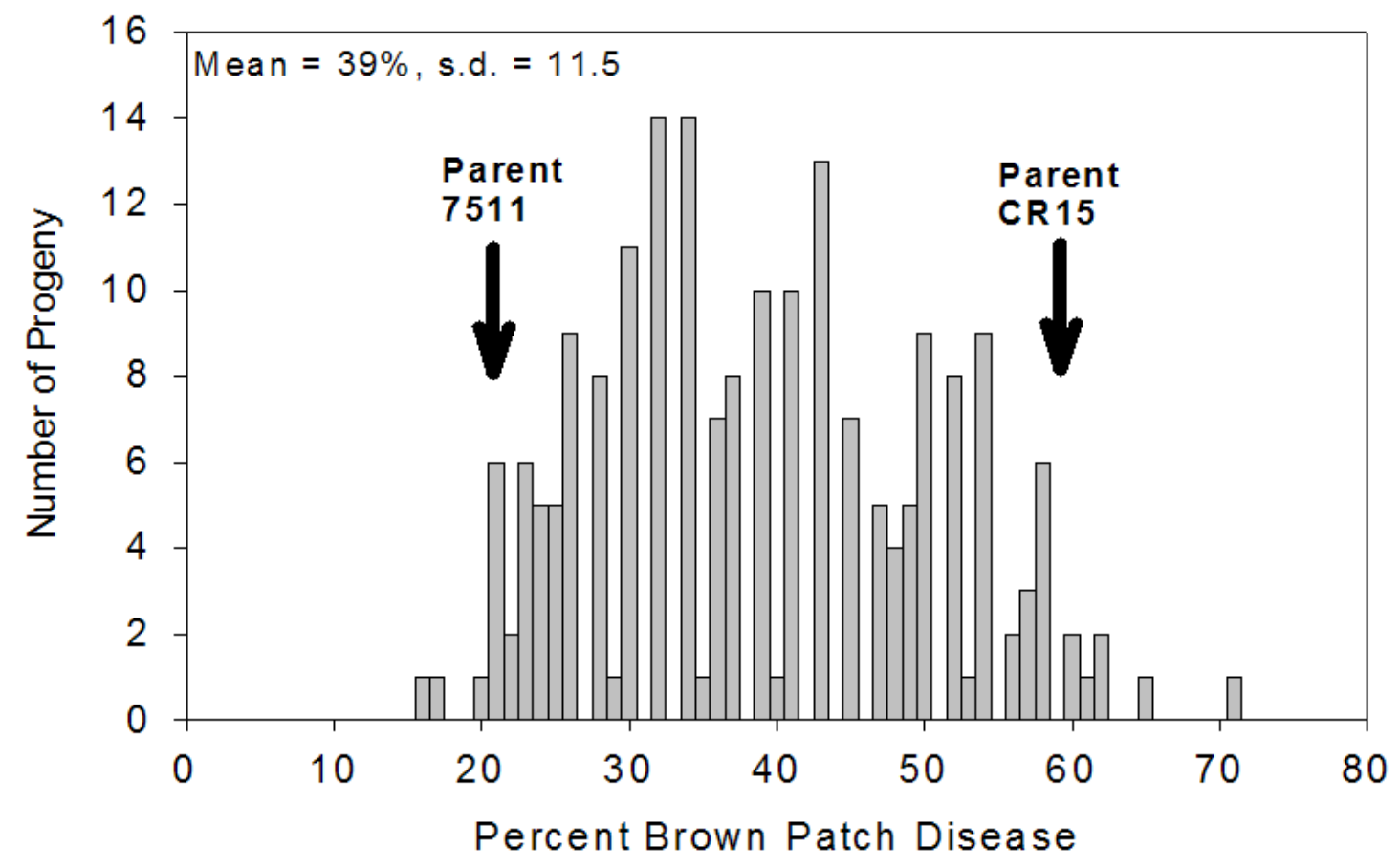


Figure 2.9. Population distribution of $F_{1}$ progeny of a cross between a brown patch resistant (7511) and a susceptible tall fescue genotype (RP34).

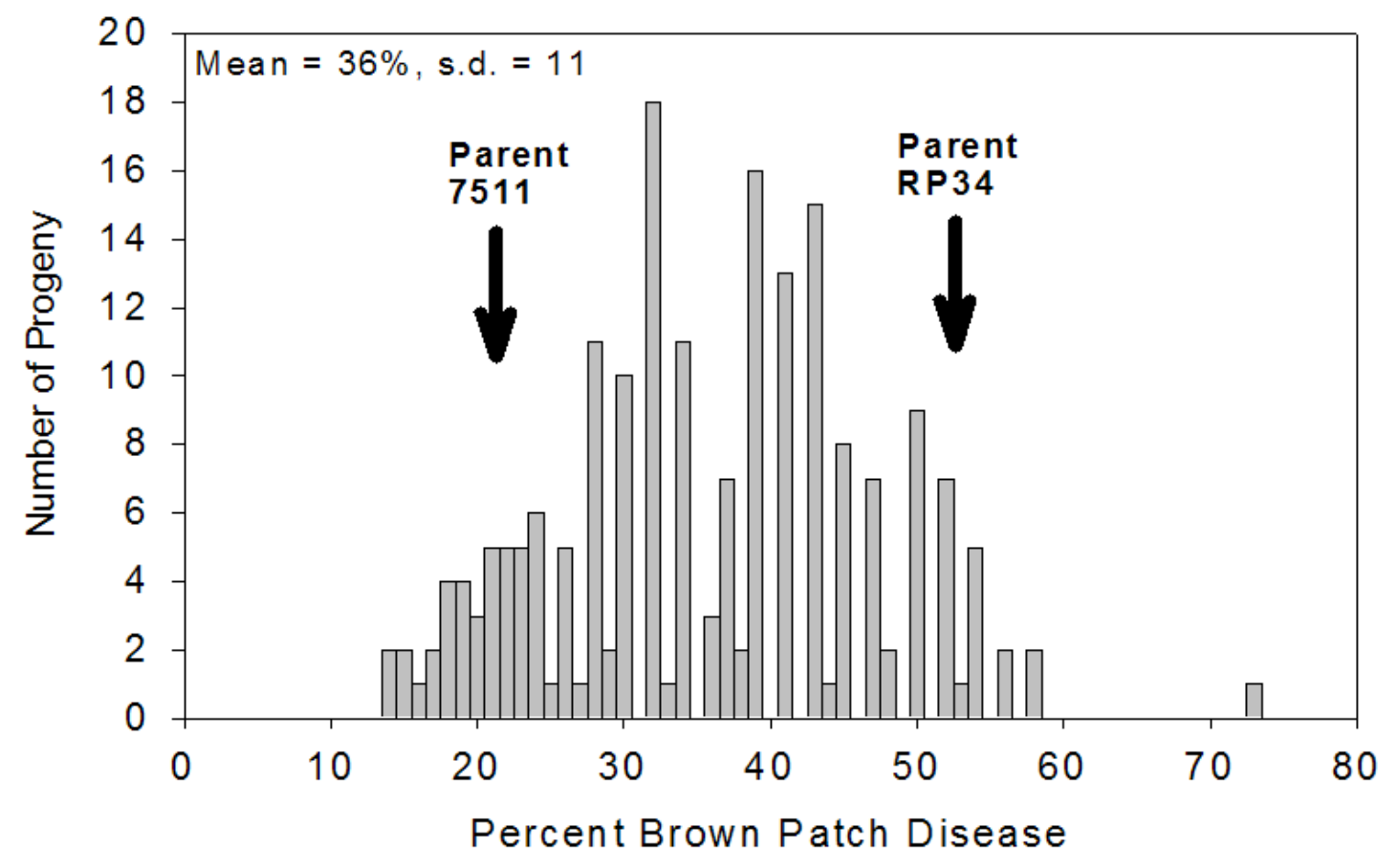

Figure 2.10. Population distribution of $F_{1}$ progeny of a cross between a brown patch resistant (7587) and a susceptible tall fescue genotype (CL5).

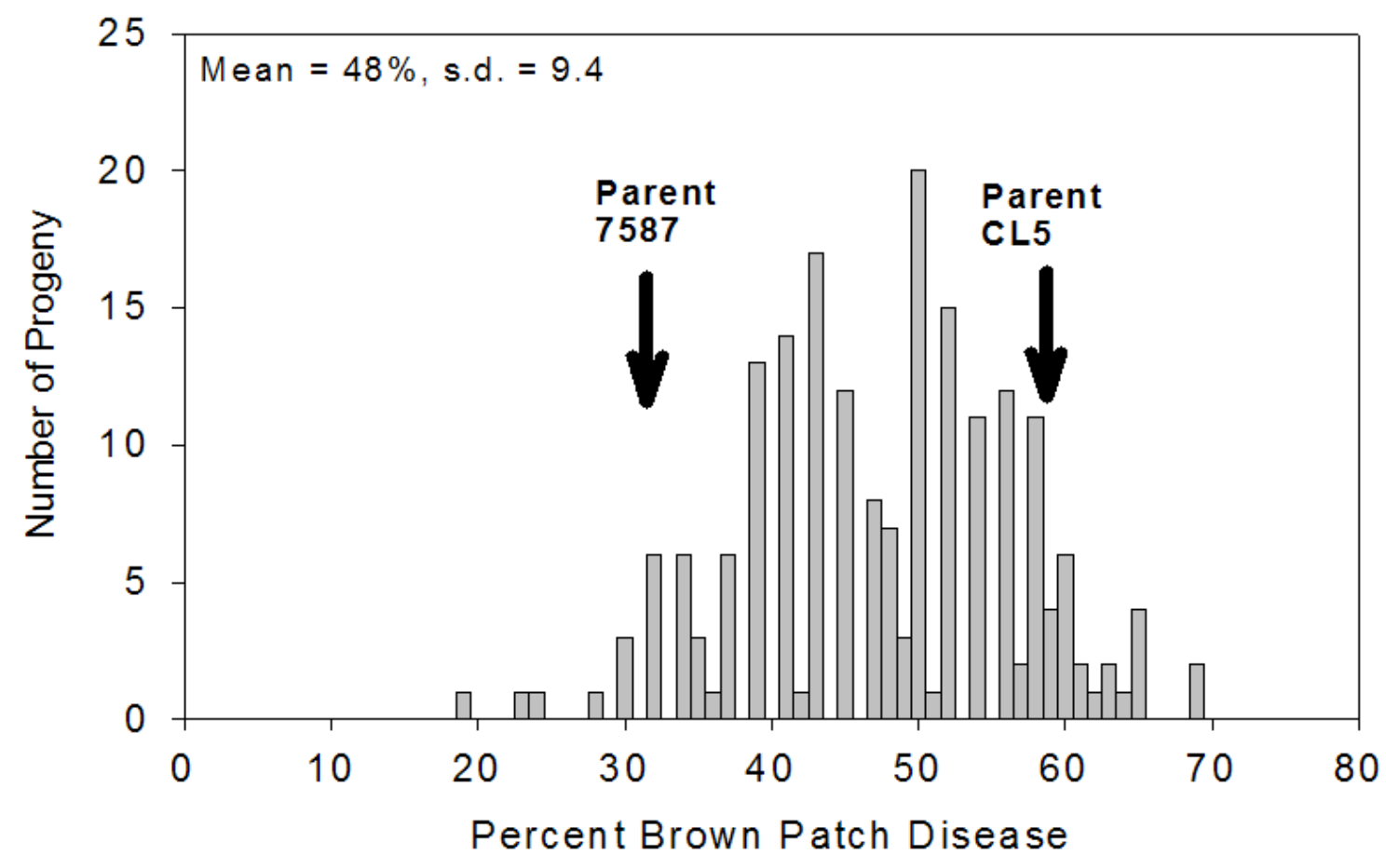


Figure 2.11. Population distribution of $F_{1}$ progeny of a cross between a brown patch resistant (7587) and a susceptible tall fescue genotype (CR15).

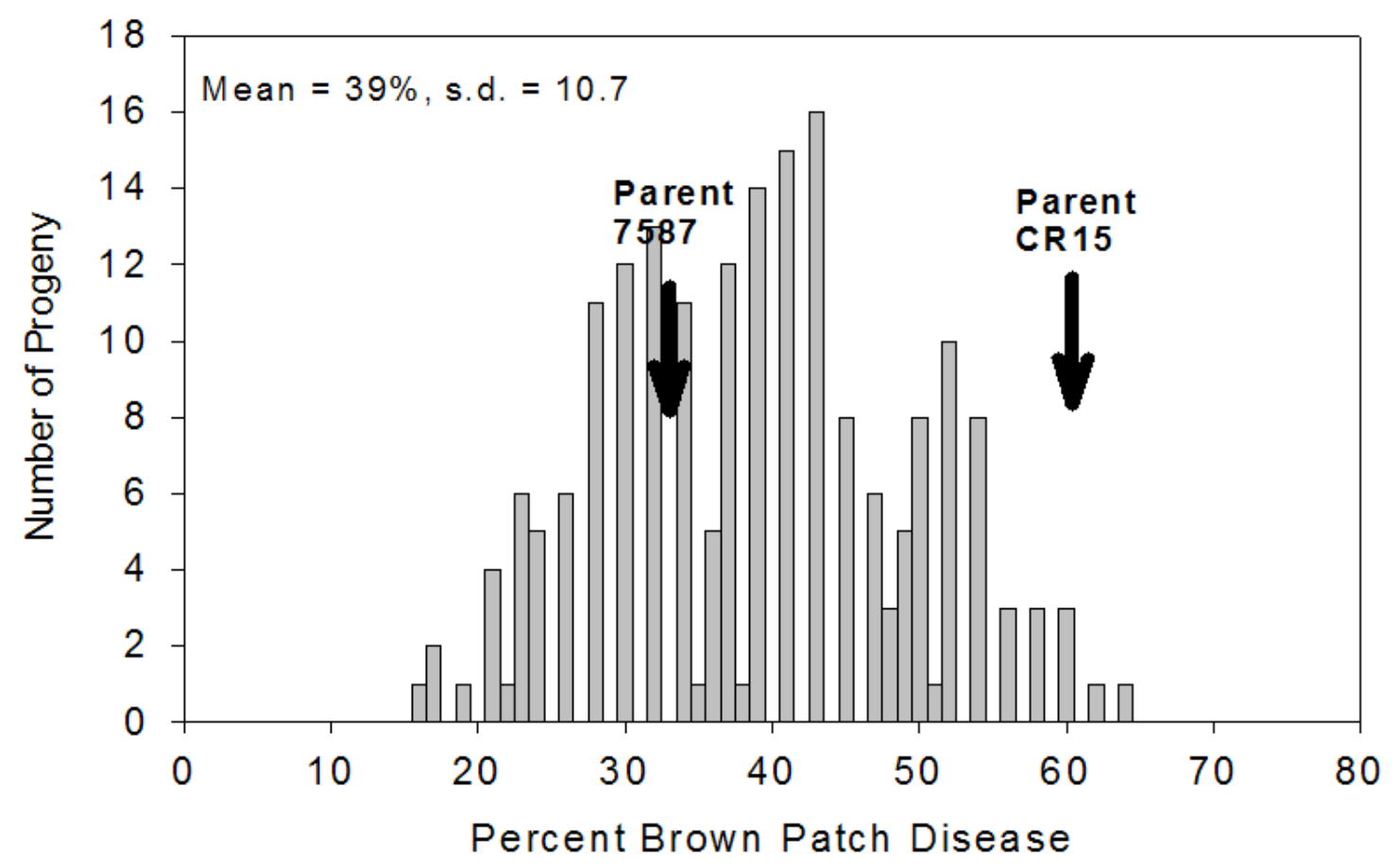

Figure 2.12. Population distribution of $F_{1}$ progeny of a cross between a brown patch resistant (7587) and a susceptible tall fescue genotype (RP34).

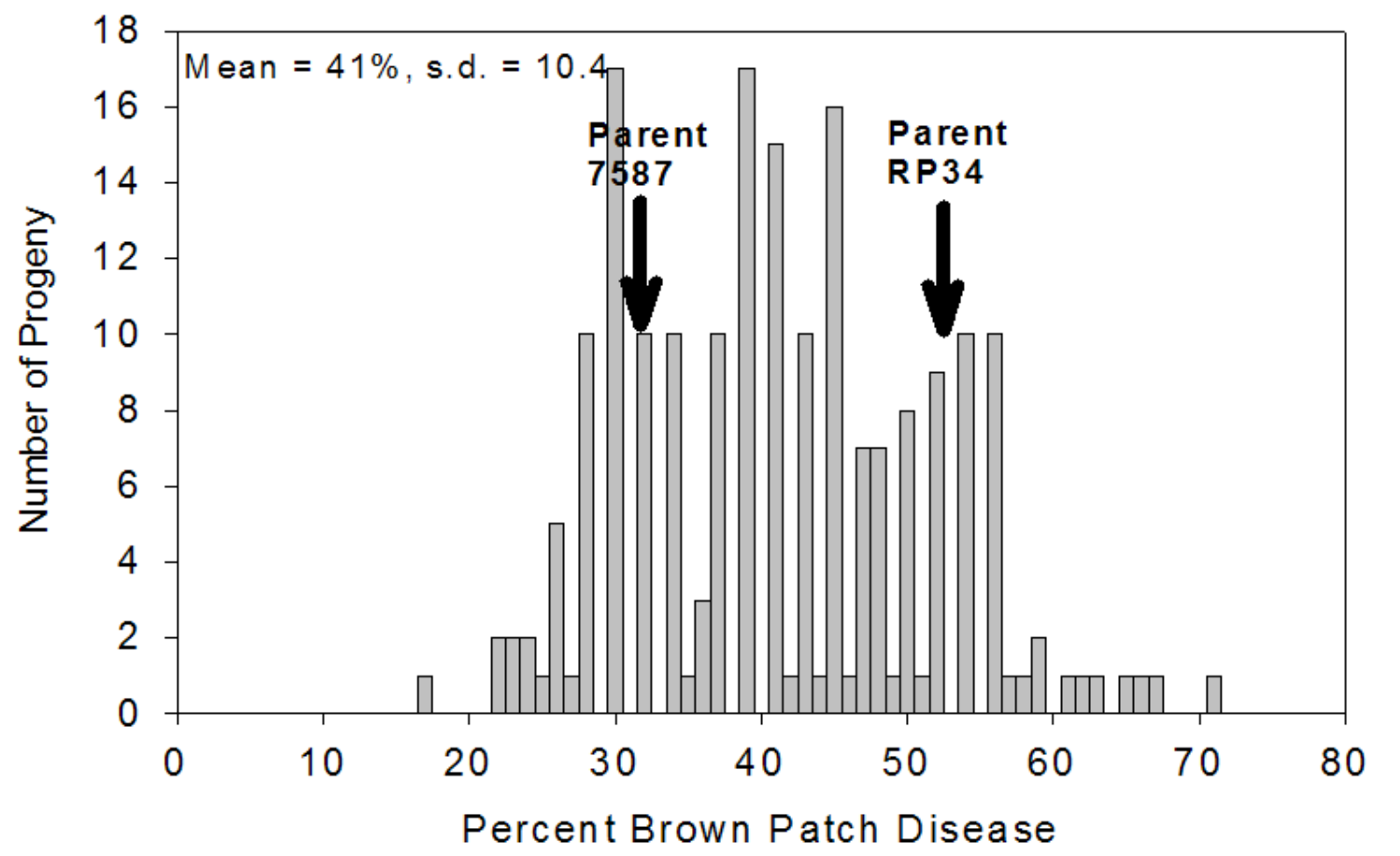


Figure 2.13. Population distribution of $F_{1}$ progeny of a cross between a brown patch resistant (RP66) and a susceptible tall fescue genotype (CL5).

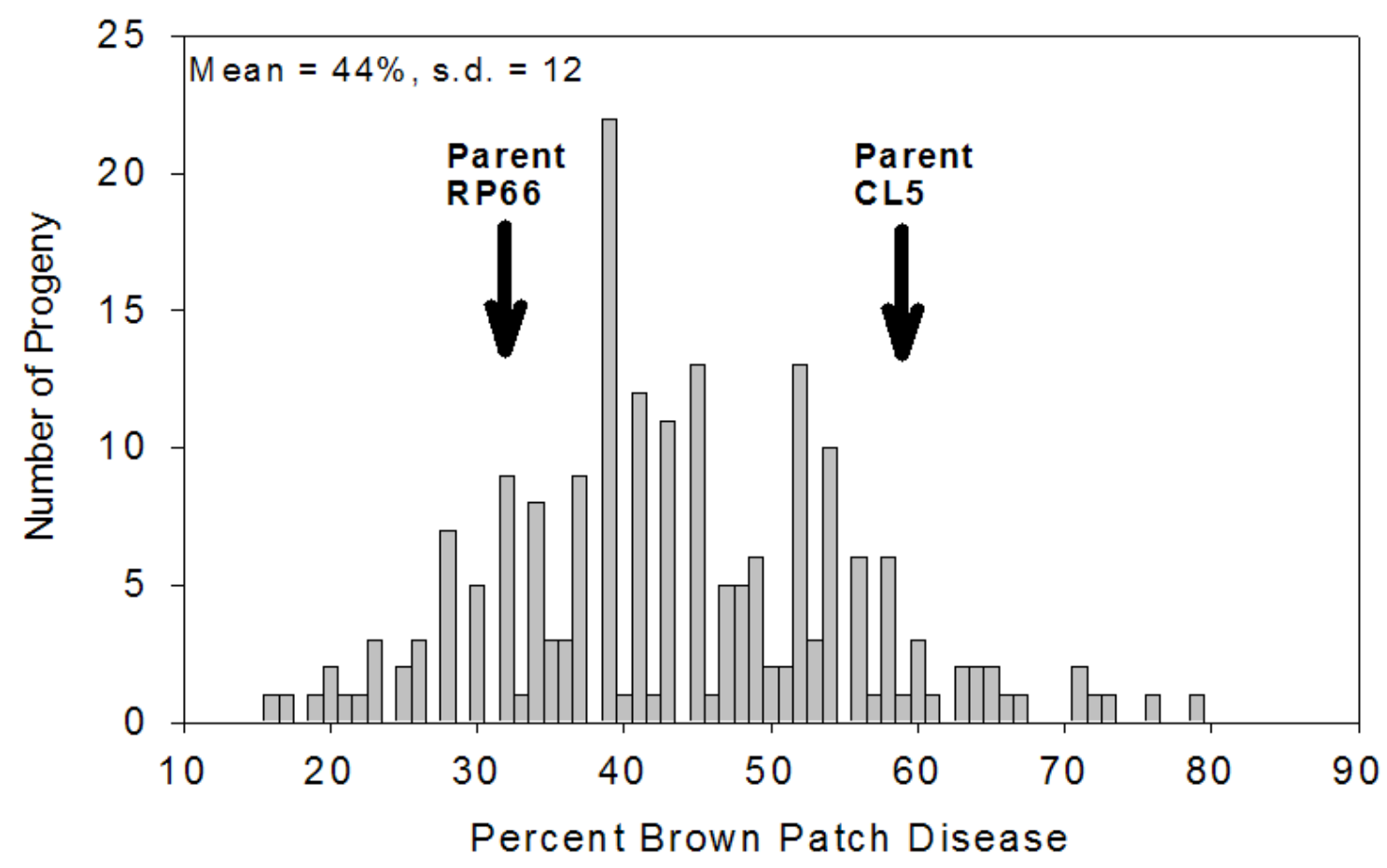

Figure 2.14. Population distribution of $F_{1}$ progeny of a cross between a brown patch resistant (RP66) and a susceptible tall fescue genotype (CR15).

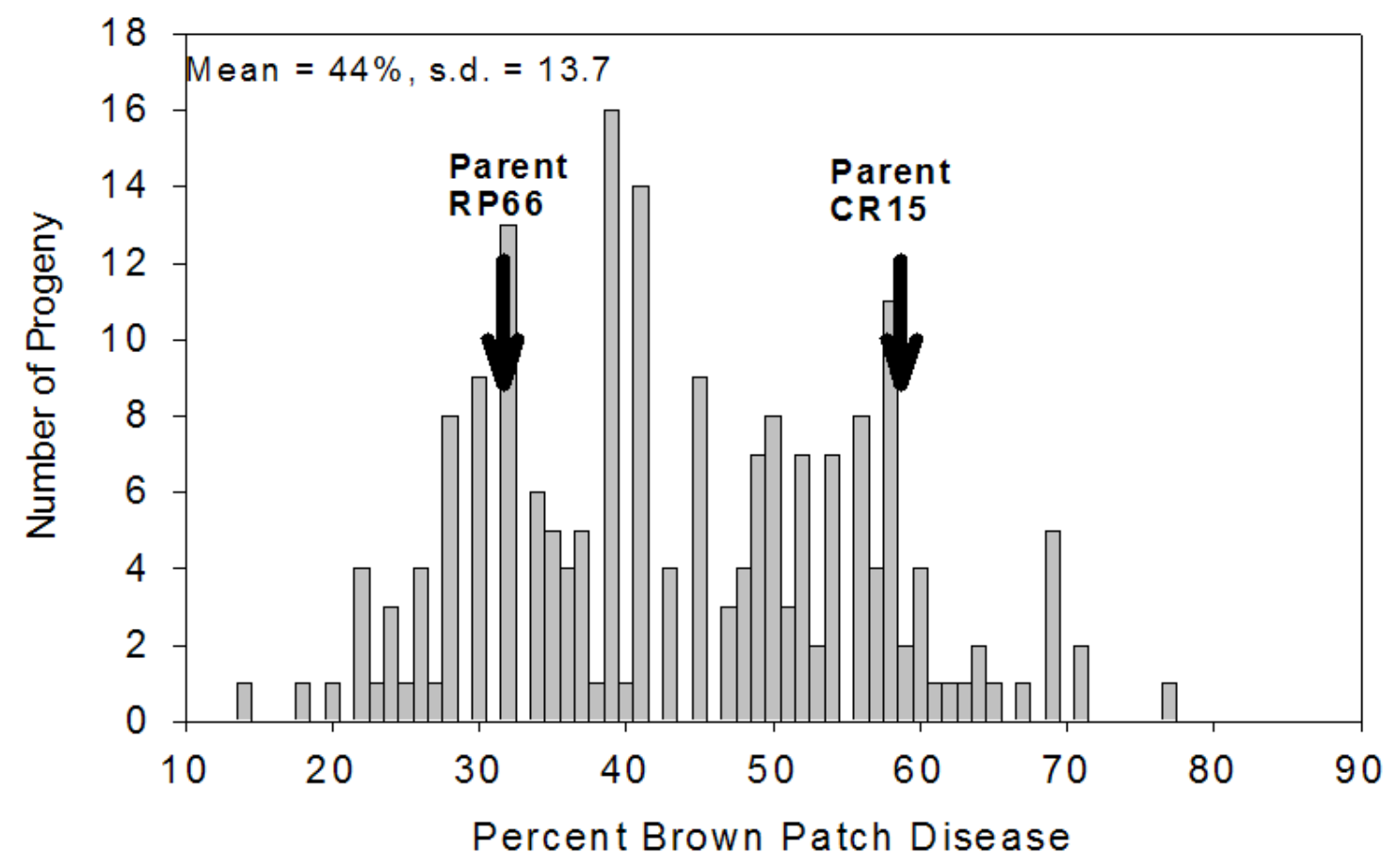


Figure 2.15. Population distribution of $F_{1}$ progeny of a cross between a brown patch resistant (RP66) and a susceptible tall fescue genotype (RP34).

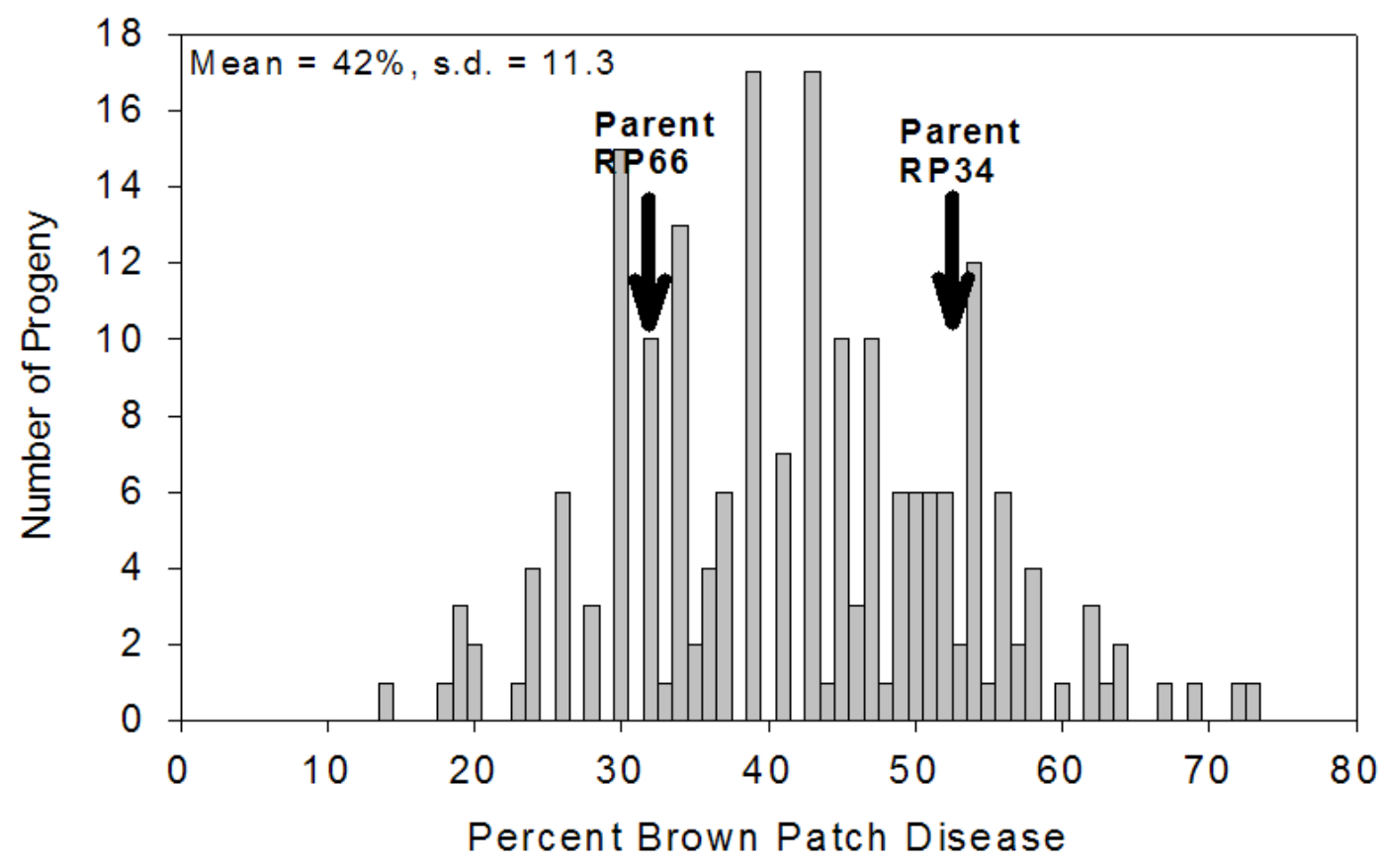


Figure 2.16. Mid-parent-offspring regression of $F_{1}$ population means regressed on the mid-parent value from 15 crosses between six tall fescue parental genotypes evaluated for brown patch resistance in 2007.

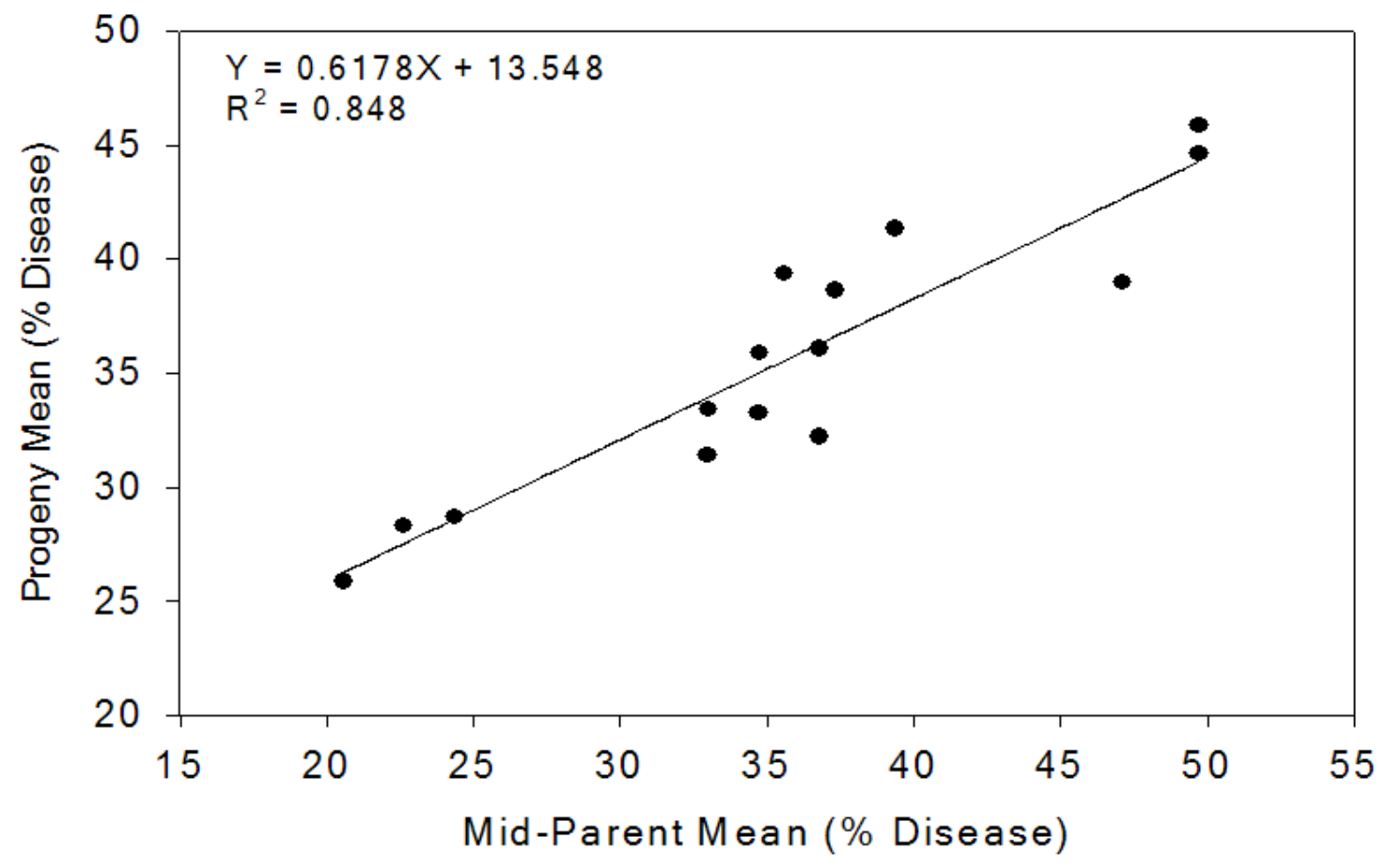


Figure 2.17. Mid-parent-offspring regression of $F_{1}$ population means regressed on the mid-parent value from 15 crosses between six tall fescue parental genotypes evaluated for brown patch resistance in 2008.

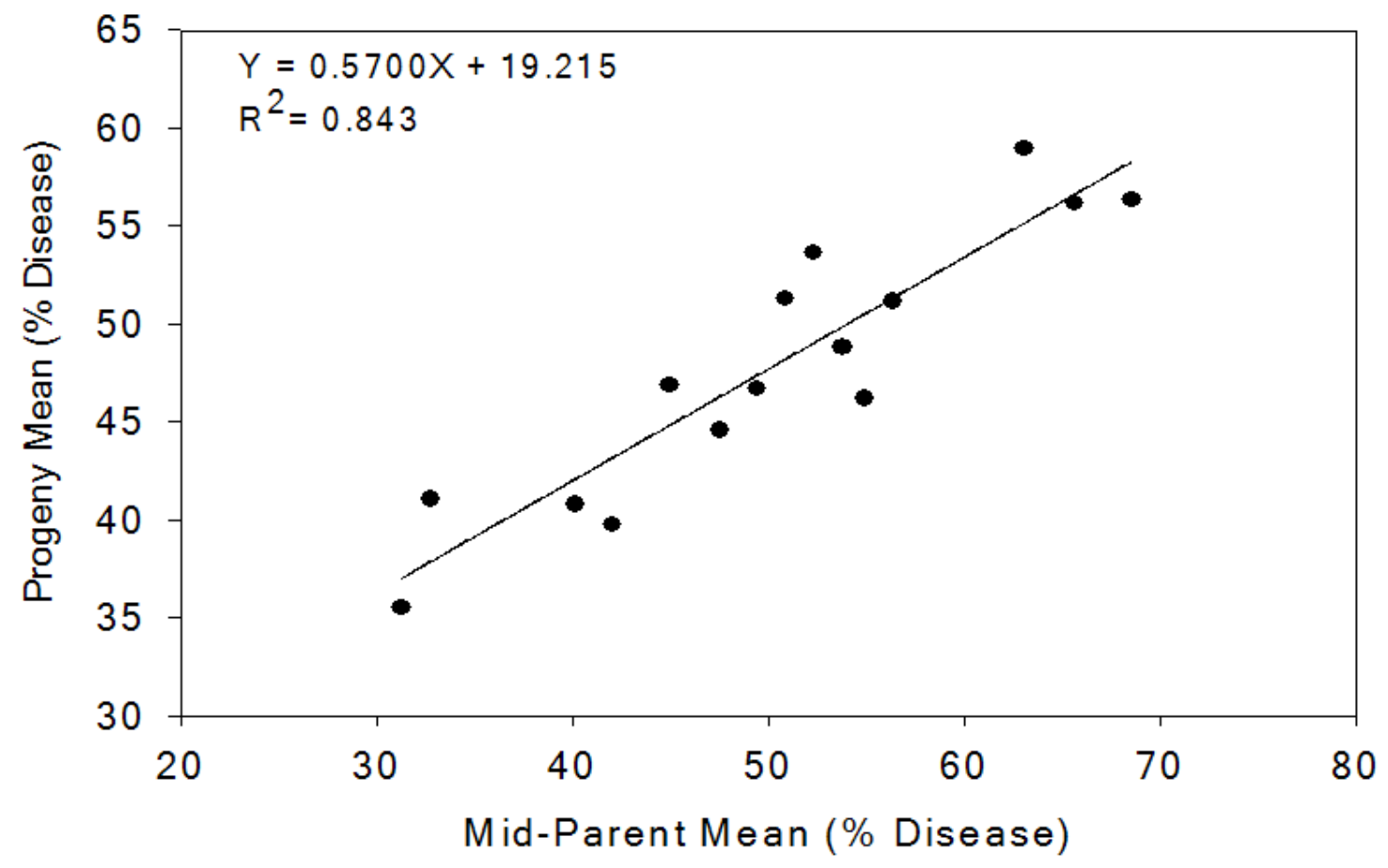




\section{Chapter III.}

\section{Polycross analysis of brown patch resistance in tall fescue}

\section{INTRODUCTION}

To successfully breed for improved brown patch resistance in tall fescue, the appropriate selection procedure that will most rapidly and effectively produce an acceptable level of improvement must be identified (Dudley and Moll, 1969). Quantitative genetic information pertaining to source populations is needed to plan an effective breeding program (Nguyen and Sleper, 1983b). An understanding of the ratio of the additive genetic variance to the total genetic variance is important in cross pollinated grasses since the most effective breeding design maximizes the utilization of the additive genetic variation, which is usually achieved through some form of recurrent selection (Vogel and Pendersen, 1993).

Recently, research has shed light on the genetic inheritance of brown patch (Rhizoctonia solani Kühn) resistance in tall fescue (Festuca arundinaceae Schreb.). Both Bokmeyer et al. (2009a) and Watkins et al. (2009) estimated the broad-sense heritability of brown patch resistance and reported moderate values ranging from 0.56 to 0.76 . Bokmeyer et al. (2009b) reported a moderate narrow-sense heritability of 0.57 and 0.63 for brown patch resistance from a diallel analysis involving six parents. They also found that both additive and non-additive genetic variance influenced brown patch resistance. These reports have all indicated a strong environmental influence on disease severity as 
well as continuous distribution of phenotypic responses and no completely resistant phenotypes; all indicating this is a quantitatively inherited trait.

The goal of breeding cross-pollinated crops is to improve heterogeneous populations and develop superior synthetic or composite cultivars (Nguyen and Sleper, 1983a; Vogel and Pedersen, 1993). Half-sib progeny testing is the most widely and extensively used grass breeding method (Vogel and Penderson, 1993). In an openpollinated species, polycross mating can be implemented to develop half-sib progenies that can be studied to determine the genetic variances, general combining ability (GCA), heritability, and gain from selection (Nguyen and Sleper, 1983a). In tall fescue, polycross progeny tests have been effectively used to estimate the genetic parameters of several quantitative traits and have been preferred over the diallel design (Bughrara et al., 1991;McQuinn et al, 1991; Nguyen and Sleper, 1983a). In developing synthetic cultivars information on the GCA of individuals is vital in determining which plants should be inter-pollinated, as this is measurement of the additive gene action. This was an effective approach in developing genetic resistance to gray leaf spot (Pyricularia oryzae Cavara) in perennial ryegrass (Lolium perenne L.). Half-sib progeny were evaluated to obtain information in regards to the contribution of resistance from each parental genotype. Genotypes that transmitted favorable alleles to their progeny were interpollinated, resulting in a realized heritability equivalent to 1.0 (Bonos et al., 2004).

The objectives of this study were to evaluate parents and polycross progenies for brown patch resistance to (i) estimate heritability and gain from selection, (ii) evaluate general combining ability of parental clones, and (iii) determine the most effective selection program. 


\section{Materials and Methods}

\section{Polycross and Field Trial}

In the fall of 2005, nine tall fescue genotypes were selected for resistance to brown patch from a broad-base population to be used in a polycross. Each genotype was clonally propagated into three replicates and planted in the field prior to the beginning of winter to fulfill vernalization requirements. In the spring of 2006, all three clonal replicates of each parent were removed from the field, potted up, and arranged in a randomized complete block design to ensure an equal chance of pollination by all parents. The polycross was isolated from other crosses by the use of physical barriers.

Seed was harvested from every parent and dried down. Once dry, seed was sown into a seed tray and placed in a cold room to break dormancy. After germination, 50 seedlings were randomly selected from every parent used in the polycross. A field experiment was established at Rutgers Plant Biology and Pathology Research and Extension Farm in Freehold, NJ. The soil type was a Freehold sandy-loam (fine-loamy, mixed, active, mesic Aquic Hapludult). The seedlings were planted in the field on 10 Oct. 2006 along with 15 vegetative replicates of the nine parents. The field experiment was arranged in a randomized complete block design with five replications. Each replication consisted of 10 progeny from each parent as well as three vegetative clones of the nine parents. Plants were spaced $31 \mathrm{~cm}$ apart and were mowed with a Toro Groundsmaster two times per week during the growing season at a height of $6.4 \mathrm{~cm}$. A total of $13.4 \mathrm{~g} \mathrm{~N} \mathrm{~m}^{-2}$ was applied to the field trial in 2007 and 2008. In April of 2007 and 
2008 applications of 34-0-0 (N-P-K) fertilizer was applied at $4 \mathrm{~g} \mathrm{~N} \mathrm{~m}^{-2}$. In May, June, and July of 2007 and 2008 applications of 16-2-7 (N-P-K) fertilizer was applied at a rate of $4 \mathrm{~g} \mathrm{~N} \mathrm{~m}^{-2}, 2.7 \mathrm{~g} \mathrm{~N} \mathrm{~m}^{-2}$, and $2.7 \mathrm{~g} \mathrm{~N} \mathrm{~m}^{-2}$ respectively. Pythium blight (Pythium aphanidermatum) was prevented with labeled rates of Subdue (metalaxyl).

\section{Inoculation Method}

Inoculum was prepared by growing a single isolate of $R$. solani on sterilized Kentucky bluegrass seed following the method described by Bonos et al. (2003). The isolate was collected from Agrostis species growing at The Valentine Turfgrass Research Center, The Pennsylvania State University, University Park, PA. Pathogencity of the $R$. solani isolate on tall fescue was confirmed in a growth chamber study prior to initiation of this experiment. The prepared inoculum was then placed in a drop spreader and applied to the field at a rate of $0.8 \mathrm{~g} \mathrm{~m}^{-2}$. The field trail was inoculated 18 June 2007 and again on 20 June 2008. To ensure favorable conditions for disease development, light irrigation was applied to the field immediately after inoculation. To encourage growth and development of the pathogen, light irrigation was periodically applied in the afternoon during the course of the study. Assessment of brown patch disease severity was taken in August of 2007 and 2008 using a 1-9 scale: nine represented 0 to 5\% diseased turf, eight represented 5 to $15 \%$ diseased turf, seven represented 15 to $30 \%$ diseased turf, six represented 30 to $45 \%$ diseased turf, five represented 45 to $55 \%$ diseased turf, four represented 55 to $70 \%$ diseased turf, three represented 70 to $85 \%$ diseased turf, two represented 85 to $95 \%$ diseased turf, and one represented 95 to $100 \%$ diseased turf. For data analysis, each 1-9 value was assigned the mid-point percent value 
for the disease range that it represented. All data analysis was conducted on percent disease using the combined average across both years.

\section{Statistical Analysis}

All data analysis was conducted on percent disease using the average of the rating dates from each year. Broad-sense heritability estimates were determined from restricted maximum likelihood (REML) variance and covariance components using the random model PROC MIXED (SAS Institute, Cary, NC). Broad-sense heritability was calculated on a clonal mean $(\mathrm{Hc})$ basis by the following formula

$\mathrm{Hc}=\sigma_{\mathrm{c}}^{2} /\left(\sigma_{\mathrm{c}}^{2}+\sigma_{\mathrm{cy}}^{2} / \mathrm{y}+\sigma_{\mathrm{e}}^{2} / \mathrm{rly}\right)$ $\sigma^{2} \mathrm{c}=$ the total genetic variance of clones, $\sigma_{\mathrm{cy}}^{2}=$ clone $\times$ year variance, and $\sigma_{\mathrm{e}}^{2}=$ experimental error $($ clone $\times$ rep within year) $($ Poehlman and Sleper, 1995).

Narrow-sense heritability was estimated using parent-progeny regression analysis. Means of the half-sib progeny were regressed against the mean of the parents where the regression coefficient $(b)$ is equal to one-half the narrow-sense heritability. The $b$ value is multiplied by two to obtain the narrow-sense heritability estimate (Fehr, 1987).

Gain from selection was calculated using the formula Gs $=i \sigma_{\mathrm{p}} h^{2}$, where Gs is the genetic gain from selection, $i$ is a constant based on selection intensity, $\sigma_{\mathrm{p}}$ is the standard deviation of the phenotypic variance, and $h^{2}$ is the narrow-sense heritability (Poehlman and Sleper, 1995).

General combing ability was calculated for each parent as the deviation of each half-sib progeny from the population mean (De Araujo and Coulman, 2002). 


\section{Results}

The analysis of variance of the parental clones for brown patch resistance showed that the mean squares of the parental clones were the largest significant source of variation (Table 3.1). Significant differences were observed among the nine parents with overall percent disease severity ranging from $23 \%$ to $43 \%$ (Table 3.2 ). The broad-sense heritability estimate for the nine parents evaluated over two years was 0.75 (Table 3.1). This estimate is similar to what has been reported in the literature for brown patch resistance in tall fescue by Bokmeyer et al. (2009a) (0.74) and Watkins et al. (2009) (0.54 to 0.76$)$.

Analysis of variance of the half-sib progeny means showed that progeny lines, year, and replications within years were significant sources of variation (Table 3.3). Significant differences were observed among progeny means (Table 3.2) with the overall percent disease severity ranging from $27 \%$ to $34 \%$. The population distribution of the progeny displayed a large amount of genetic variation for brown patch resistance. A continuous phenotypic response to brown patch was observed with no discrete reaction classes of resistance or susceptibility (Fig. 3.1). The narrow-sense heritability estimated from the parent-offspring regression was 0.47 (Table 3.4). This estimate of narrow-sense heritability is lower than what was previously reported for brown patch resistance in tall fescue of 0.57 and 0.63 by Bokmeyer et al. (2009b). Selection of the top 5\% of the population would result in an expected gain from selection of 5\% (Table 3.4).

General combining ability was significant for five of the nine parents utilized in the polycross (Table 3.2). From this study, two parents (ATE-21 and ATM-8) had 
significant negative GCA indicating they are good combiners for brown patch resistance. Three parents (ATN-23, RP-84, and RP-94) had significant positive GCA indicating that they had good combining ability for susceptibility. 


\section{Discussion}

Both the parental genotypes and half-sib progeny were significant sources of variation in response to brown patch (Table 3.1 and 3.3). While there was no significant genetic $\times$ environmental interaction in either analysis of variance, the magnitude of the error variance in the parental genotype analysis of variance and year effect in the half-sib analysis of variance indicates that there is a strong environmental effect. Selection for brown patch resistance should be conducted over multiple environments to account for the environmental effect.

The heritability of any trait depends upon the particular population being evaluated as well as the environment in which it is grown (Nguyen and Sleper, 1983a). For this study, the ratio of the total genetic variance to the phenotypic variance estimated by the broad-sense heritability was 0.75 (Table 3.1 ). This is consistent with other broadsense heritability estimates for brown patch resistance in tall fescue (Bokmeyer et al., 2009a; Watkins et al., 2009). This indicates that there is a moderate genetic component associated with brown patch resistance in tall fescue; however, the environmental effect can not be overlooked as it accounts for one-fourth of the variation observed.

The narrow-sense heritability estimate which accounts for the additive genetic variance was 0.47 (Table 3.4). This indicates that only about half of the total genetic variance can be attributed to additive genetic variance; indicating the presence of other types of gene effects. This estimate is lower than what has been previously reported for brown patch resistance in tall fescue (0.57 to 0.63) (Bokmeyer et al., 2009b) and other turf pathosytems such as dollar spot (Sclerotinia homoeocarpa F.T. Bennet.) resistance in 
creeping bentgrass (Agrostis stolonifera L.) (0.79) (Bonos, 2006), and gray leaf spot resistance in perennial ryegrass ( 0.57 to 0.76 ) (Han et al., 2006).

Additive and additive $\times$ additive epistatic variances are what are selected for using a phenotypic recurrent selection program (Hallauer, 1981). The formula for gain from selection utilizes the additive genetic variance to provide an estimate of what would be expected with phenotypic selection based on a specific selection intensity. From this study it was estimated that a $5 \%$ gain would be expected if the top $5 \%$ of the population was selected (Table 3.4). This number is considerably smaller than the gain of $28 \%$ and $44 \%$ Bonos (2006) reported assuming the same selection intensity for dollar spot resistance in creeping bentgrass. Based on the low narrow-sense heritability estimate and gain from selection, a phenotypic recurrent selection may not be the most efficient method for improving brown patch resistance in this particular tall fescue population. De Araujo and Coulman (2002) also concluded that phenotypic selection for plant spread in meadow bromegrass (Bromus riparius Rehm.) would be difficult based on a narrowsense heritability estimate of 0.41 and 0.28 . McQuinn et al. (1991) reported that the narrow-sense heritability of 0.68 for selenium content in tall fescue would allow for the use of phenotypic recurrent selection or simple mass selection. Bughrara et al. (1991) reported that predicted gains from phenotypic selection of 58,21 , and $48 \%$ were high enough to continue with a phenotypic selection program for improving digestibility in tall fescue.

Evaluating progeny lines from a polycross enables researchers to gather information on the GCA of the parents utilized in the crosses. For a cross-pollinated species like tall fescue, the GCA estimates of parents can be used to determine which 
genotypes should be selected and inter-pollinated to improve brown patch resistance. Following the method of Han et al. (2006) the GCA of each parent was calculated and compared back to its own performance to determine how efficiently each parent contributed to resistance. Parents ATE-21, ATM-8, ATP-02, ATN-23, A97-155, and RP84 response to brown patch could not be statically differentiated; however, they did vary greatly for GCA (Table 3.2). Parents ATE-21 and ATM-8 had significant negative GCA indicating that they transmitted favorable alleles for brown patch resistance to their progeny (Table 3.2). Parent ATN-23 had a significant positive GCA, as did parent RP84, indicating that they did not transmit favorable alleles for brown patch resistance to their progeny (Table 3.2 ). While all seven parents responded statistically similarly to brown patch they transmitted resistance differently to their progeny. This illustrates the importance of progeny testing to identify parents that contribute favorable alleles for resistance. Selection based solely on phenotypic response of clones will continue to incorporate parents into crossing blocks that contribute unfavorable alleles for brown patch resistance hindering potential genetic improvements. Bokmeyer et al. (2009b) found similar results when comparing parent vs. progeny data using a six parent diallel analysis. Both studies indicate that strictly additive genetic effects are not enough to improve brown patch resistance in tall fescue and that there may be other epistatic effects that increase susceptibility in a population. Both studies also indicate the importance of progeny testing prior to parent selection for composite cultivar development. The presence of non-additive effects has been detected in other turfgrass pathosytems. Bonos (2006) reported significant SCA and GCA for creeping bentgrass genotypes that had been crossed in diallel design. From this data, it was concluded that selecting for creeping 
bentgrass parents with significant GCA for dollar spot resistance would be effective for improving resistance in subsequent generations. An alternative strategy to a phenotypic recurrent selection program to improve brown patch resistance would be to employ a genotypic recurrent selection program. This form of recurrent selection involves evaluating progeny performance to obtain information on the genotypes that were used to make the cross in order to determine which genotypes should be advanced in the breeding program. Selecting genotypes to be advanced in a breeding program based off of progeny data is more labor intensive than a phenotypic selection program, but is necessary when non-additive effect are present. This method has proven to be effective in selecting for gray leaf spot resistance in perennial ryegrass (Bonos et al., 2004). 


\section{CONCLUSIONS}

The results from this study of a moderate broad-sense heritability estimate, low narrow-sense heritability estimate, and significant GCA are consistent with previous research investigating the genetic inheritance of brown patch resistance. Based on the low narrow-sense heritability for brown patch resistance, phenotypic recurrent selection may not be the most effective selection program. The data supports progeny testing to select for parents with significant GCA that can be used to develop synthetic and composite cultivars for improved brown patch resistance. Evaluation of polycross progeny can be an effective tool to estimate GCA of plants for brown patch resistance. The advantage of using a polycross mating design over a diallel design is it allows for a larger number of genotypes to be evaluated. Two out of the nine parents from this study were identified as good general combiners for brown patch resistance. Even though all the parents had been selected for improved brown patch resistance among a broader range of genotypes, the significant positive GCA indicates they still may be harboring genes for susceptibility that are only uncovered in progeny evaluation. 


\section{REFERENCES}

Araujo M. R. A. and B. E. Coulman. 2002. Genetic variation, heritability and progeny testing in meadow bromegrass. Plant Breeding 121:417-424.

Bokmeyer, J.M, S.A Bonos, and W.A. Meyer. 2009. Broad-sense heritability and stability analysis of brown patch resistance in tall fescue. HortScience 44:289292.

Bokmeyer, J. M., S. A. Bonos, and W. A. Meyer. 2009b. Inheritance characteristics of brown patch resistance in tall fescue. Tentatively accepted April 3, 2009 to Crop Sci.

Bonos, S.A., M.A. Casler, and W.A. Meyer. 2003. Inheritance of dollar spot resistance in creeping bentgrass. Crop Sci. 43:2189-2196.

Bonos, S.A., C. Kubik, B.B. Clarke, and W.A. Meyer. 2004. Breeding perennial ryegrass for resistance to gray leaf spot. Crop Sci. 44:575-580.

Bonos, S. A. 2006. Heritability of dollar spot resistance in creeping bentgrass. Phytopathology 96:808-812.

Bughrara S. S., D. A. Sleper, and G. F. Krause. 1991. Genetic variation in tall fescue digestibility estimated using a prepared cellulose solution. Crop Sci. 31:883-889.

Dudley, J. W. and R. H. Moll. 1969. Interpretation and use of estimates of heritability and genetic variance in plant breeding. Crop Sci. 9:257-262.

Fehr, W.R. 1987. Principles of cultivar development. Vol. 1. Theory and technique. Iowa State University, Ames, IA

Hallauer, A. R. 1981. Selection and breeding methods. In: Plant breeding II (ed. Frey, K. F.) Iowa State University Press, Ames.

Han, Y., S.A. Bonos, B.B. Clarke, and W.A. Meyer. 2006. Inheritance of resistance to gray leaf spot disease in perennial ryegrass. Crop Sci. 46:1143-1148.

McQuinn, S. D., D. A. Sleper, H. F. Mayland, and G. F. Krause. 1991. Genetic variation for selenium content in tall fescue. Crop Sci. 31:617-620.

Nguyen, H. T. and D. A. Sleper. 1983a. Theory and application of half-sib mating in forage grass breeding. Theor. Appl. Genet. 64:187-196.

Nguyen, H. T. and D. A. Sleper. 1983b. Genetic variability of seed yield and reproductive characters in tall fescue. Crop Sci. 23:621-626. 
Poehlman, J.M. and D.A. Sleper. 1995. Breeding Field Crops. Iowa State University Press, Ames.

Vogel, K. P. and J. F. Pedersen. 1993. Breeding systems for cross-pollinated perennial grasses. Plant Breed. Rev. 11:251-274.

Watkins, E., S.A. Bonos, and W.A. Meyer. 2009. Heritability of brown patch resistance in tall fescue. Int. Turfgrass Soc. Res. J. 11:271-282. 
Table 3.1. Analysis of variance of brown patch disease severity of nine parental tall fescue clones established in mowed spaced-plant trial and evaluated over 2 years (2007 and 2008).

\begin{tabular}{lcccc}
\hline Source of variation & df & MS & $F$ value & $\begin{array}{c}\text { Variance } \\
\text { Component }\end{array}$ \\
\hline Year & 1 & 286.5223 & 3.66 & \\
Rep(Year) & 8 & 201.53372 & $2.57^{*}$ & \\
Clone & 8 & 389.26906 & $4.97 * * *$ & 30.6165 \\
Clone $\times$ Year & 8 & 83.104244 & 1.06 & 0.4751 \\
Error $=$ Clone $\times$ Year $($ Rep $)$ & 64 & 78.35308 & & 9.794138 \\
$\mathrm{H}=0.75$ 95\% confidence $=0.71-0.79$ & & \\
\hline
\end{tabular}


Table 3.2. Means of parents, progeny, and GCA estimate for nine parental tall fescue genotypes evaluated for brown patch resistance over 2 years (2007 and 2008).

\begin{tabular}{lccc}
\hline Parent genotype & Parent Mean $(\%)$ & Progeny Mean $(\%)$ & GCA \\
\hline RP-64 & 23 & 30 & -0.6 \\
ATE-21 & 23 & 27 & $-3.9^{* *}$ \\
ATM-8 & 24 & 29 & $-2.2^{* *}$ \\
ATP-02 & 25 & 31 & 0 \\
ATN-23 & 27 & 32 & $1.4^{* *}$ \\
A97-155 & 28 & 31 & 0.1 \\
RP-84 & 29 & 33 & $1.7^{* *}$ \\
ATN-9 & 33 & 32 & 0.7 \\
RP-94 & 43 & 34 & $2.8^{* *}$ \\
LSD $(0.05)$ & 7.9 & 3.9 & \\
\hline
\end{tabular}

** denotes significance at the 0.01 level 
Table 3.3. Analysis of variance of brown patch resistance of nine tall fescue half-sib families evaluated over 2 years (2007 and 2008).

\begin{tabular}{lclc}
\hline Source of variation & df & \multicolumn{1}{c}{ MS } & F Value \\
\hline Line & 8 & 41.7141697 & $2.15^{*}$ \\
Year & 1 & 388.3401054 & $20.04^{* * *}$ \\
Replications(Year) & 8 & 100.8271939 & $5.20^{* * *}$ \\
Line $\times$ Year & 8 & 38.2044493 & 1.97 \\
Error & 64 & 19.380188 & \\
\hline
\end{tabular}


Table 3.4. Narrow-sense heritability and predicted gain from selection for brown patch resistance from a polycross of nine tall fescue genotypes and half-sib progeny evaluated over 2 years (2007 and 2008).

\begin{tabular}{ccccc}
\hline \multicolumn{2}{c}{ Parent Offspring Regression } & & Expected Gain from selection \\
\cline { 1 - 2 } $0.236 \pm .08$ & $\mathrm{r}$ & $h^{2}$ & & (i) $5 \%$ \\
& 0.73 & 0.472 & & $5.2 \%$ \\
\hline
\end{tabular}


Figure 3.1. Distribution of half-sib progeny from a polycross of nine tall fescue genotypes evaluated for brown patch resistance over 2 years (2007 and 2008).

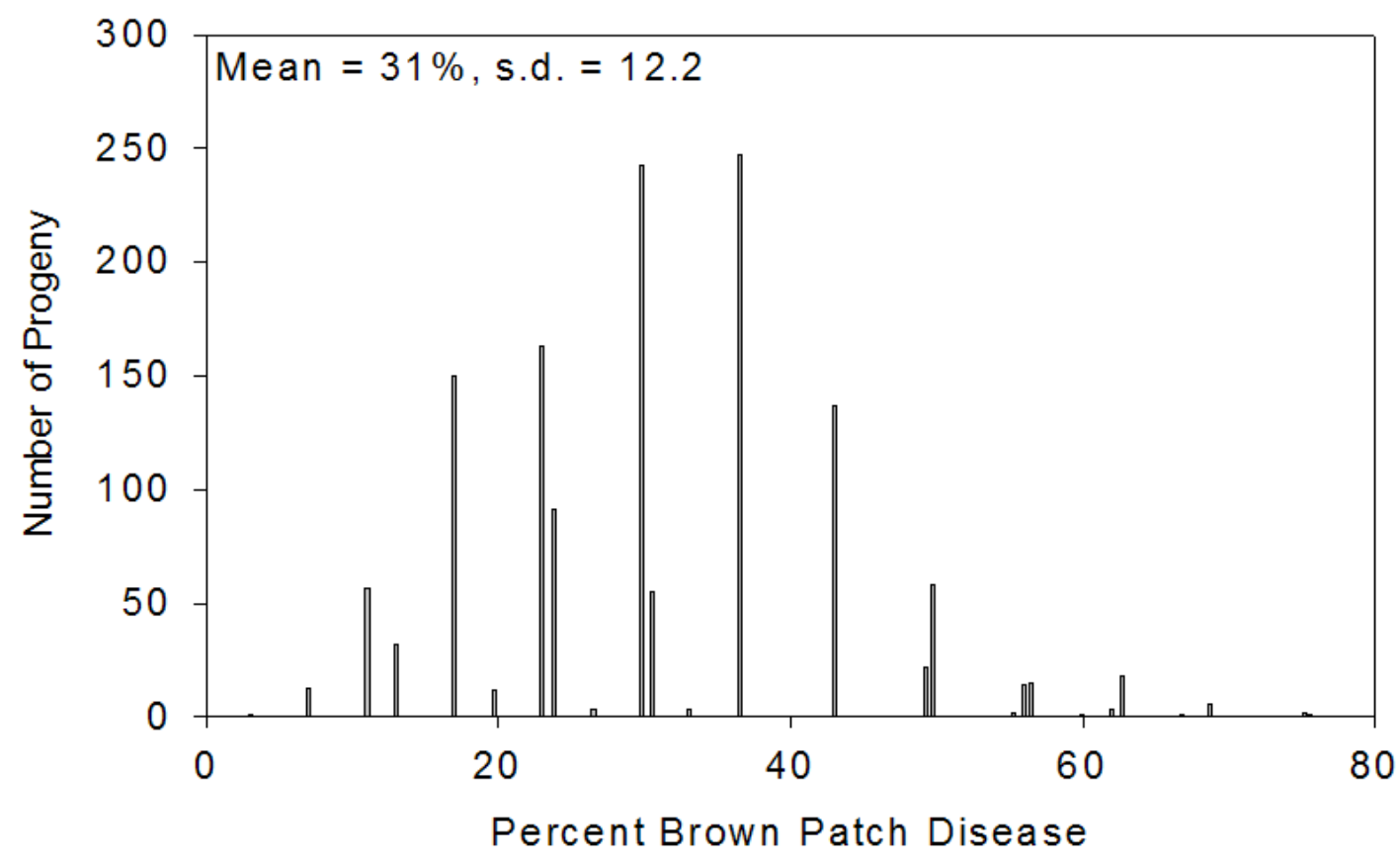




\section{Chapter IV.}

\section{Molecular marker analysis of brown patch resistance in tall fescue}

\section{INTRODUCTION}

Genetic linkage maps provide the framework for the study of genome structure, localization of genes of interest, and the identification of quantitative trait loci (QTLs) (Liebhard et al., 2003). The development of genetic linkage maps enables the use of marker assisted selection (MAS) to indentify the presence of favorable alleles in the early stages of plant screening. Marker assisted selection should allow plant breeders to assemble multiple traits in the same genotype more precisely and with fewer cycles of selection than what is capable with traditional plant breeding methods $\mathrm{Xu}$ and $\mathrm{Crouch}$, 2008). To effectively construct a genetic linkage map markers should be highly polymorphic, very abundant to ensure coverage of the entire genome, and preferably codominant so that all possible genotypes at a marker locus can be identified. Historically the development of genetic linkage maps have been hindered by the cost and time involved in there construction; however, the situation has since changed with the advent of DNA based markers (Falconer and Mackay, 1996).

Simple sequence repeats (SSRs) have become a powerful tool in developing genetic linkage maps because they are co-dominant, extremely abundant, amplified by the polymerase chain reaction (PCR) (Rafalski et al., 1996), and have been shown to be transferable across species within a genus (Gaitan-Solis et al., 2002; Mian et al., 2005; Saha et al., 2004; Saha et al., 2006) as well across genera (Kuleung et al., 2004). The 
high information content of SSRs coupled with there ease of automation provides researchers with a fast approach to develop genetic linkage maps (Jones et al., 2002a). SSRs can be developed from presumably non-coding regions (genomic) or expressed sequence tag (EST) libraries. EST-SSRs are derived from transcribed regions of DNA, therefore they are associated with expressed genes and are more conserved with less polymorphism than genomic-SSRs (Saha et al., 2006). Conversely, genomic-SSRs are highly polymorphic and are found throughout the genome providing larger genome coverage than EST-SSRs (Saha et al., 2005; Warnke et al.,2004).

SSR-based genetic linkage maps have been constructed for many important agriculture crops such as rice (Oryza sativa L.) (Chen et al., 1997; Temnykh et al., 2000), sorghum (Sorghum bicolor (L.) Moench) (Kong et al., 2000), maize (Zea mays L.) (Taramino and Tingey, 1996), and wheat (Triticum aestivum L.) (Roder et al., 1998). Saha et al. (2005) developed the first PCR-based genetic linkage map of tall fescue $(2 n=$ $6 \mathrm{x}=42$ ) using SSR and amplified fragment length polymorphisms (AFLP) markers. One strategy for utilizing genetic information that is attained from developing these genetic linkage maps is to perform comparative mapping. The EST-SSRs that were used to develop the genetic linkage map of tall fescue (Saha et al., 2005) were also shown to be transferable across several members of the Poaceae family (Saha et al., 2004). Saha et al. (2006) also reported the development of the first genomic-SSR markers from tall fescue that are transferable across other forage, turf, and cereal grass species, indicating the potential for use in comparative genome studies.

The quantitative nature of resistance to the pathogen Rhizoctonia solani Kühn has been well document in several field crops (Li et al., 1995; Zou et al., 2000; Zhao et al., 
2006). Breeding for resistance to this pathogen has been slow because of the strong environmental interaction and lack of resistant germplasm that can be incorporated into a breeding program. Currently, plant breeders identify resistant genotypes to brown patch (R. solani) by evaluating them in the field after natural or artificial inoculations. The identification of genomic regions that influence resistance can help to develop more efficient and effective breeding programs (Muylle et al., 2005). QTL mapping is an effective tool in understanding complex forms of disease resistance enabling researchers to analyze specific loci for resistance and how they interact with the environment (Zhao et al., 2006). Researchers studying rice and maize have identified several QTLs for resistance to $R$. solani with the goal to develop specific markers that can be used to screen plants for resistance thus limiting the time and space needed for field trials ( $\mathrm{Li}$ et al., 1995; Pinson et al., 2005; Zou et al., 2000; Zhao et al., 2006).

In recent years the identification of QTLs for disease resistance in turfgrass species has also been documented. Warnke et al. (2004) developed a genetic linkage map of an annual (Lolium multiflorum Lam.) x perennial (L. perenne L.) ryegrass population using AFLPs, random amplification of polymorphic DNA (RAPDs), RFLPs, and SSR markers. Curley et al (2005) used the genetic linkage map of Warnke et al. (2004) and supplemented additional RFLP data from Sim et al. (2005) and found several putative QTLs for gray leaf spot (Magnaporthe grisea) resistance. Sim et al. (2007) using the same mapping population and genetic linkage map derived from Warnke et al. (2004) identified four QTLs associated with crown rust (Puccinia coronata F. sp. lolli). Muylle et al (2005) identified four QTLs for crown rust resistance in a perennial ryegrass 
population. These studies indicate that there is a strong potential for the use of MAS in breeding for disease resistance.

The objectives of this study were to (i) develop a SSR-based genetic linkage map of tall fescue and (ii) search for possible QTLs associated with brown patch resistance in tall fescue. 


\title{
MATERIALS AND METHODS
}

\section{Plant materials}

\begin{abstract}
A mapping population comprised of 190 individuals was derived from a controlled cross between two heterozygous tall fescue genotypes that was made in the spring of 2006. The cross was made between a resistant genotype (ATM-21) and a susceptible genotype (110-7). Resistance and susceptibility of both parents was determined from a field trial in which they were previously screened for brown patch resistance. Germination of seed from the controlled cross occurred in the fall of 2006 with the resulting seedlings grown throughout the winter in a greenhouse. During the winter, after the progeny had attained sufficient growth, they along with the parents used in the cross were clonally replicated six times.
\end{abstract}

\section{Field trials and disease assessment}

Two field trials were established to evaluate brown patch resistance among the mapping population. Each field experiment was arranged in a randomized complete block design with three replications including clonal replications of each parent. Both field trials were established in April of 2007. Site 1 was located at the Horticultural Research Farm II in North Brunswick, NJ, and Site 2 was located at the Rutgers Plant Biology and Pathology Research and Extension Farm in Freehold, NJ. The plants were transplanted into the field $31 \mathrm{~cm}$ apart and were mowed two times per week during the 
growing season at a height of $6.4 \mathrm{~cm}$. Each experimental turf area received approximately $14 \mathrm{~g} \mathrm{~N} \mathrm{~m}^{-2}$ annually in 2007 and 2008 .

A single isolate of $R$. solani collected from Agrostis species growing at The Valentine Turfgrass Research Center, The Pennsylvania State University, University Park, PA., was used as inoculum. Inoculum was prepared by growing the isolate of $R$. solani on sterilized Kentucky bluegrass seed following the method described by Bonos et al. (2003). The prepared inoculum was then placed in a drop spreader and applied to the field at a rate of $0.8 \mathrm{~g} \mathrm{~m}^{-2}$. Both field trials were inoculated $18 \mathrm{Jun} 2007$ and again on 20 Jun 2008. To ensure favorable conditions for disease development, light irrigation was applied to the field immediately after inoculation. To encourage growth and development of the pathogen, light irrigation was periodically applied in the afternoon throughout the duration of the study. Assessment of brown patch disease severity was made in July and August in 2007 and 2008 using a 1-9 scale: nine represented 0 to 5\% diseased turf, eight represented 5 to $15 \%$ diseased turf, seven represented 15 to $30 \%$ diseased turf, six represented 30 to $45 \%$ diseased turf, five represented 45 to $55 \%$ diseased turf, four represented 55 to $70 \%$ diseased turf, three represented 70 to $85 \%$ diseased turf, two represented 85 to $95 \%$ diseased turf, and one represented 95 to $100 \%$ diseased turf. For data analysis, each 1-9 value was assigned the mid-point percent value for the disease range that it represented.

\section{Statistical Analysis}


Analysis of variance (ANOVA) for percent brown patch data was conducted using the General Linear Model (Proc GLM) procedure of SAS (SAS Institute, Inc., Cary, NC). A random model for all effects was used to analyze the data set.

\section{Molecular Marker Analysis}

From each genotype of the mapping population, approximately $200 \mathrm{mg}$ of leaf tissue from greenhouse grown plants was harvested and immediately frozen in liquid nitrogen. Tissue samples were ground into a find powder using a mortar and pestle and DNA was extracted following the chloroform phenol protocol of Pallota et al. (2000). A set of 43 tall fescue (TF) genomic-SSRs (nffg) and 24 tall fescue (TF) expressed sequenced tags (EST)-SSRs (nffa) were used to construct a genetic linkage map (Table 4.1). The TF-genomic-SSRs and TF-EST-SSRs were developed at the Noble Foundation. The primer sequences for the TF-EST-SSRs are reported by Saha et al. (2004) and the primer sequences for the TF-genomic-SSRs are reported by Saha et al. (2006). The PCR reactions for all primers along with the detection of polymorphisms were done following the protocol of Saha et al. (2005). Linkage map construction was accomplished using JoinMap 3.0 software (Van Ooijen and Voorrips, 2001) in which the data was treated as a cross pollinator (CP). Markers were grouped into linkage groups (LGs) with a minimum logarithm of odds (LOD) grouping threshold of 5.0. The calculation of the linkage map utilized all pair-wise recombination estimates of less than 0.499 and LOD score greater than 0.001. Map distances were calculated using the Kosambi function. QTL analysis was carried out with MapQTL 5.0 (Van Ooijen, 2004). 
Interval QTL mapping with a genome wide LOD threshold of 3.7 was used for declaring the presence of a putative QTL. 


\section{RESULTS}

\section{Genetic variation for resistance to $R$. solani}

The percent brown patch ratings of the mapping population over two locations and 2 years showed a continuous distribution of phenotypic response (Fig. 4.1). Data from 2007 at both locations was skewed toward resistance, whereas data from 2008 at both locations was skewed towards susceptibility. Similar differences in disease severity were observed over 2007 and 2008 in other field trials at the same locations evaluating brown patch severity in tall fescue. Differences in disease severity over years may be a cause of inoculum buildup from 2007 to 2008, as well as differences in environmental conditions. The analysis of variance indicated the 190 individuals of the mapping population were a significant source of variation for brown patch resistance as was year, location, clone $\times$ year, and clone $\times$ location $($ Table 4.2$)$. This is consistent with variation observed in another QTL study involving resistance to $R$. solani in rice (Li et al., 1995). No genotypes were completely resistant to brown patch over the course of the study. Resistant parent ATM 21 had a percent brown patch disease average over both years and locations of $28 \%$ and susceptible parent $110-7$ had a percent brown patch disease average over both years and locations of $60 \%$.

\section{Molecular Marker Analysis}


The TF-EST-SSR primer pairs generated 45 polymorphic loci and the TFgenomic-SSR primer pairs generated 90 polymorphic loci that were used to construct the genetic linkage map. Of these, 43 were polymorphic in parent ATM-21, 72 were polymorphic in parent 110-7, and the remaining 20 were segregating from both parental genotypes. As reported by Saha et al. (2005), Mendelian inheritance of 1:1 and 3:1 is expected for the segregating molecular markers because tall fescue is an allohexaploid with disomic inheritance. Sixty-one percent of the markers scored followed normal Mendelian segregation, with approximately $79 \%$ segregating $1: 1$ and the remaining $21 \%$ segregating $3: 1$. Of the $39 \%$ of the markers that showed skewed segregation, approximately $53 \%$ showed segregation from the resistant parent ATM-21, 29\% showed segregation from the susceptible parent 110-7, and the remaining $18 \%$ segregated from both parents.

\section{Genetic Linkage Map}

Twenty-one linkage groups were constructed from the TF-EST-SSRs and the TF genomic-SSRs (Fig. 4.2). Linkage groups were arbitrarily numbered $1-21$. Markers in the 21 linkage groups covered a length of $1293 \mathrm{cM}$ with the average linkage group spanning $62 \mathrm{cM}$. The least amount of loci on a linkage group is three (4 groups), whereas the most loci covering a linkage group is 16 (Fig. 4.2). The smallest linkage group spans only $11 \mathrm{cM}$ and the largest linkage group spans $168 \mathrm{cM}$.

\section{QTL Analysis}


Results of the QTL analysis for each location in 2007 and 2008 as well as the combined data of both locations over both years are presented in Table 4.3. A total of two putative QTLs that were associated with susceptible plants were indentified on linkage groups 18 and 21. The putative QTL on linkage group 18 was only present in the combined QTL analysis. In 2007 at Site 1 it displayed a LOD value of 3.59 which is just under the threshold LOD of 3.7; however, in the other three environments it had a LOD score ranging from 1.31 - 2.36. The putative QTL located on linkage group 21 was present at Site 1 in both 2007 and 2008 as well as in the combined data analysis (Table 4.3). In 2007 and 2008 at Site 2 it had a LOD value of 1.78 and 2.9, respectively. In the combined data analysis the putative QTL on linkage group 21 accounted for $40.4 \%$ of the phenotypic variation and at Site 1 in 2007 and 2008 it accounted for $25.6 \%$, and $32.5 \%$ of the phenotypic variation, respectively. The putative QTL identified on linkage group 18 accounted for $23.8 \%$ of the phenotypic variation in the combined analysis. All of the putative QTLs identified in this study would be considered strong QTLs because they explain over $20 \%$ of the variance (Manly and Olsen, 1999). 


\section{DISCUSSION}

The construction of an SSR-based genetic linkage map of tall fescue presented in this paper is the first step to incorporating marker assisted selection into a conventional breeding program. Over half of the markers showed Mendelian segregation ratios, with the majority segregating $1: 1$. Saha et al. (2005) reported similar findings for the markers segregating in their mapping population. Thirty nine percent of the markers showed segregation distortion which is higher than the $23 \%$ marker segregation disorder reported by Saha et al. (2005) using similar markers for the construction of their genetic linkage map of tall fescue. Segregation disorder can be a result of many factors including statistical error, genotyping and scoring errors, or a real biological phenomenon (Warnke et al., 2004). It has been reported by Xu et al. (1995) that in tall fescue and other grasses that are self-incompatible, genes linked to incompatibility loci may cause segregation distortion. Warnke et al. (2004) speculated that the marker distortion clustered onto their linkage group 1 of their annual x perennial ryegrass genetic linkage map was a result of the S self-incompatibility locus. The idea of self-incompatibility genes causing segregation distortion is somewhat doubtful in this particular study because this mapping population was derived from a cross of two unrelated heterozygous tall fescue parents.

Brown patch resistance in tall fescue has been described as a quantitative trait, strongly influenced by the environment by both Bokmeyer et al. (2009) and Watkins et al. (2009). One of the major factors that can hinder the use of MAS is that of the genotype by environment interaction. To precisely map QTLs, accurate phenotypic data of the mapping population is essential. Paterson et al. (1991) reported QTLs for tomato 
displayed a strong sensitivity to the environment. Three hundred fifty $F_{2}$ individuals were evaluated over three locations with a total of 29 putative QTLs identified for several traits in tomato. Of these 29 QTLs, only four were detected in all three environments. Similar QTL by environment interactions have been reported by researchers studying $R$. solani. Zou et al. (2000) identified 6 QTLs associated with sheath blight (R. solani) resistance in rice with only two of the 6 QTLs present in both years of the study. Similarly, Zhao et al. (2006) indentified 11 QTLs for resistance to banded leaf and sheath blight (R. solani) in maize over two environments with only four QTLs present in both environments. In order to reduce the environmental effects that could skew the phenotypic data in this study, a clonal population was established and evaluated in two locations. Although these measures could increase the accuracy of the field experiments by increasing the number of replications in each environment, differences were still observed across locations in this study. While both putative QTLs that were identified in this study were significant when data was averaged across both locations and years, results were not consistent when analyzed in each specific environment. Zou et al. (2000) elected to use a clonal mapping population to evaluate rice for resistance to $R$. solani to minimize the influence of the environment but as previously mentioned they also found a QTL by environment interaction. Based on the findings of our research and what has been reported in the literature, QTLs associated with $R$. solani resistance vary depending upon the environment in which they are evaluated in. It is likely that the QTLs reported in these studies will also vary depending on the genetic background and inoculate source. 
A powerful tool to understanding how resistance to $R$. solani is controlled could be achieved through comparative mapping. In the past comparative mapping was done by using common sets of probes with good cross-hybridization ability across species, with the majority being cDNAs. The large-scale sequencing of ESTs in several grass species has provided a more efficient way to conduct comparative mapping (Devos, 2005). Jones et al. (2002a) reported conserved syntenic relationships between perennial ryegrass linkage groups and genetic maps of the Triticeae cereals. This observed synteny among the grass family enables researchers to align and assign chromosomes across multiple mapping populations through the use of SSR markers (Jones et al., 2002b). Saha et al. (2004) reported a high percentage of tall fescue EST-SSR markers producing clear bands across a set of diverse grass species. The genetic linkage map that was developed from this study shares common TF-EST-SSR markers used to construct the tall fescue genetic linkage map of Saha et al. (2005) which were also shown to be transferable across several grass species (Saha et al., 2004). This can allow for the alignment of these two genetic linkage maps as well as facilitate comparative mapping with other grass species. Sim et al. (2007) through comparative mapping analysis investigated the syntenic relationships between ryegrass rust resistant genes and those in oats (Avena sativa L.). From this study they suggested that ortholoci for crown rust resistance might be present between ryegrass and oats which indicates comparative mapping can be an effective tool for understanding genetic systems of disease resistance.

One limitation to the QTL analysis in this study is the lack of markers that were used to construct the linkage map. No QTLs were identified that were associated with markers segregating from the resistant parent although the mapping population displayed 
a continuous distribution of phenotypes ranging from resistant to susceptible (Fig. 4.1). Screening the mapping population with more markers could lead to the identification of a QTL segregating from the resistant parent. Another area of research that was not looked at by this study but may warrant investigation in the future is that of associating morphological measurements with disease resistance. Research by Pinson et al. (2005) has indicated that QTLs for plant height and maturity coincide with QTLs for resistance to $R$. solani in rice. Screening the tall fescue mapping population used in this study for various morphological measurements that have been suggested to impact resistance such as, leaf width and density, could be a useful tool in further understanding the mechanism of brown patch resistance in tall fescue. 


\section{CONCLUSIONS}

The application of MAS for improving disease resistance continues to show a lot of promise. One issue that exists with the use of QTLs as tool for MAS is the lack of confirmation. Reports of QTL mapping to date are usually based on small mapping populations that are screened with a relatively small number of markers (Xu and Crouch, 2008). Numerous putative QTLs have been reported for disease resistance in a wide range of mapping populations, yet few ever report confirmation of a particular QTL present over multiple mapping populations. This lack of confirmation across population does not allow for the incorporation of these QTLs into a breeding program. Before plant breeders will begin to rely on MAS as a tool for population improvement, research confirming the presence of putative QTLs, such as those described in this study, over multiple populations will be required. Progress is being made to utilize the QTLs identified for rice sheath blight resistance. Li et al. (1995) identified six putative QTLs for rice sheath blight resistance as did Zou et al. (2000) both using separate mapping populations; however, there was no overlap between any of the putative QTLs limiting the potential for marker assisted selection. Pinson et al. (2005) was able to confirm six of the 12 putative QTLs reported by Li et al. (1995) and Zou et al. (2000) which greatly increase the probability of developing MAS for rice sheath blight resistance.

In summary, we have constructed a genetic linkage map of tall fescue using PCRbased SSR markers with know transferability across grass species (Saha et al, 2004). This provides the means for map alignment and chromosome assignment across multiple mapping populations. Screening of the mapping population for brown patch resistance 
has led to the identification of two putative QTLs associated with susceptible plants to $R$. solani. Confirmation of these putative QTLs is needed if they are to be used for MAS. Based on the synteny reported among the grass family (Sim et al., 2007; Jones et al., 2002b), comparative mapping may be an effective method for understanding the genetic mechanism of resistance to $R$. solani. 


\section{REFERENCES}

Bokmeyer, J. M., S.A. Bonos, and W.A. Meyer. 2009. Broad-sense heritability and stability analysis of brown patch resistance. HortScience 44:289-292

Bonos, S.A., M.A. Casler, and W.A. Meyer. 2003. Inheritance of dollar spot resistance in creeping bentgrass. Crop Sci. 43:2189-2196.

Chen, X., S. Temnykh, Y. Xu, Y.G. Cho, and S.R. McCouch. 1997. Development of a microsatellite framework map providing genome-wide coverage in rice (Oryza sativa L.) Theor. Appl. Genet. 95:553-567.

Curley, J., S.C. Sim, S. Warnke, S. Leong, and R. Baker. 2005. QTL mapping of resistance to gray leaf spot in ryegrass. Theor. Appl. Genet. 111:1107-1117.

Devos, K.M. 2005. Updating the 'crop circle'. Current Opinion in Plant Biology 8:155162.

Falconer, D.S. and T.F.C. Mackay. 1996. Introduction to quantitative genetics. Longman Grp. Ltd., Essex, England.

Gaitan-Solis, E., M.C. Duque, K.J. Edwards, and J. Tohme. 2002. Microsatellite repeats in common bean (Phaseolus vulgaris): isolation, characterization, and crossspecies amplification in Phaseolus ssp. Crop Sci. 42:2129-2136.

Jones, E.S., M.P. Dupal, J.L. Dumsday, L.J. Hughes, and J.W. Forster. 2002a. An SSRbased genetic linkage map for perennial ryegrass (Lolium perenne L.) Theor. Appl. Genet. 105:577-584.

Jones, E.S. N.L. Mahoney, M.D. Hayward, I.P. Armstead, J.G. Jones, M.O. Humphreys, I.P. King, T. Kishida, T. Yamada, F. Balfourier, G. Charmet, and J.W. Forster. $2002 \mathrm{~b}$. An enhanced molecular marker based genetic map of perennial ryegrass (Lolium perenne) reveals comparative relationships with other Poaceae genomes. Genome 45:282-295.

Kong, L., J. Dong, and G.E. Hart. 2000. Characteristics, linkage map positions, and allelic differentiation of Sorghum bicolor (L.) Moench DNA simple sequence repeats (SSRs). Theor. Appl. Genet. 101:438-448.

Kuleung, C., P.S. Baenziger, and I Dweikat. 2004. Transferability of SSR markers among wheat, rye, and triticale. Theor. Appl. Genet. 108:1147-1150.

Li, Z. K., S.R.M. Pinson, M.A. Marchetti, J.W. Stansel, and W.D. Park. 1995. Characterization of quantitative trait loci (QTLs) in cultivated rice contributing to 
field resistance to sheath blight (Rhizoctonia solani). Theor. Appl. Genet. 91:382:388.

Liebhard, R., B. Koller,. L. Gianfranceschi, C. Gessler. 2003. Creating a saturated reference map for the apple (Malus $x$ domestica Borkh.) genome. Theor. Appl. Genet. 106:1497-1508.

Manly, K.F. and J.M. Olson. 1999. Overview of QTL mapping software and introduction to Map Manger QT. Mammalian Genome 10:327-334.

Mian, M.A.R., M.C. Saha, A.A. Hopkins, and Z.Y. Wang. 2005. Use of tall fescue ESTSSR markers in phylogenetic analysis of cool-season forage grasses. Genome 48:637-647.

Muylle, H., J. Baert, E.V. Bockstaele, J. Pertijs, and I.R. Ruiz. 2005. Four QTLs determine crown rust (Puccinia coronate f. sp. lolii) resistance in a perennial ryegrass (Lolium perenne) population. Heredity 95:348-357.

Pallotta, M.A., R.D. Graham, P. Landgridge, D.H.B. Sparrow, and S.J. Barker. 2000. RFLP mapping of manganese efficiency in barley. Theor. Appl. Genet. 101:11001108 .

Patterson, A.H., S. Damon, J.D. Hewitt, D. Zamir, H.D. Rabinowitch, S.E. Lincoln, E.S. Lander, and S.D. Tanksley. 1991. Mendelian factors underling quantitative traits in tomato: Comparison across species, generations, and environments. Genetics 127:181-197.

Pinson, S.R.M., F.M. Capdevielle, and J.H. Oard. 2005. Confirming QTLs and finding additional loci conditioning sheath blight resistance in rice using recombinant inbred lines. Crop Sci. 45:503-519.

Rafalski, J.A., J.M. Vogel, M. Morgante, W. Powell, C. Andre, and S.V. Tingey. 1996. Generating and using DNA markers in plants. In Birren B and Lai E. eds Nonmammalian genomic analysis: a practical guide. Academic Press, San Diego, pp $75-135$.

Roder, M.S., V. Korzun, K. Wendehake, J. Plasschke, M.H. Tixier, P. Leroy, and M.W. Ganal. 1998. A microsatellite map of wheat. Genetics 149:2007-2023.

Saha, M.C., M.A.R. Mian, I. Eujayl, J.C. Zwonitzer, L. Wang, and G.D. May. 2004. Tall fescue EST-SSR markers with transferability across several grass species. Theor. Appl. Genet. 109:783-781.

Saha, M.C., R. Mian, J.C. Zwonitzer, K. Chekhovskiy and A.A. Hopkins. 2005. An SSR-and AFLP-based genetic linkage map of tall fescue (Festuca arundinaceae Schreb.). Theor. Appl. Genet. 110:323-336. 
Saha, M.C., J.D. Cooper, M.A.R. Mian, K. Chekhovskiy, and G.D. May. 2006. Tall fescue genomic SSR markers: development and transferability across multiple grass species. Theor Appl. Genet. 113:1449-1458.

Sim, S., T. Chang, J. Curley, S. Warnke, R. Baker, and G. Jung. 2005. Chromosomal rearrangements differentiating the ryegrass genome from the Triticeae, oat, and rice genomes using common heterologous RFLP probes. Theor Appl. Genet. 110:1011-1019.

Sim, S., K. Diesburg, M. Casler, and G. Jung. 2007. Mapping and comparative analysis of QTL for crown rust resistance in an Italian x perennial ryegrass population. Phytopathology 97:767-776.

Taramino, G. and S. Tingey. 1996. Simple sequence repeats for germplasm analysis mapping in maize. Genome 39:277-287.

Temnykh, S., W.D. Park, N. Ayers, S. Cartinhour, N. Hauch, L. Lipovich, Y.G. Cho, T. Ishii, and S.R. McCouch. 2000. Mapping and genome organization of microsatellite sequences in rice (Oryza sativa L.) Theor. Appl. Genet. 100:697712.

Van Ooijen J.W. 2004. MapQTL ${ }^{\circledR}$ 5, Software for the mapping of quantitative trait loci in experimental populations. Kyasma B.V.,Wageningen, Netherlands.

Van Ooijen, J.W. and R.E. Voorrips. 2001. Joinmap ${ }^{\circledR}$ 3.0: Software for the calculation of genetic linkage maps. Plants Res. Int., Wageningen, the Netherlands.

Watkins, E., S.A. Bonos, and W.A. Meyer. 2009. Heritability of brown patch resistance in tall fescue. 2009. Int. Turfgrass Soc. Res. J. 11:271-282.

Warnke, S.E., R.E. Barker, G. Jung, S. Sim, M.A. Mian, M.C. Saha, L.A. Brilman, M.P. Dupal, and J.W. Forster. 2004. Genetic linkage mapping of an annual $\mathrm{x}$ perennial ryegrass population. Theor. Appl. Genet. 109: 294-304.

Xu, Y. and J.H. Crouch. 2008. Marker-Assisted selection in plant breeding: From publications to practice. Crop Sci. 48:391-407.

Xu, W.W., D.A. Sleper, and S. Chao. 1995. Genome mapping of tall fescue (Festuca arundinaceae Schreb.) with RFLP markers. Theor. Appl. Genet. 91:947-955.

Zhao, M., Z. Zhang, S. Zhang, W. Li, D.P. Jeffers, T. Rong, and G. Pan. 2006. Quantitative trait loci for resistance to banded leaf and sheath blight in maize. Crop Sci. 46:1039-1045. 
Zou, J.H., X.B. Pan, Z.X. Chen, J.Y. Xu, J.F. Lu, W. Zhai, and L.H. Zhu. 2000. Mapping quantitative trait loci controlling sheath blight resistance in two rice cultivars (Oryza sativa L.) Theor. Appl. Genet. 101:569-573. 
Table 4.1. SSRs primer combinations used for the development of a linkage map of tall fescue.

\begin{tabular}{|c|c|c|}
\hline TF EST-SSRs & \multicolumn{2}{|c|}{ TF Genomic SSRs } \\
\hline nffa 002 & nffg 009 & nffg 236 \\
\hline nffa 013 & nffg 016 & nffg 253 \\
\hline nffa 017 & nffg 017 & nffg 260 \\
\hline nffa 020 & nffg 026 & nffg 275 \\
\hline nffa 040 & nffg 032 & nffg 279 \\
\hline nffa 047 & nffg 040 & nffg 282 \\
\hline nffa 059 & nffg 042 & nffg 305 \\
\hline nffa 074 & nffg 043 & nffg 342 \\
\hline nffa 075 & nffg 068 & nffg 343 \\
\hline nffa 088 & nffg 079 & nffg 354 \\
\hline nffa 096 & nffg 096 & nffg 379 \\
\hline nffa 103 & nffg 101 & nffg 391 \\
\hline nffa 129 & nffg 106 & nffg 405 \\
\hline nffa 134 & nffg 107 & nffg 407 \\
\hline nffa 154 & nffg 110 & nffg 429 \\
\hline nffa 155 & nffg 111 & nffg 476 \\
\hline nffa 159 & nffg 134 & nffg 480 \\
\hline nffa 169 & nffg 140 & nffg 505 \\
\hline nffa 192 & nffg 167 & nffg 506 \\
\hline nffa 233 & nffg 175 & \\
\hline nffa 346 & nffg 197 & \\
\hline nffa 383 & nffg 209 & \\
\hline nffa 386 & nffg 219 & \\
\hline nffa 397 & nffg 228 & \\
\hline
\end{tabular}


Table 4.2. Analysis of variance of brown patch disease severity in a tall fescue mapping population averaged over two locations and two years (2007 and 2008).

\begin{tabular}{|l|c|c|c|}
\hline Source of Variation & df & Mean Square & F- Value \\
\hline Year & 1 & 84067.47 & $262.8^{* * * *}$ \\
\hline Location & 1 & 11218.73 & $35.07 * * * *$ \\
\hline Rep(Location) & 4 & 4357.48 & $13.62^{* * * *}$ \\
\hline Location $\times$ Year & 1 & 133.51 & 0.42 \\
\hline Year $\times$ Rep(Location) & 4 & 3131.70 & $9.79 * * * *$ \\
\hline Clone & 189 & 980.29 & $3.06^{* * * *}$ \\
\hline Clone $\times$ Year & 189 & 399.07 & $1.25^{*}$ \\
\hline Clone $\times$ Location & 189 & 463.62 & $1.45^{* * *}$ \\
\hline Clone $\times$ Rep(Location) & 754 & 357.72 & 1.12 \\
\hline Clone $\times$ Location $\times$ Year & 188 & 347.72 & 1.09 \\
\hline
\end{tabular}


Table 4.3. Summary of the QTL analysis to a single isolate of $R$. solani in a tall fescue mapping population.

\begin{tabular}{|c|c|c|c|c|c|c|}
\hline Rating & $\mathrm{LG}^{\mathrm{Z}}$ & Marker $^{\mathrm{y}}$ & $\begin{array}{l}\text { Kruskal- } \\
\text { Wallis }\end{array}$ & & $\mathrm{IM}^{\mathrm{X}}$ & $\begin{array}{l}\text { LOD } \\
\text { threshold } \\
\text { w }\end{array}$ \\
\hline & & & & LOD & $\%$ Variance & $\alpha g$ \\
\hline Combined & 21 & snffg405-183 & 0.0001 & 6.61 & 40.4 & 3.7 \\
\hline Combined & 18 & snffg009-219 & 0.0001 & 3.98 & 23.8 & 3.7 \\
\hline Site 107 & 21 & snffg405-183 & 0.0001 & 3.93 & 25.6 & 3.7 \\
\hline Site 108 & 21 & snffg405-183 & 0.0001 & 3.43 & 32.5 & 3.7 \\
\hline${ }^{\mathrm{Z}}$ Linkage $\xi$ & $\mathrm{pp}$ & hich QTL w & detected & & & \\
\hline${ }^{\mathrm{y}}$ Name of th & $\mathrm{ma}$ & $r$ most closel & nked to th & in que & & \\
\hline $\begin{array}{l}{ }^{\mathrm{x}} \text { For interva } \\
\text { phenotypic }\end{array}$ & mar & $\begin{array}{l}\text { ing the logarit } \\
\text { ce explained a }\end{array}$ & $\begin{array}{l}\text { of odds (I } \\
\text { ach of the } 1\end{array}$ & $\begin{array}{l}\text { core an } \\
\text { marker }\end{array}$ & percentage & \\
\hline $\begin{array}{l}{ }^{\mathrm{w}} \text { LOD thres } \\
\text { thresholds }\end{array}$ & $1 d$ & $\begin{array}{l}\text { erived from pe } \\
1 \text { linkage grou }\end{array}$ & $\begin{array}{l}\text { iutation an } \\
\text { of the ger }\end{array}$ & The 0 & dicates the & LOD \\
\hline
\end{tabular}


Figure 4.1. Distribution of brown patch disease severity in a mapping population of 190 individuals from a cross between a resistant genotype (ATM 110) and a susceptible genotype (110-7) evaluated over two year and two locations (2007 and 2008).

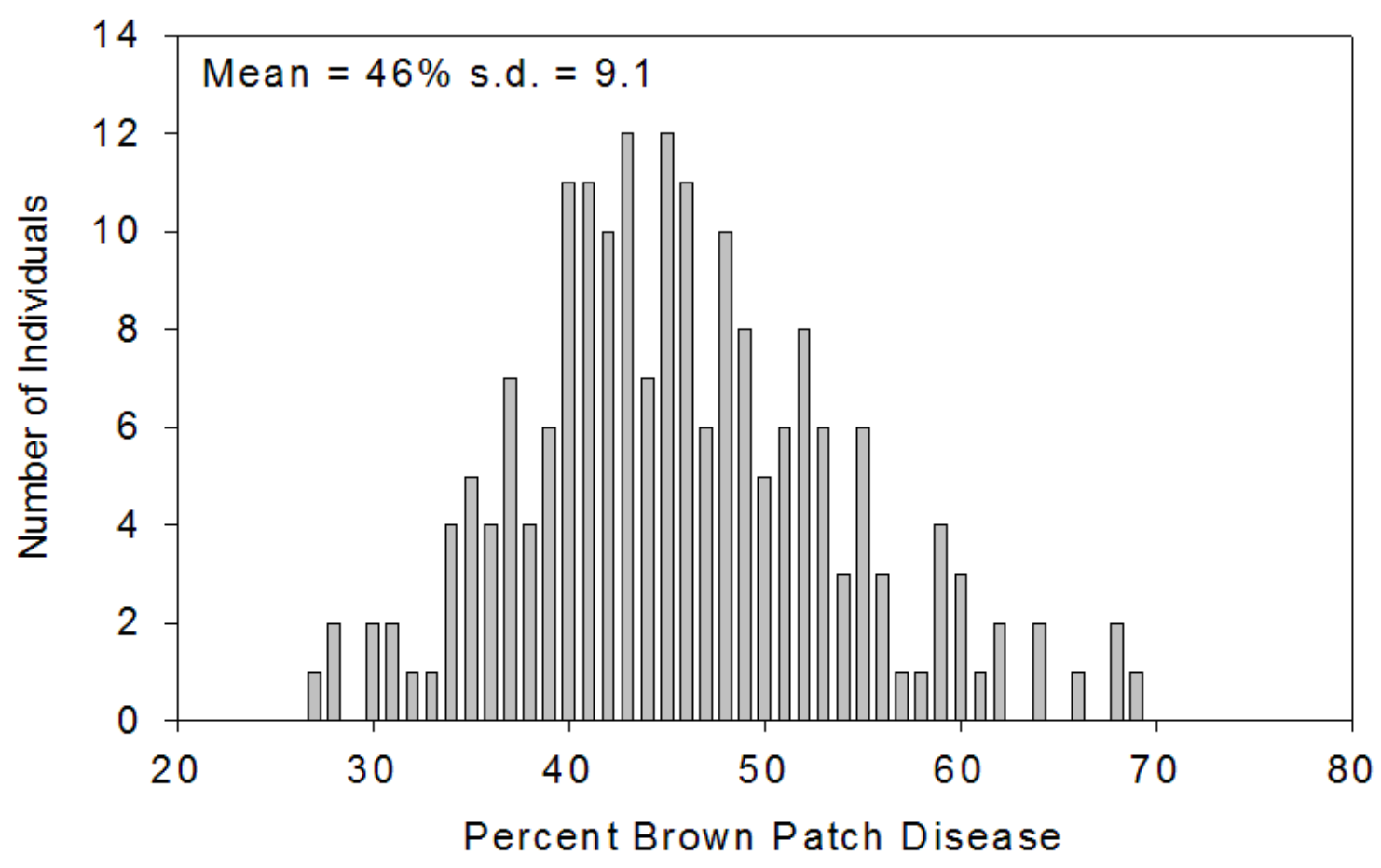


Figure 4.2. Linkage map of the mapping population derived from the cross between resistant genotype (ATM-21) and susceptible genotype (110-7) use for QTL analysis.

1

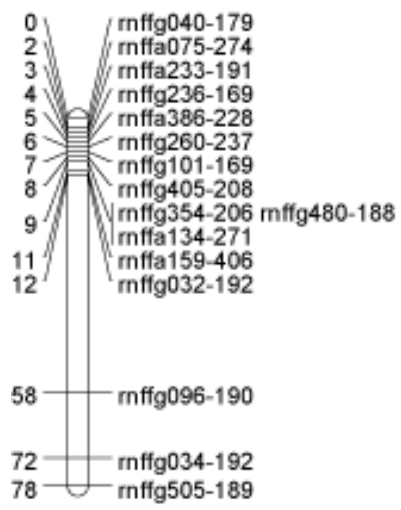

6

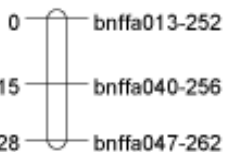

12

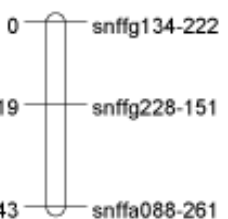

7

13
2
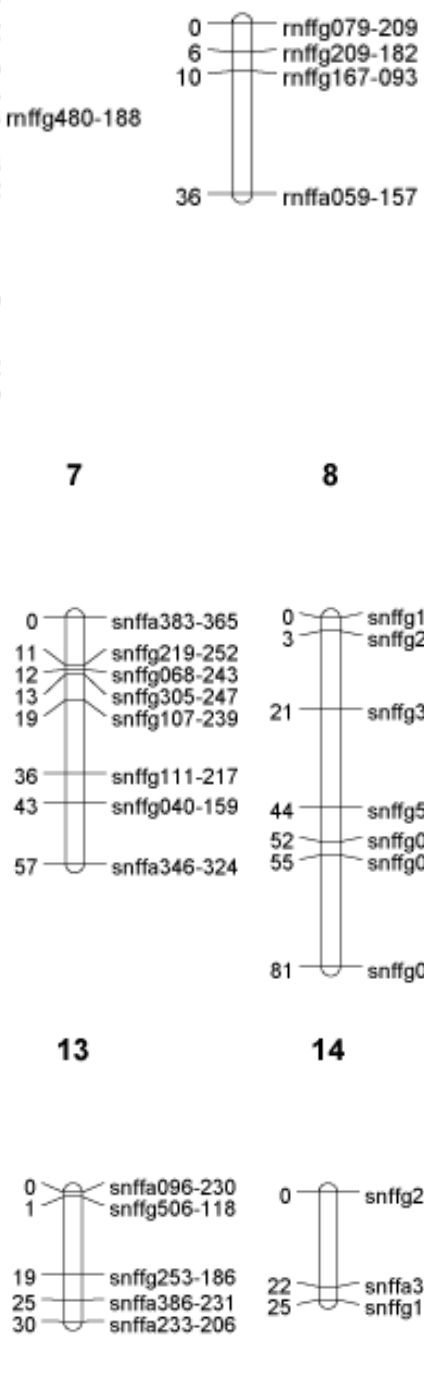

3
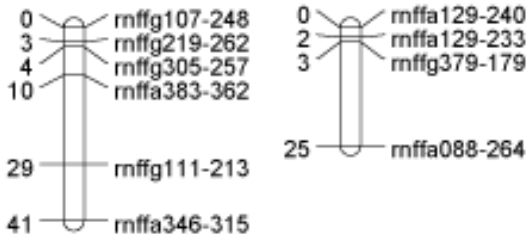

10

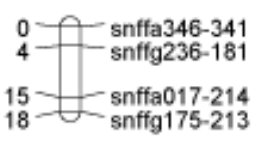

9

5
8

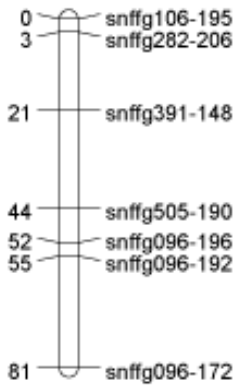

14

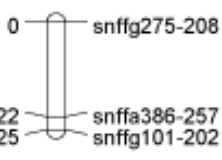

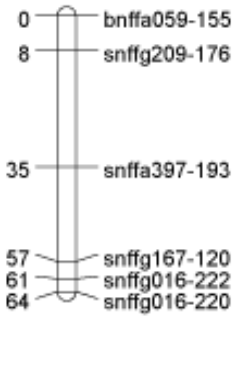

15
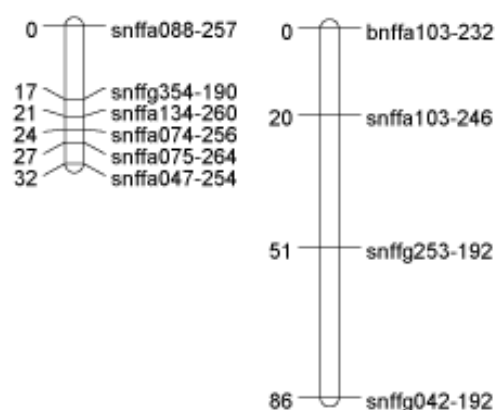

16

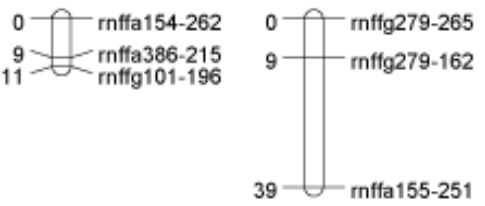

17

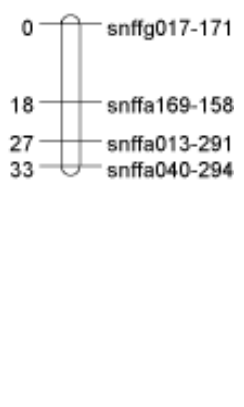


18

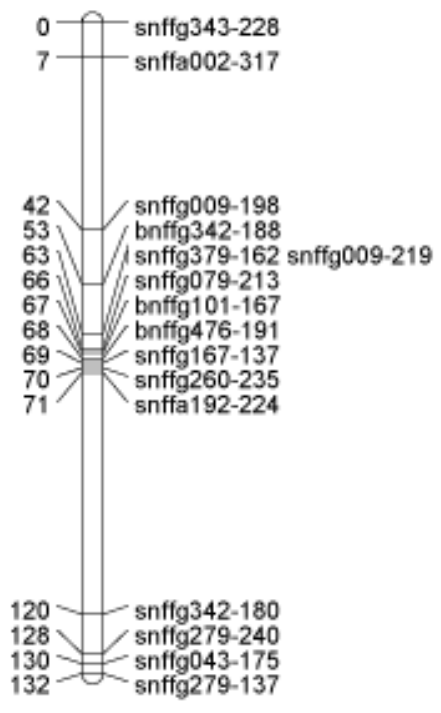

19

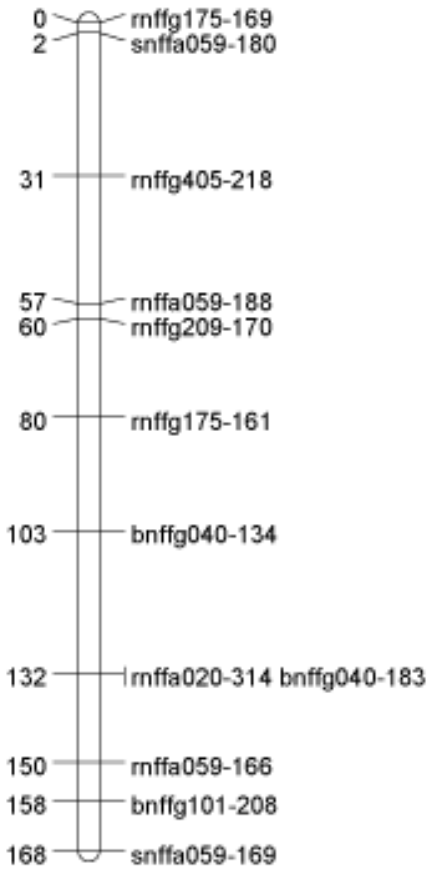

20

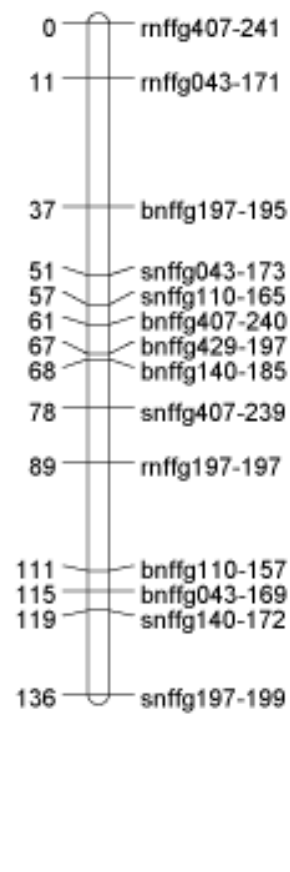

21

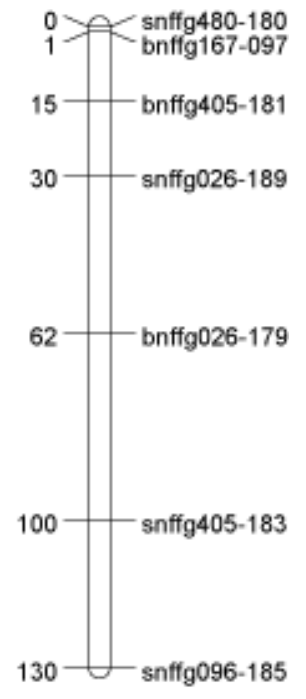




\section{APPENDIX}

Table A. Mean location deviations of tall fescue clones responses to brown patch disease across two locations and two years.

\begin{tabular}{|c|c|c|c|c|c|c|c|}
\hline & \multirow{3}{*}{ Clone } & \multirow{3}{*}{ Designation $^{Z}$} & \multirow{3}{*}{$\begin{array}{c}\text { Brown } \\
\text { Patch Avg. }\end{array}$} & \multicolumn{2}{|c|}{ Freehold } & \multicolumn{2}{|c|}{ North Brunswick } \\
\hline & & & & 2005 & 2006 & 2005 & 2006 \\
\hline & & & & \multicolumn{4}{|c|}{-Deviation from location year means- } \\
\hline 1 & 79 & $\mathrm{R}$ & 21 & $-27^{X}$ & -7 & -21 & -26 \\
\hline 2 & 193 & $\mathrm{R}$ & 21 & -20 & -9 & -29 & -23 \\
\hline 3 & 161 & $\mathrm{R}$ & 23 & -19 & -16 & -16 & -24 \\
\hline 4 & 224 & $\mathrm{R}$ & 23 & -24 & -3 & -21 & -24 \\
\hline 5 & 257 & $\mathrm{R}$ & 23 & -18 & -14 & -15 & -25 \\
\hline 6 & 175 & $\mathrm{R}$ & 24 & -25 & -10 & -17 & -17 \\
\hline 7 & 136 & $\mathrm{R}$ & 24 & -23 & -8 & -14 & -22 \\
\hline 8 & 256 & $\mathrm{R}$ & 24 & -8 & -17 & -19 & -24 \\
\hline 9 & 93 & $\mathrm{R}$ & 25 & -18 & -17 & -18 & -10 \\
\hline 10 & 148 & $\mathrm{R}$ & 27 & -5 & -11 & -14 & -28 \\
\hline 11 & 141 & $\mathrm{R}$ & 27 & -11 & -17 & -13 & -18 \\
\hline 12 & 8 & $\mathrm{R}$ & 27 & -16 & -8 & -5 & -29 \\
\hline 13 & 240 & $\mathrm{R}$ & 27 & -14 & -12 & -13 & -17 \\
\hline 14 & 35 & $\mathrm{R}$ & 27 & -15 & -8 & -16 & -16 \\
\hline 15 & 139 & $\mathrm{R}$ & 27 & -3 & -13 & -15 & -24 \\
\hline 16 & 134 & $\mathrm{R}$ & 28 & -14 & -6 & -13 & -21 \\
\hline 17 & 234 & $\mathrm{R}$ & 28 & -21 & -13 & -9 & -10 \\
\hline 18 & 127 & $\mathrm{R}$ & 29 & -15 & -17 & -12 & -6 \\
\hline 19 & 181 & $\mathrm{R}$ & 29 & -2 & -2 & -19 & -26 \\
\hline 20 & 252 & $\mathrm{R}$ & 29 & -3 & -7 & -12 & -27 \\
\hline 21 & 159 & $\mathrm{R}$ & 30 & -19 & -10 & -4 & -13 \\
\hline 22 & 218 & $\mathrm{R}$ & 30 & -11 & -9 & -7 & -18 \\
\hline 23 & 47 & $\mathrm{R}$ & 30 & -14 & -9 & -7 & -14 \\
\hline 24 & 25 & $\mathrm{R}$ & 30 & -10 & -14 & -3 & -16 \\
\hline 25 & 129 & NA & 31 & -10 & -11 & -7 & -12 \\
\hline 26 & 241 & NA & 31 & -12 & -4 & -14 & -9 \\
\hline 27 & 146 & NA & 31 & 16 & -14 & -20 & -23 \\
\hline 28 & 39 & NA & 31 & -15 & -11 & -7 & -6 \\
\hline 29 & 195 & NA & 32 & -15 & -9 & -4 & -9 \\
\hline 30 & 88 & NA & 32 & -15 & -7 & -10 & -4 \\
\hline 31 & 201 & NA & 32 & -13 & -4 & -4 & -14 \\
\hline 32 & 135 & NA & 32 & -12 & 0 & -18 & -4 \\
\hline 33 & 261 & NA & 32 & -22 & 1 & -12 & -2 \\
\hline 34 & 100 & NA & 32 & -9 & -21 & -13 & 5 \\
\hline 35 & 250 & NA & 33 & -7 & -9 & -1 & -17 \\
\hline 36 & 230 & NA & 33 & -12 & -10 & -3 & -8 \\
\hline 37 & 192 & NA & 33 & -14 & -3 & -8 & -7 \\
\hline 38 & 198 & NA & 33 & -6 & -12 & -1 & -13 \\
\hline 39 & 225 & NA & 33 & -12 & -14 & 3 & -8 \\
\hline
\end{tabular}




\begin{tabular}{|c|c|c|c|c|c|c|c|}
\hline & Table A & ontinued & Brown & Fre & old & North & nswick \\
\hline & Clone & Designation $^{\mathrm{Z}}$ & Patch Avg. ${ }^{\text {Y }}$ & 2005 & 2006 & 2005 & 2006 \\
\hline & & & & -Devic & on fros & ation $\mathrm{ye}$ & neans- \\
\hline 40 & 222 & $\mathrm{NA}$ & 33 & -15 & 7 & -20 & -3 \\
\hline 41 & 143 & NA & 33 & -9 & -6 & -15 & -1 \\
\hline 44 & 19 & NA & 34 & -16 & -5 & -12 & 3 \\
\hline 45 & 131 & NA & 34 & -9 & -1 & -3 & -15 \\
\hline 46 & 191 & NA & 34 & -14 & -1 & -14 & 2 \\
\hline 47 & 253 & NA & 34 & -15 & -7 & -5 & -1 \\
\hline 48 & 233 & NA & 34 & -4 & -10 & 4 & -17 \\
\hline 49 & 28 & NA & 34 & -12 & 5 & -9 & -11 \\
\hline 50 & 142 & NA & 34 & -9 & 2 & -21 & 1 \\
\hline 51 & 168 & NA & 34 & -6 & -1 & -9 & -12 \\
\hline 52 & 42 & NA & 34 & 0 & -8 & -6 & -13 \\
\hline 53 & 4 & NA & 35 & -9 & -7 & 2 & -11 \\
\hline 54 & 23 & NA & 35 & -1 & -6 & -3 & -16 \\
\hline 55 & 145 & NA & 35 & -2 & -3 & -10 & -9 \\
\hline 56 & 231 & NA & 35 & 0 & -6 & -2 & -15 \\
\hline 57 & 174 & NA & 35 & -8 & -5 & 0 & -11 \\
\hline 58 & 183 & NA & 35 & -9 & -7 & -4 & -4 \\
\hline 59 & 103 & NA & 35 & -7 & -5 & -4 & -7 \\
\hline 60 & 268 & NA & 35 & -3 & -12 & 2 & -11 \\
\hline 61 & 21 & NA & 36 & -6 & -9 & -5 & -1 \\
\hline 62 & 166 & NA & 36 & -9 & -6 & -2 & -4 \\
\hline 63 & 149 & NA & 36 & -12 & -5 & -9 & 5 \\
\hline 64 & 176 & NA & 36 & -14 & -5 & -6 & 5 \\
\hline 65 & 152 & NA & 36 & -6 & -7 & 2 & -10 \\
\hline 66 & 30 & NA & 36 & 0 & -16 & -2 & -4 \\
\hline 67 & 197 & NA & 36 & -7 & -2 & -4 & -6 \\
\hline 68 & 114 & NA & 36 & -14 & -2 & -3 & -1 \\
\hline 69 & 170 & NA & 36 & -8 & -2 & -6 & -3 \\
\hline 70 & 162 & NA & 36 & -7 & -4 & 3 & -10 \\
\hline 71 & 24 & NA & 37 & -6 & -2 & -4 & -7 \\
\hline 72 & 221 & NA & 37 & -11 & -3 & -5 & 2 \\
\hline 73 & 264 & NA & 37 & -3 & -5 & 2 & -11 \\
\hline 74 & 244 & NA & 37 & -6 & 2 & -10 & -3 \\
\hline 75 & 17 & NA & 37 & -4 & 7 & -16 & -2 \\
\hline 76 & 89 & NA & 37 & -2 & 2 & -25 & 9 \\
\hline 77 & 54 & NA & 37 & -11 & 0 & -4 & 0 \\
\hline 78 & 130 & NA & 37 & -6 & 2 & -16 & 5 \\
\hline 79 & 169 & NA & 38 & -8 & 2 & 1 & -8 \\
\hline 80 & 56 & NA & 38 & 4 & -4 & -3 & -9 \\
\hline 81 & 91 & NA & 38 & -12 & 3 & 4 & -8 \\
\hline 82 & 120 & NA & 38 & -5 & -1 & -14 & 7 \\
\hline 83 & 110 & NA & 38 & -1 & -10 & 5 & -5 \\
\hline 84 & 232 & NA & 38 & -4 & 3 & -5 & -5 \\
\hline
\end{tabular}




\begin{tabular}{|c|c|c|c|c|c|c|c|}
\hline & Table A & ontinued & Brown & Fre & old & North & nswick \\
\hline & Clone & Designation $^{\mathrm{Z}}$ & Patch Avg. ${ }^{\text {Y }}$ & 2005 & 2006 & 2005 & 2006 \\
\hline & & & & -Devi & on fros & ation y & neans- \\
\hline 85 & 155 & $\mathrm{NA}$ & 38 & 9 & -5 & -1 & -15 \\
\hline 86 & 164 & NA & 38 & 2 & -5 & -2 & -6 \\
\hline 87 & 20 & NA & 39 & 5 & -2 & -4 & -8 \\
\hline 88 & 101 & NA & 39 & -14 & 3 & 1 & 1 \\
\hline 89 & 157 & NA & 39 & 0 & 0 & -6 & -3 \\
\hline 90 & 16 & NA & 39 & -6 & 9 & -9 & -4 \\
\hline 91 & 38 & NA & 39 & -3 & -10 & 11 & -7 \\
\hline 92 & 67 & NA & 39 & -4 & 3 & -11 & 4 \\
\hline 93 & 41 & NA & 39 & -2 & 1 & -7 & 1 \\
\hline 94 & 109 & NA & 39 & 6 & -6 & 0 & -7 \\
\hline 95 & 226 & NA & 39 & 4 & -8 & -4 & -1 \\
\hline 96 & 64 & NA & 39 & 0 & -3 & 1 & -4 \\
\hline 97 & 122 & NA & 40 & -8 & 15 & -7 & -4 \\
\hline 98 & 167 & NA & 40 & 9 & -8 & 5 & -11 \\
\hline 99 & 60 & NA & 40 & -4 & -2 & 0 & 2 \\
\hline 100 & 147 & NA & 40 & -16 & 2 & 0 & 10 \\
\hline 101 & 2 & NA & 40 & -5 & 2 & -4 & 5 \\
\hline 102 & 213 & NA & 40 & 1 & -9 & 7 & -1 \\
\hline 103 & 158 & NA & 41 & 2 & -9 & 7 & -1 \\
\hline 104 & 104 & NA & 41 & -3 & -3 & -1 & 6 \\
\hline 105 & 43 & NA & 41 & 1 & -7 & 7 & 0 \\
\hline 106 & 76 & NA & 41 & 3 & 7 & 0 & -9 \\
\hline 107 & 5 & NA & 41 & 1 & 0 & -5 & 5 \\
\hline 108 & 68 & NA & 42 & -6 & 0 & 7 & 1 \\
\hline 109 & 108 & NA & 42 & 9 & -8 & 7 & -7 \\
\hline 110 & 196 & NA & 42 & -1 & -6 & 11 & -2 \\
\hline 111 & 61 & NA & 42 & 6 & 6 & 1 & -10 \\
\hline 112 & 125 & NA & 42 & 0 & 6 & -1 & -2 \\
\hline 113 & 178 & NA & 42 & 6 & 5 & 0 & -7 \\
\hline 114 & 11 & NA & 42 & 2 & 3 & -1 & 1 \\
\hline 115 & 15 & NA & 42 & 2 & -3 & -4 & 9 \\
\hline 116 & 66 & NA & 42 & 0 & 1 & 2 & 1 \\
\hline 117 & 200 & NA & 42 & 0 & 1 & 4 & 2 \\
\hline 118 & 1 & NA & 42 & 4 & -4 & 6 & -1 \\
\hline 119 & 229 & NA & 42 & 9 & -6 & 5 & -2 \\
\hline 120 & 194 & NA & 42 & -2 & -4 & 3 & 8 \\
\hline 121 & 63 & NA & 43 & 11 & 4 & -4 & -5 \\
\hline 122 & 270 & NA & 43 & 3 & 2 & 6 & -6 \\
\hline 123 & 185 & NA & 43 & -5 & 4 & 2 & 5 \\
\hline 124 & 80 & NA & 43 & -9 & 12 & 0 & 5 \\
\hline 125 & 208 & NA & 43 & 8 & 3 & 4 & -7 \\
\hline 126 & 92 & NA & 43 & -2 & -4 & 2 & 11 \\
\hline 127 & 111 & NA & 43 & 3 & -7 & 13 & 1 \\
\hline
\end{tabular}




\begin{tabular}{|c|c|c|c|c|c|c|c|}
\hline & Table A & ontinued & Brown & Fre & old & North & nswick \\
\hline & Clone & Designation $^{\mathrm{Z}}$ & Patch Avg. ${ }^{\text {Y }}$ & 2005 & 2006 & 2005 & 2006 \\
\hline & & & & -Devi & on fros & ation y & neans- \\
\hline 128 & 36 & $\mathrm{NA}$ & 43 & -6 & 7 & 8 & 0 \\
\hline 129 & 150 & NA & 43 & -1 & 7 & 0 & 4 \\
\hline 130 & 121 & NA & 43 & 7 & -3 & 7 & -1 \\
\hline 131 & 78 & NA & 43 & 13 & 4 & 4 & -12 \\
\hline 132 & 212 & NA & 43 & 4 & 1 & 4 & -1 \\
\hline 133 & 126 & NA & 44 & 8 & -1 & 10 & -7 \\
\hline 134 & 77 & NA & 44 & 10 & -3 & 6 & -3 \\
\hline 135 & 46 & NA & 44 & 4 & 2 & 1 & 4 \\
\hline 136 & 99 & NA & 44 & 2 & -2 & 7 & 4 \\
\hline 137 & 199 & NA & 44 & 14 & -4 & 4 & -5 \\
\hline 138 & 140 & NA & 44 & 0 & 5 & -3 & 9 \\
\hline 139 & 84 & NA & 44 & 1 & -2 & 9 & 2 \\
\hline 140 & 12 & NA & 44 & 7 & -1 & -13 & 18 \\
\hline 141 & 115 & NA & 44 & 10 & 0 & 5 & -3 \\
\hline 142 & 204 & NA & 44 & 7 & 7 & 0 & -2 \\
\hline 143 & 216 & NA & 44 & 2 & 7 & 3 & -1 \\
\hline 144 & 62 & NA & 44 & 8 & 2 & 2 & -1 \\
\hline 145 & 223 & NA & 44 & -2 & 6 & 0 & 9 \\
\hline 146 & 65 & NA & 44 & 4 & 1 & 7 & 1 \\
\hline 147 & 53 & NA & 45 & -3 & 9 & -1 & 9 \\
\hline 148 & 258 & NA & 45 & 5 & 1 & -5 & 12 \\
\hline 149 & 243 & NA & 45 & 5 & -1 & 12 & -2 \\
\hline 150 & 214 & NA & 45 & 1 & 1 & 7 & 6 \\
\hline 151 & 269 & NA & 45 & 3 & 5 & 1 & 5 \\
\hline 152 & 29 & NA & 45 & 6 & -2 & 7 & 4 \\
\hline 153 & 116 & NA & 45 & 3 & -1 & 6 & 7 \\
\hline 154 & 265 & NA & 45 & -3 & 16 & -4 & 7 \\
\hline 155 & 207 & NA & 45 & -1 & -1 & 5 & 14 \\
\hline 156 & 102 & NA & 45 & 5 & 6 & 7 & -1 \\
\hline 157 & 50 & NA & 45 & 6 & 7 & 0 & 3 \\
\hline 158 & 98 & NA & 45 & 4 & -4 & 2 & 12 \\
\hline 159 & 51 & NA & 45 & -1 & 5 & 5 & 9 \\
\hline 160 & 90 & NA & 46 & 6 & 3 & 9 & 0 \\
\hline 161 & 238 & NA & 46 & 0 & 1 & -4 & 20 \\
\hline 162 & 227 & NA & 46 & 13 & -7 & 7 & 3 \\
\hline 163 & 242 & NA & 46 & 12 & -5 & 2 & 7 \\
\hline 164 & 7 & NA & 46 & 10 & 4 & 5 & 0 \\
\hline 165 & 151 & NA & 46 & 9 & 5 & 5 & 1 \\
\hline 166 & 58 & NA & 46 & 5 & 6 & 12 & -4 \\
\hline 167 & 45 & NA & 46 & 3 & -7 & 5 & 16 \\
\hline 168 & 94 & NA & 46 & 4 & 11 & 3 & 3 \\
\hline 169 & 10 & NA & 46 & 2 & 11 & 5 & 2 \\
\hline 170 & 165 & NA & 46 & 6 & 7 & 3 & 5 \\
\hline
\end{tabular}




\begin{tabular}{|c|c|c|c|c|c|c|c|}
\hline & Table A & ontinued & Brown & Free & old & North & inswick \\
\hline & Clone & Designation $^{\mathrm{Z}}$ & Patch Avg. ${ }^{Y}$ & 2005 & 2006 & 2005 & 2006 \\
\hline & & & & -Devia & on fror & ation $\mathrm{y}$ & means- \\
\hline 171 & 118 & $\mathrm{NA}$ & 46 & 11 & 9 & -6 & 7 \\
\hline 172 & 219 & NA & 46 & 11 & -5 & 10 & 5 \\
\hline 173 & 81 & NA & 46 & 9 & 0 & -1 & 13 \\
\hline 174 & 33 & NA & 46 & -10 & 4 & 5 & 23 \\
\hline 175 & 206 & NA & 47 & 9 & 1 & 6 & 5 \\
\hline 176 & 138 & NA & 47 & -6 & 12 & 0 & 16 \\
\hline 177 & 205 & NA & 47 & 9 & 2 & 3 & 10 \\
\hline 178 & 237 & NA & 47 & 1 & 0 & 2 & 21 \\
\hline 179 & 203 & NA & 47 & 12 & -2 & 10 & 5 \\
\hline 180 & 202 & NA & 47 & 11 & 4 & 6 & 4 \\
\hline 181 & 215 & NA & 47 & 12 & 7 & 6 & -1 \\
\hline 182 & 3 & NA & 47 & 7 & 10 & 5 & 3 \\
\hline 183 & 259 & NA & 47 & 16 & 4 & -9 & 14 \\
\hline 184 & 48 & NA & 48 & 1 & 12 & 4 & 9 \\
\hline 185 & 119 & NA & 48 & -4 & 15 & 2 & 13 \\
\hline 186 & 236 & NA & 48 & 6 & 9 & -1 & 13 \\
\hline 187 & 112 & NA & 48 & 5 & 5 & 7 & 11 \\
\hline 188 & 34 & NA & 48 & 6 & -1 & 0 & 23 \\
\hline 189 & 245 & NA & 48 & 2 & 0 & 11 & 15 \\
\hline 190 & 239 & NA & 48 & -1 & 12 & 6 & 11 \\
\hline 191 & 263 & NA & 48 & 15 & 4 & 11 & -1 \\
\hline 192 & 27 & NA & 48 & 14 & -1 & 13 & 2 \\
\hline 193 & 132 & NA & 49 & -3 & 6 & 8 & 19 \\
\hline 194 & 40 & NA & 49 & 16 & 4 & 16 & -5 \\
\hline 195 & 73 & NA & 49 & 14 & 3 & 9 & 4 \\
\hline 196 & 82 & NA & 49 & 20 & 12 & 3 & -4 \\
\hline 197 & 55 & NA & 49 & 13 & 1 & 4 & 14 \\
\hline 198 & 254 & $\mathrm{~S}$ & 50 & 8 & 3 & 11 & 13 \\
\hline 199 & 235 & S & 50 & 10 & 9 & 16 & -1 \\
\hline 200 & 228 & $\mathrm{~S}$ & 50 & 8 & 5 & 4 & 17 \\
\hline 201 & 26 & $\mathrm{~S}$ & 50 & 6 & 11 & 3 & 16 \\
\hline 202 & 31 & $\mathrm{~S}$ & 50 & -7 & 21 & 2 & 22 \\
\hline 203 & 124 & $\mathrm{~S}$ & 50 & 13 & 9 & 1 & 14 \\
\hline 204 & 137 & $\mathrm{~S}$ & 51 & 6 & 10 & 8 & 15 \\
\hline 205 & 248 & S & 51 & 5 & 14 & 11 & 9 \\
\hline 206 & 262 & $\mathrm{~S}$ & 51 & 16 & 8 & 0 & 16 \\
\hline 207 & 182 & $\mathrm{~S}$ & 51 & 17 & 3 & 15 & 5 \\
\hline 208 & 179 & S & 51 & 14 & 1 & 18 & 8 \\
\hline 209 & 153 & S & 52 & 5 & 7 & 13 & 17 \\
\hline 210 & 220 & $\mathrm{~S}$ & 52 & 10 & 7 & 6 & 19 \\
\hline 211 & 247 & $\mathrm{~S}$ & 52 & 6 & 7 & 16 & 14 \\
\hline 212 & 9 & $\mathrm{~S}$ & 52 & 7 & 16 & 9 & 11 \\
\hline 213 & 71 & $\mathrm{~S}$ & 52 & 13 & 5 & 13 & 11 \\
\hline
\end{tabular}




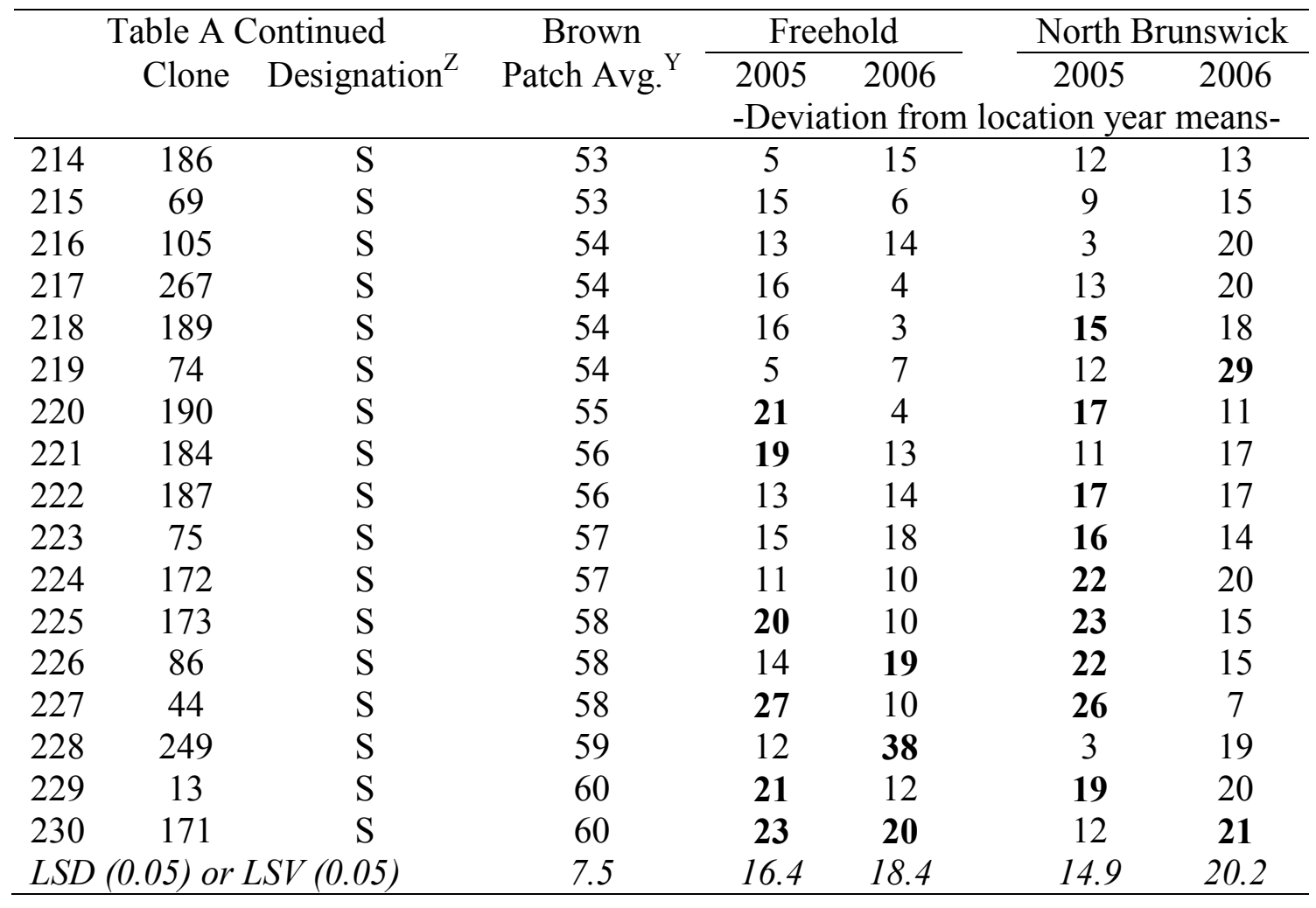

${ }^{\mathrm{Z}} \mathrm{R}=$ Resistance $\leq 30 \%$ disease, $\mathrm{S}=$ Susceptible $\geq 50 \%$ disease.

${ }_{\mathrm{Y}}$ Percent brown patch disease severity averaged across two locations and two years.

${ }^{X}$ Bold numbers indicated significance above the LSV value. 


\section{Curriculum Vita \\ Jonathan Bokmeyer}

2000-2004

2004-2009

Publications
B.S in Agronomy, Purdue University, West Lafayette, IN.

Ph.D in Plant Biology, Rutgers - The State University of New Jersey, New Brunswick, NJ.

Bokmeyer, J.M, S.A Bonos, and W.A. Meyer. 2009a. Broad-sense heritability and stability analysis of brown patch resistance in tall fescue. HortScience 44:289-292.

Bokmeyer, J. M., S. A. Bonos, and W. A. Meyer. $2009 \mathrm{~b}$.

Inheritance characteristics of brown patch resistance in tall fescue. Crop Sci. (in press)

Park, B.S., J.M. Bokmeyer, J.A. Murphy, S.A. Bonos, and W.A. Meyer, 2009. Evaluation of tall fescue under simulated wear. Int. Turfgrass Soc. Res. J. 11:563-572. 